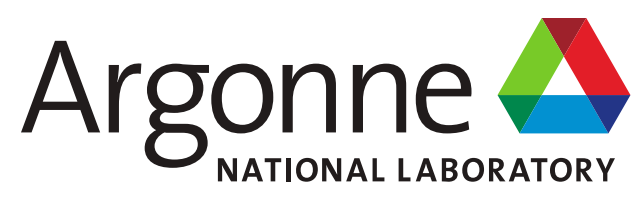

ANL/RTR/TM-19/5

\title{
Involute Working Group - Validation of CFD Turbulence Models for Steady-State Safety Analysis
}

Nuclear Science \& Engineering Division 


\begin{abstract}
About Argonne National Laboratory
Argonne is a U.S. Department of Energy laboratory managed by UChicago Argonne, LLC under contract DE-AC02-06CH11357. The Laboratory's main facility is outside Chicago, at 9700 South Cass Avenue, Argonne, Illinois 60439. For information about Argonne and its pioneering science and technology programs, see www.anl.gov.
\end{abstract}

\title{
DOCUMENT AVAILABILITY
}

Online Access: U.S. Department of Energy (DOE) reports produced after 1991 and a growing number of pre-1991 documents are available free at OSTI.GOV (http://www.osti.gov/), a service of the U.S. Dept. of Energy's Office of Scientific and Technical Information

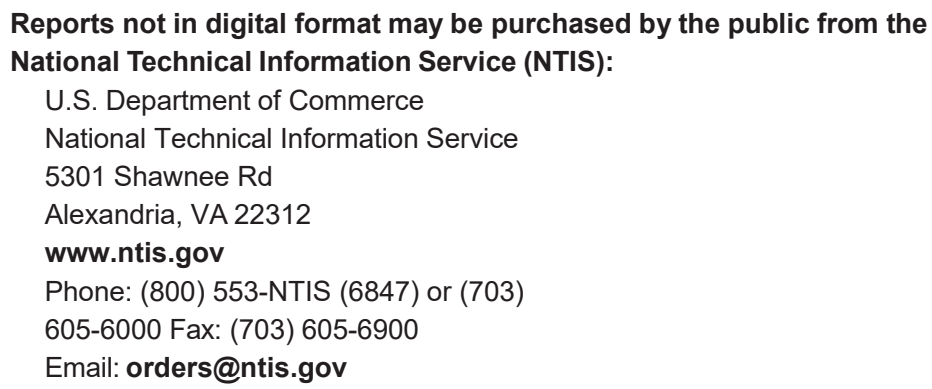

Reports not in digital format are available to DOE and DOE contractors from the Office of Scientific and Technical Information (OSTI):

U.S. Department of Energy

Office of Scientific and Technical Information

P.O. Box 62

Oak Ridge, TN 37831-0062

www.osti.gov

Phone: (865) 576-8401

Fax: (865) 576-5728

Email: reports@osti.gov

\section{Disclaimer}

This report was prepared as an account of work sponsored by an agency of the United States Government. Neither the United States Government nor any agency thereof, nor UChicago Argonne, LLC, nor any of their employees or officers, makes any warranty, express or implied, or assumes any legal liability or responsibility for the accuracy, completeness, or usefulness of any information, apparatus, product, or process disclosed, or represents that its use would not infringe privately owned rights. Reference herein to any specific commercial product, process, or service by trade name, trademark, manufacturer, or otherwise, does not necessarily constitute or imply its endorsement, recommendation, or favoring by the United States Government or any agency thereof. The views and opinions of document authors expressed herein do not necessarily state or reflect those of the United States Government or any agency thereof, Argonne National Laboratory, or UChicago Argonne, LLC. 
ANL/RTR/TM-19/5

\section{Involute Working Group - Validation of CFD Turbulence Models for Steady-State Safety Analysis}

prepared by

C. Bojanowski, A. Bergeron, J. Licht

Nuclear Science \& Engineering Division, Argonne National Laboratory

January 2020 
(This page left intentionally blank) 


\section{Table of Contents}

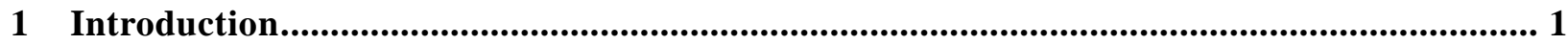

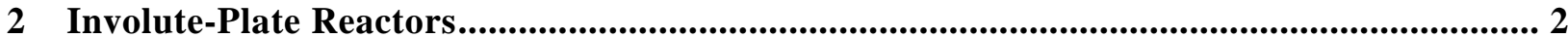

3 Involute Working Group................................................................................................. 5

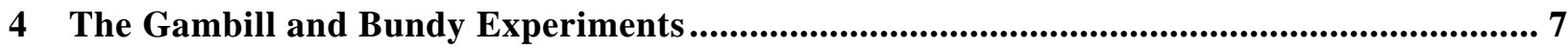

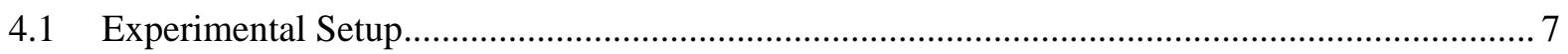

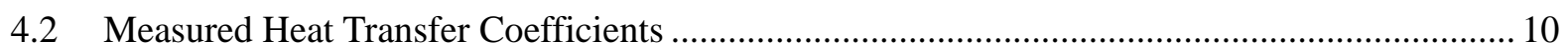

5 CFD Modeling of the Gambill and Bundy Experiment .......................................................17

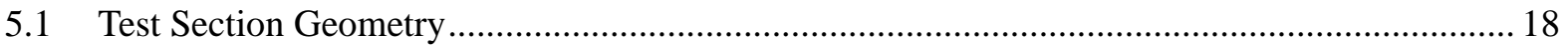

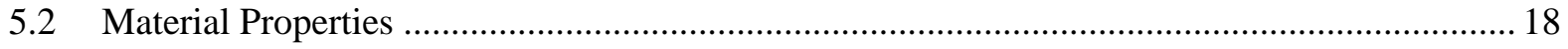

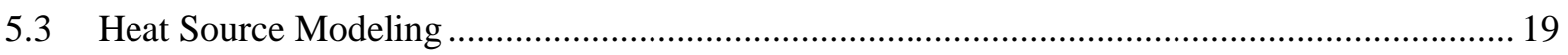

5.4 Simulation of Test \#7 Steady-State \#8 \#............................................................................. 20

5.5 Simulations for an Extended Range of Reynolds Number ...................................................... 28

6 Comparison of CFD and Empirical Correlations for an Abstract Geometry ........................34

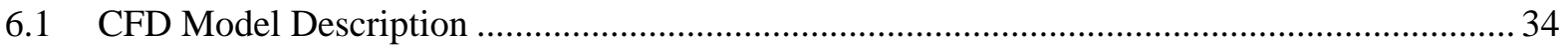

6.2 Onset of Nucleate Boiling Heat Flux..................................................................................... 35

6.3 Automatic CFD Model Generation ....................................................................................... 36

6.4 CFD Fit Functions compared to Empirical Correlations ...................................................... 36

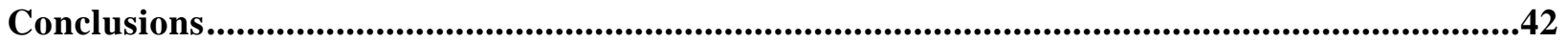

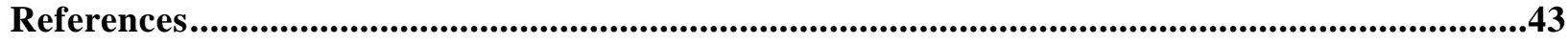

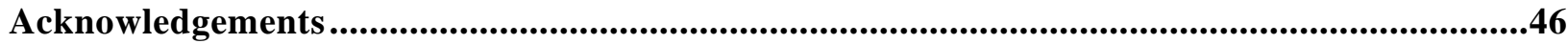

Appendix A - Gambill \& Bundy Report Digitized Data.............................................................47

Appendix B - CFD Turbulence Models ......................................................................................51

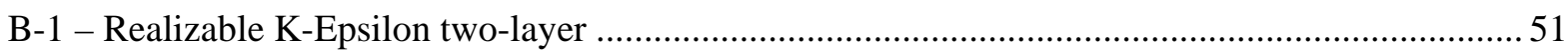

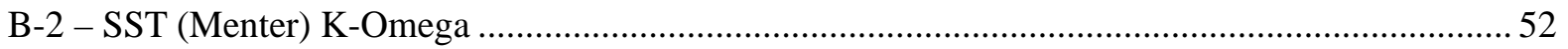

B-3 - Reynolds-Stress Transport / Elliptic Blending …...................................................................... 52

Appendix C - Fits of CFD Data ...........................................................................................54 


\section{List of Figures}

Figure 2-1 - From left to right, top view of the HFIR, RHF and FRM II fuel elements (close to true proportionality).

Figure 2-2 - Detailed view of RHF fuel plates curved as involute and welded between the two annular sideplates (picture taken from a mockup and not a real element, finish is therefore not representative of a real element)

Figure 2-3 - Schematic representation (view from top) of an involute coolant channel modeled as a rectangle heated on both side by two half-fuel plates.

Figure 2-4 - RHF power density distribution at beginning of cycle: (left) plate cross-section; (right, top) lateral power density distribution at top, midplane and bottom of the fuel; (right, bottom) axial power density distribution at inner, mid-width and outer edge of the fuel.

Figure 3-1 - schematic representation (view from top) of an involute coolant channel modeled as a rectangle and divided in several, independent sub-channels with unidimensional heat flux (noted as q" on the figure)

Figure 3-2 - illustration of the effect of modeling heat conduction in one (blue curve) or three dimensions in conjunction with the unfueled regions (dark gray curve) on the heat flux at the coolant/cladding interface. Based on data from [Bojanowski, 2018B].

Figure 4-1 - Schematic of the heat transfer system used by Gambill \& Bundy. Source: Reproduction of [Gambill, 1961], Figure 1.

Figure 4-2 - Cross-section of the aluminum test-section assembly. Source: Reproduction of [Gambill, 1961], Figure 8.

Figure 4-3 - Aluminum test section (disassembled). Top to bottom: backup plate, Mycalex insulator, test section and end blocks, Mycalex insulator, and backup plate. Source: Reproduction of [Gambill, 1961], Figure 9.

Figure 4-4 - Assembled aluminum test section. Source: Reproduction of [Gambill, 1961], Figure 11....... 9

Figure 4-5 - Installed aluminum test section. Source: Reproduction of [Gambill, 1961], Figure 13...........9

Figure 4-6 - Typical plot of variation of pertinent temperatures and of heat transfer coefficient with heated length. Source: reproduction of [Gambill, 1961], Figure 16.

Figure 4-7 - Gambill and Bundy experimentally obtained average Nusselt number (normalized using Equation 9) and comparison with the Sieder-Tate correlation. Source: digitization of [Gambill, 1961], Figure 17. Error bars are not from original work, estimated by present authors. ..................................... 14

Figure 4-8 - Gambill and Bundy experimentally obtained average Nusselt number (normalized using Equation 6) and comparison with the Hausen correlation. Source: digitization of [Gambill, 1961], Figure 18. Error bars are not from original work, estimated by present authors.

Figure 4-9 - Gambill and Bundy experimentally obtained local Nusselt number (normalized using Equation 7) and comparison with the Hausen correlation. Source: digitization of [Gambill, 1961], Figure 19. Error bars are not from original work, estimated by present authors. Data shown respects a double condition: film temperature drop $\Delta \mathrm{tf} \geq 150 \mathrm{C}$ and $\mathrm{x} / \mathrm{De} \geq 30$.

Figure 5-1 - The cross section of the specimen in Gambill’s experiment set \#7 (units: inch) 18

Figure 5-2 - (left) Dynamic viscosity as a function of temperature at 30 bar; (right) Density of water as a function of temperature at 30 bar..... 19 
Figure 5-3 - (left) Thermal conductivity of water as a function of temperature at 30 bar; (right) Specific heat of water as a function of temperature at 30 bar (3 MPa).

Figure 5-4 - Cross section of Gambill's experiment test \#7 CFD Model with mesh visible (gray: aluminum

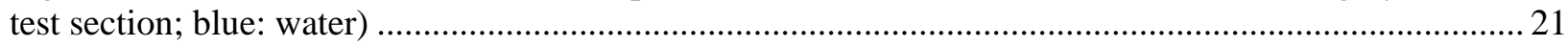

Figure 5-5 - Wall Y+ in the steady-state \#8 Test \#7 model ................................................................. 22

Figure 5-6 - Temperature distribution in the cut through the coolant channel in the steady-state \#8 Test \#7 model (obtained with K-Epsilon turbulence model) .......................................................................... 23

Figure 5-7 - Temperature distribution in the center of the specimen and the coolant channel in the steadystate \#8 Test \#7 model (obtained with K-Epsilon turbulence model) .................................................... 23

Figure 5-8 - Temperature and heat transfer coefficient obtained by Gambill and Bundy in Test \#7 steadystate \#8 and comparison with CFD using K-Epsilon model ................................................................. 25

Figure 5-9 - Temperature and heat transfer coefficient obtained by Gambill and Bundy in Test \#7 steadystate \#8 and comparison with CFD using K-Omega model.................................................................. 26

Figure 5-10 - Temperature and heat transfer coefficient obtained by Gambill and Bundy in Test \#7 steadystate \#8 and comparison with CFD using Reynolds-Stress model .......................................................2 27

Figure 5-11 - Comparison of experimental averaged Nusselt number with the ones obtained with the KEpsilon, K-Omega and Reynold-Stress CFD models and with the Sieder-Tate correlation ....................... 30

Figure 5-12 - Comparison of experimental averaged Nusselt number with the ones obtained with the KEpsilon, K-Omega and Reynold-Stress CFD models and with the Hausen correlation ............................ 31

Figure 5-13 - Comparison of experimental local heat Nusselt number with the ones obtained with the KEpsilon, K-Omega and Reynold-Stress CFD models and with the Hausen correlation ............................ 32

Figure 5-14 - Distribution of the deviation between CFD calculations (marked C) relative the experimental results (marked E) for the local Nusselt number case ................................................................................ 33

Figure 6-1 - Simplified model used in the sensitivity study .................................................................... 34

Figure 6-2 - Comparison of CFD fit functions obtained with the Gambill and Bundy experiment model and the abstract geometry model used for comparison with the Sieder-Tate correlation ................................. 38

Figure 6-3 - Comparison of CFD fit functions obtained with the Gambill and Bundy experiment models and the abstract geometry models used for comparison with the Hausen correlation

Figure 6-4 - Comparison of CFD fit functions obtained with the abstract geometry models and comparison with the Sieder-Tate correlation

Figure 6-5 - Comparison of CFD fit functions obtained with the abstract geometry models and comparison with the Hausen correlation 


\section{List of Tables}

Table 2-1 - Key parameters of fuel elements in involute reactors ............................................................ 2

Table 2-2 - Key thermal-hydraulic parameters in involute reactors ......................................................... 3

Table 4-1 - Range of conditions in Gambill and Bundy experiment...................................................... 10

Table 5-1 - Material constants for the solid parts (aluminum alloy 1100) .............................................. 18

Table 5-2 - Analyzed cases based on Gambill experiment geometry...................................................... 28

Table 6-1 - Input variables and their values in the sensitivity analysis .................................................. 35 


\section{Introduction}

There are three research reactors in the world having fuel plates curved as circle-involute (a spiral generated around a circle):

- The Oak Ridge National Laboratory (ORNL) High Flux Isotope Reactor (HFIR) located in Tennessee, U.S.A. [ORNL, 2018]

- The Laue-Langevin Institute (ILL) High Flux Reactor (RHF) located in Grenoble, France [ILL, 2018] and;

- The Technical University of Munich (TUM) Research Neutron Source Heinz Maier-Leibnitz (FRM II) located in Garching, Germany [TUM, 2018]

All three reactors are currently using Highly Enriched Uranium (HEU, ${ }^{235} \mathrm{U} / \mathrm{U} \geq 20$ wt. \%) as fuel and all three are actively engaged in activities to convert to Low Enriched Uranium (LEU, ${ }^{235} \mathrm{U} / \mathrm{U}<20 \mathrm{wt}$. $\%)$ fuel. More information on these reactors can be found in Section two.

For various reasons, these reactors have expressed interest in using Computational Fluid Dynamics (CFD) tools to perform their Steady-State Thermal-Hydraulic (SSTH) safety calculations. Using CFD tools for SSTH analysis represents generally a significant departure from traditional methods and requires thorough verification and validation $(\mathrm{V} \& \mathrm{~V})$ to be accepted by regulators. This is why Argonne National Laboratory (ANL) and the involute reactors formed an informal group to help each other in this endeavor. This so-called Involute Working Group (IWG) aims at supporting the qualification of CFD tools for SSTH safety calculations. Activities include benchmarking, code-to-code comparison, Verification and Validation $(\mathrm{V} \& \mathrm{~V})$ as well as technical support. More information on the IWG and the reasons why involute-plate reactors are interested in CFD can be found in Section three.

Qualifying CFD tools for involute-plate reactors implies providing solid justifications on the appropriateness of all aspects of the CFD analysis. For this type of application, a key item is to demonstrate the ability of CFD to model the heat transfer between the fuel plate and the coolant. While "classic", one-dimensional, thermal-hydraulic analysis typically makes use of empirical correlations (e.g. Dittus-Boelter, Sieder-Tate, Hausen), CFD analyses rely on turbulence models and an appropriate discretization of the physical space (i.e. meshing) to characterize the solid to liquid heat transfer.

The present study aims at testing three turbulence models commonly implemented in commercial software (namely K-Epsilon, K-Omega and Reynolds-Stress) and assessing their relevance for involute-plate reactor application. An experiment performed by Gambill and Bundy in 1961 was performed to measure heat transfer coefficients in conditions prototypic of the HFIR reactor [Gambill, 1961]. More details on this experiment are provided in Section four. Based on the information available, CFD models of this experiment have been created and the experimental results have been compared to the ones obtained with these CFD models. CFD models and the results of this comparison are provided in Section five.

In the last section, generalization to an abstract geometry is performed aiming at covering a broader range of conditions than considered by Gambill and Bundy in their experiment. The goal is to cover completely the range of conditions applicable to involute-plate reactors. CFD results are compared to the Sieder-Tate and Hausen correlation which were found to be suitable by Gambill and Bundy. 


\section{Involute-Plate Reactors}

The fuel elements of involute-plate reactors have an annular shape as depicted in Figure 2-1 below, which shows a top view, from left to right, of the HFIR, RHF and FRM II fuel elements. HFIR has two elements while RHF and FRM II have only one. Fuel elements have to be replaced at every new cycle (i.e. once through core). Figure 2-2 provides a more detailed view of the RHF plates and channels. As one can see in this figure, the fuel plates curved as involute are attached (welded) to two concentric tubes (commonly referred as side-plates). The space between two adjacent fuel plates forms a coolant channel in which water passes at very high speed $(\approx 15 \mathrm{~m} / \mathrm{s})$ to evacuate the heat generated in the fuel plate by nuclear reactions.

The fuel plates are very thin $(1.27-1.36 \mathrm{~mm})$ and have a sandwich-like structure. The fuel is made of highly enriched uranium (93 wt. \%) mixed with aluminum. This so-called "meat" is cladded on each side by aluminum alloy foils. More information on these reactors and elements can be found in Table 2-1 and in Table 2-2. RHF uses heavy water as coolant while FRM II and HFIR use light water. The coolant flows from top to bottom for all three reactors. The involute shape allows for:

- the thickness of a coolant channel to be constant from the inner to the outer edge of the element

- all these channels to be identical (granted some local deviations introduced during the manufacturing process)

- all these fuel plates to experience very similar irradiations conditions (granted some possible local azimuthal variations induced by the presence of safety or experimental components located at the vicinity of the fuel elements)

These features are particularly interesting for Steady-State Thermal-Hydraulic (SSTH) analysis, since it only requires to model one or few channels (and not all of them) to characterize the entire element. In addition, one could argue that the constant channel thickness allows modeling of the involuteshaped channel as a simple rectangular channel heated on both sides as depicted in Figure 2-3.

Table 2-1 - Key parameters of fuel elements in involute reactors

\begin{tabular}{|l|c|c|c|}
\hline \multicolumn{1}{|c|}{ Parameters } & $\begin{array}{c}\text { HFIR } \\
\text { [Bergeron, 2012] }\end{array}$ & $\begin{array}{c}\text { RHF } \\
\text { [Bergeron, 2014] }\end{array}$ & $\begin{array}{c}\text { FRM II } \\
\text { [Röhrmoser, 2010] }\end{array}$ \\
\hline Fuel type & $\mathrm{U}_{3} \mathrm{O}_{8} / \mathrm{Al}$ & UAlx / $\mathrm{Al}$ & $\mathrm{U}_{3} \mathrm{Si}_{2} / \mathrm{Al}$ \\
\hline Number of elements & 2 & 1 & 1 \\
\hline Number of plates & $540(171+369)$ & 280 & 113 \\
\hline Plate thickness (mm) & 1.27 & 1.27 & 1.36 \\
\hline Plate length (cm) & 60.96 & 90.30 & 72.00 \\
\hline Channel width between side plates (cm) & $8.548 / 7.679$ & 7.594 & 6.940 \\
\hline Channel thickness (mm) & 1.27 & 1.80 & 2.20 \\
\hline Cladding thickness (mm) & 0.254 & 0.380 & 0.380 \\
\hline Meat thickness (mm) & Varies along width, & 0.51 & 0.60 \\
\hline $\begin{array}{l}\text { Meat width (cm) } \\
\text { Width inner unfueled region (from outer radius } \\
\text { of inner side-plate to inner fuel radius, cm) }\end{array}$ & 0.693 & 6.734 & 6.240 \\
\hline $\begin{array}{l}\text { Width outer unfueled region (from outer fuel } \\
\text { radius to inner radius of outer side-plate, cm) }\end{array}$ & $0.516 / 0.374$ & 0.314 & 0.259 \\
\hline
\end{tabular}


Table 2-2 - Key thermal-hydraulic parameters in involute reactors

\begin{tabular}{|l|c|c|c|}
\hline Parameters & $\begin{array}{c}\text { HFIR } \\
\text { [Jain, 2019] }\end{array}$ & $\begin{array}{c}\text { RHF } \\
\text { [Thomas, 2019] }\end{array}$ & $\begin{array}{c}\text { FRM II } \\
\text { [Reiter, 2019] }\end{array}$ \\
\hline Average coolant velocity (m/s) & 15.5 & 17 & 15.9 \\
\hline Nominal inlet / outlet bulk temperature (Celsius) & $49 / 69$ & $30 / 50$ & $38 / 53$ \\
\hline Nominal inlet / outlet pressure (Bar) & $33.3 / 25.72$ & $14 / 4$ & $8.8 / 2.3$ \\
\hline Reynolds number & $\sim 100,000$ & $\sim 100,000$ & $\sim 100,000$ \\
\hline Peak heat flux (W/cm ${ }^{2}$ ) & $<400$ & $<400$ & 382.3 \\
\hline
\end{tabular}
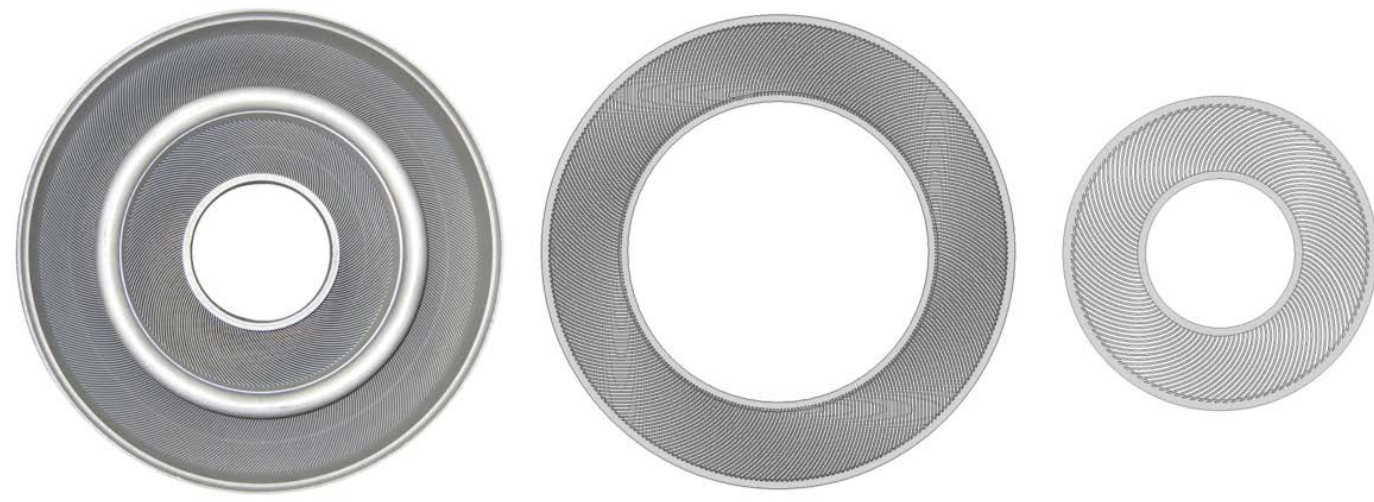

Figure 2-1 - From left to right, top view of the HFIR, RHF and FRM II fuel elements (close to true proportionality)

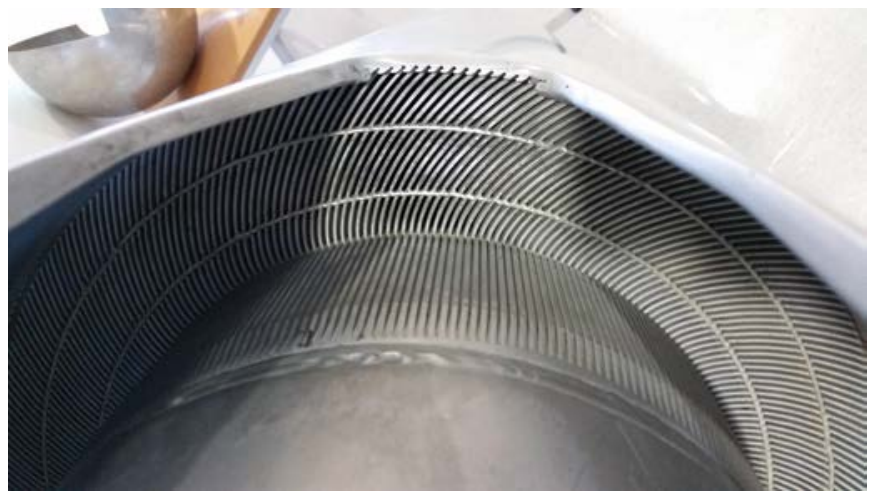

Figure 2-2 - Detailed view of RHF fuel plates curved as involute and welded between the two annular side-plates (picture taken from a mockup and not a real element, finish is therefore not representative of a real element) Inner side-plate

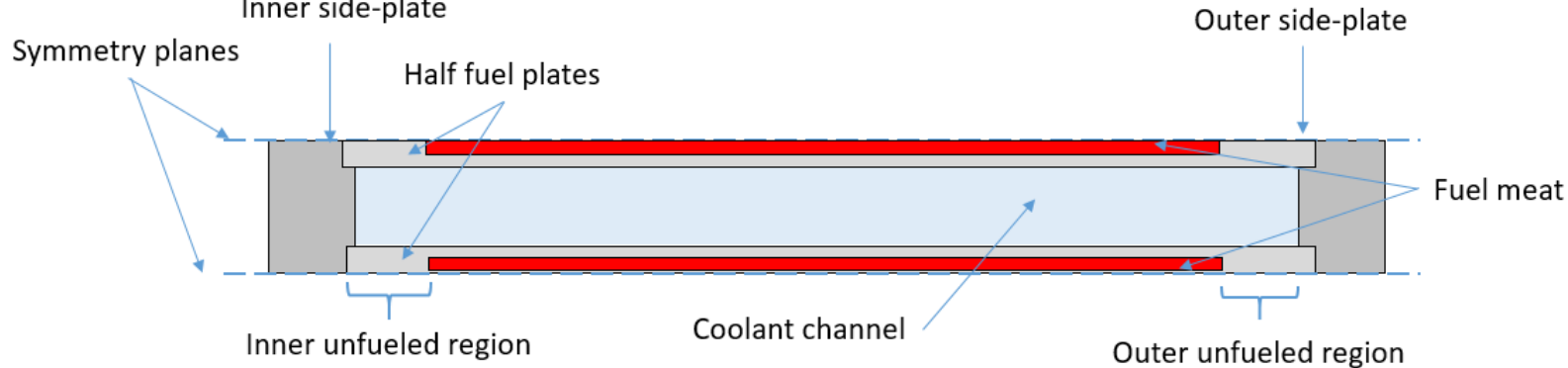

Figure 2-3 - Schematic representation (view from top) of an involute coolant channel modeled as a rectangle heated on both side by two half-fuel plates. 
The fuel element of these reactors is located at the center of a larger vessel that contains the reflector (heavy water for RHF and FRM II, beryllium for HFIR) and experimental and safety devices. The cylindrical volume located at the center of the annular fuel elements is often referred to as the central cavity. FRM II and RHF use this space for the control elements, which move vertically to control the reactivity during the cycle. HFIR uses this central cavity for isotope production. HFIR reactivity control is assured by an inner and outer shroud located near the outer edge of the outer element.

Due to these geometric characteristics, fast neutrons born from fission will thermalize in the reflector and the central cavity. Because the fuel plates are "edge-on", thermalized neutrons that are coming back to the fuel elements tend to be captured more frequently on the edges of the fuel where more fissions and therefore more heat will be generated. This will lead to a non-uniform distribution of power within the plates where the power tends to spike at the edges. To illustrate this point, Figure 2-4 shows the typical power density distribution within the fuel of an RHF plate at beginning of cycle. As one can see, large power gradients exist and for this reactor, the fuel outer edge is where the limiting safety margin typically occurs.
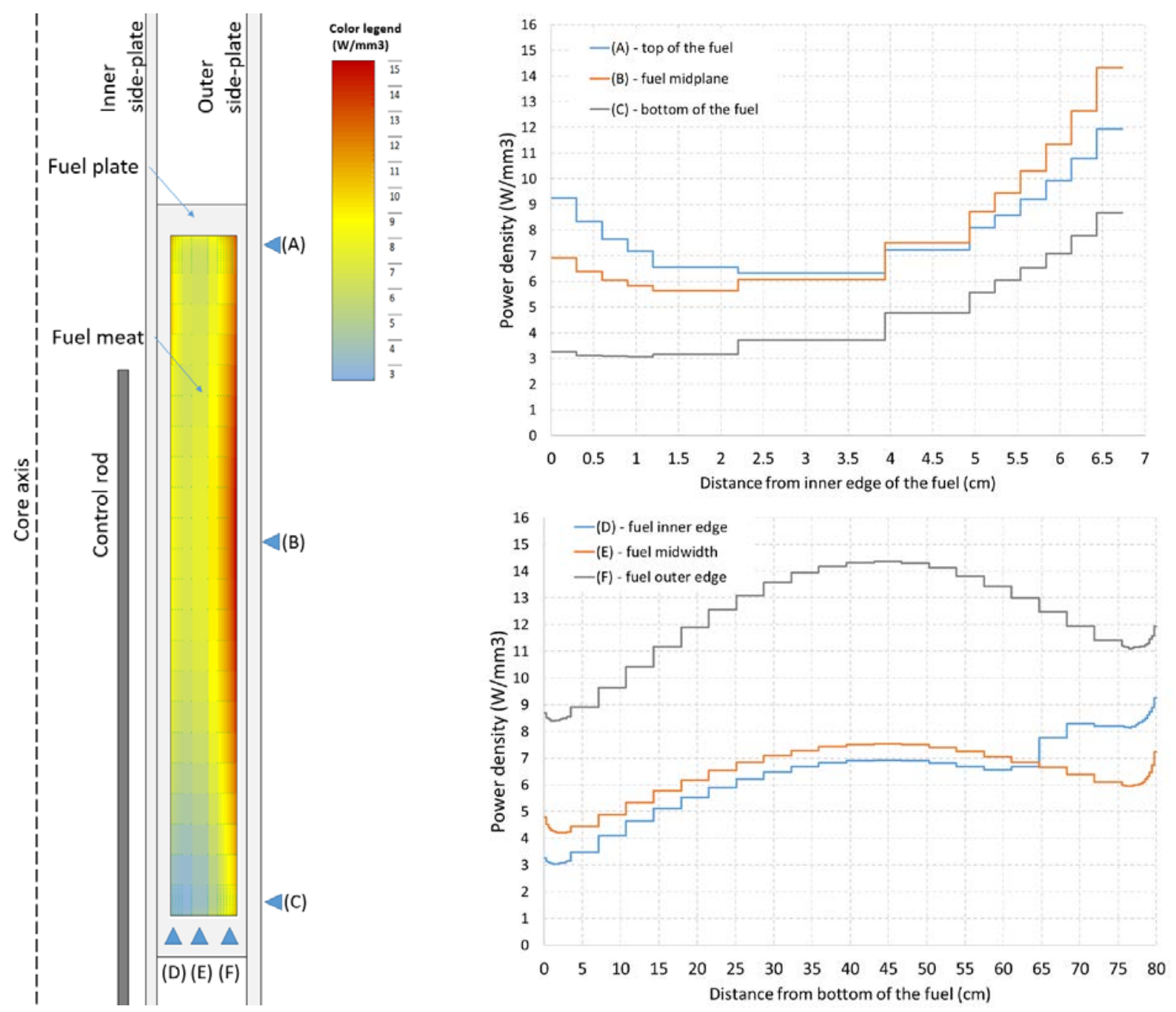

Figure 2-4 - RHF power density distribution at beginning of cycle: (left) plate cross-section; (right, top) lateral power density distribution at top, midplane and bottom of the fuel; (right, bottom) axial power density distribution at inner, mid-width and outer edge of the fuel. 


\section{Involute Working Group}

Historically, steady-state thermal-hydraulic (SSTH) analysis have been carried out with simple but conservative methods in which the coolant channel is divided into several independent sub-channels (no energy exchange between sub-channels). Heat, in this simplified representation, comes from the direction normal to the plates as illustrated in Figure 3-1 below. Lateral and axial heat conduction, heat-induced mass flow redistribution or effect of unfueled region are often ignored which, translate into a relatively conservative physical representation of the heat transfer in the coolant channel. This in turn results in a relatively conservative estimation of the safety margin.

In the framework of its non-proliferation policies, the international community aims at eliminating the use of HEU fuel in civilian facilities (such as research reactors) [RERTR, 2019]. Many organizations worldwide are developing high density, LEU fuel to replace the HEU fuel. All three involute reactors are actively engaged in conversion to LEU activities.

Conversion to LEU implies changing the fuel and therefore changing the material properties, which will influence the thermal-hydraulic behavior of the elements. In many cases, it also implies making geometric modifications (plate length, channel thickness, and others) which also affects the thermalhydraulic performance of the elements. While performing conversion related thermal-hydraulic analysis, some involute-plate reactors encountered several issues with existing tools and methods:

- $\quad$ Lack of flexibility of legacy codes to model the changes described above

- $\quad$ LEU fuels being denser than HEU, power peaking is typically aggravated which increases the cladding/coolant interface heat flux and therefore reduces safety margins

In order to overcome the limitations described above, the three involute reactors have expressed interest in using Computational Fluid Dynamics (CFD) codes to perform their thermal-Hydraulic safety calculations. These simulation tools are able to model virtually any kind of geometry and are able to more accurately model the complex physical phenomena than the legacy codes currently used by involute-plate reactors. The ability to model complex physical phenomena can eliminate some unnecessary conservatism inherently present with legacy methods and recover some of the margin losses.

For instance, in [Bojanowski, 2018], the ability of CFD to easily model the unfueled region of the plates and to model heat conduction in three dimensions allowed quantifying the amount of heat transferred to the unfueled regions of the plate. It has been shown that a non-negligible fraction of heat was conducted through these unfueled regions, which in turn, causes a substantial decrease of the heat flux at the cladding/coolant interface near the fuel edges as illustrated in Figure 3-2. Because the fuel edges are often the regions of the plates having less margin to boiling-related phenomena, the decreased heat flux tends to increase safety margins substantially.

Using CFD for SSTH analysis represents however, a significant departure from traditional methods and requires thorough $\mathrm{V} \& \mathrm{~V}$ to be accepted by regulators. This is why ANL and the involute reactors formed an informal group to help each other in this endeavor. The IWG aims at, among other things, supporting the qualification of CFD tools for thermal-hydraulic safety calculations [Bojanowski, 2018B], [Bergeron, 2019]. Activities include benchmarking, code-to-code comparison, Verification and Validation (V\&V) as well as technical support.

As part of the IWG scope of work, the analysis presented here focuses on CFD turbulence models and their influence on the cladding/coolant heat transfer. 


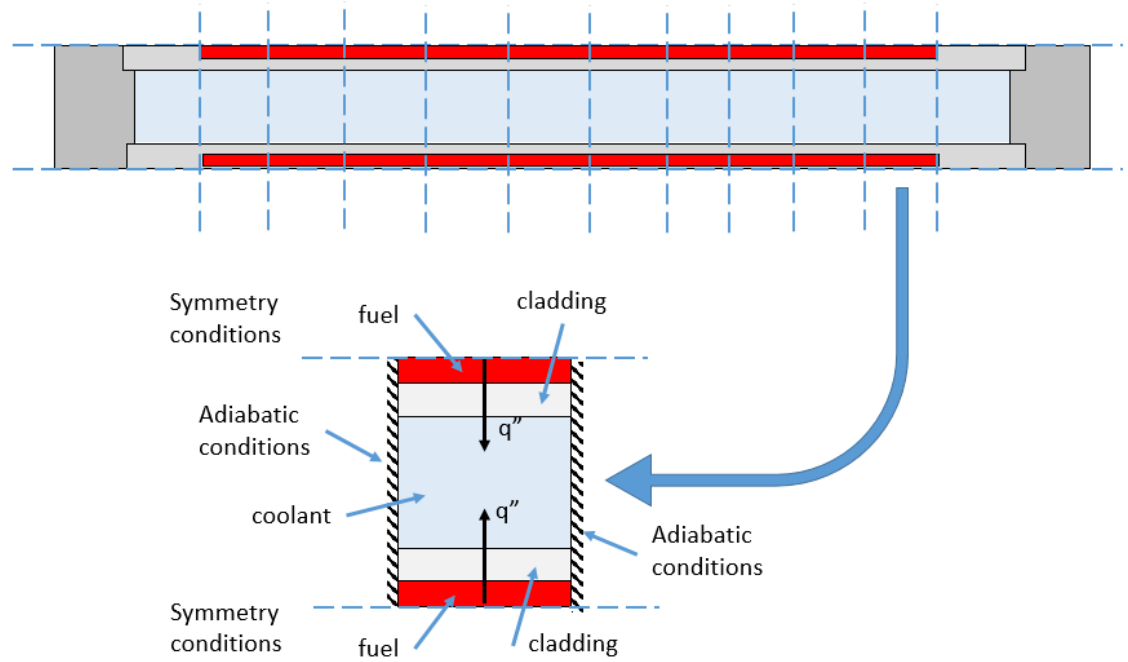

Figure 3-1 - schematic representation (view from top) of an involute coolant channel modeled as a rectangle and divided in several, independent sub-channels with unidimensional heat flux (noted as q" on the figure)

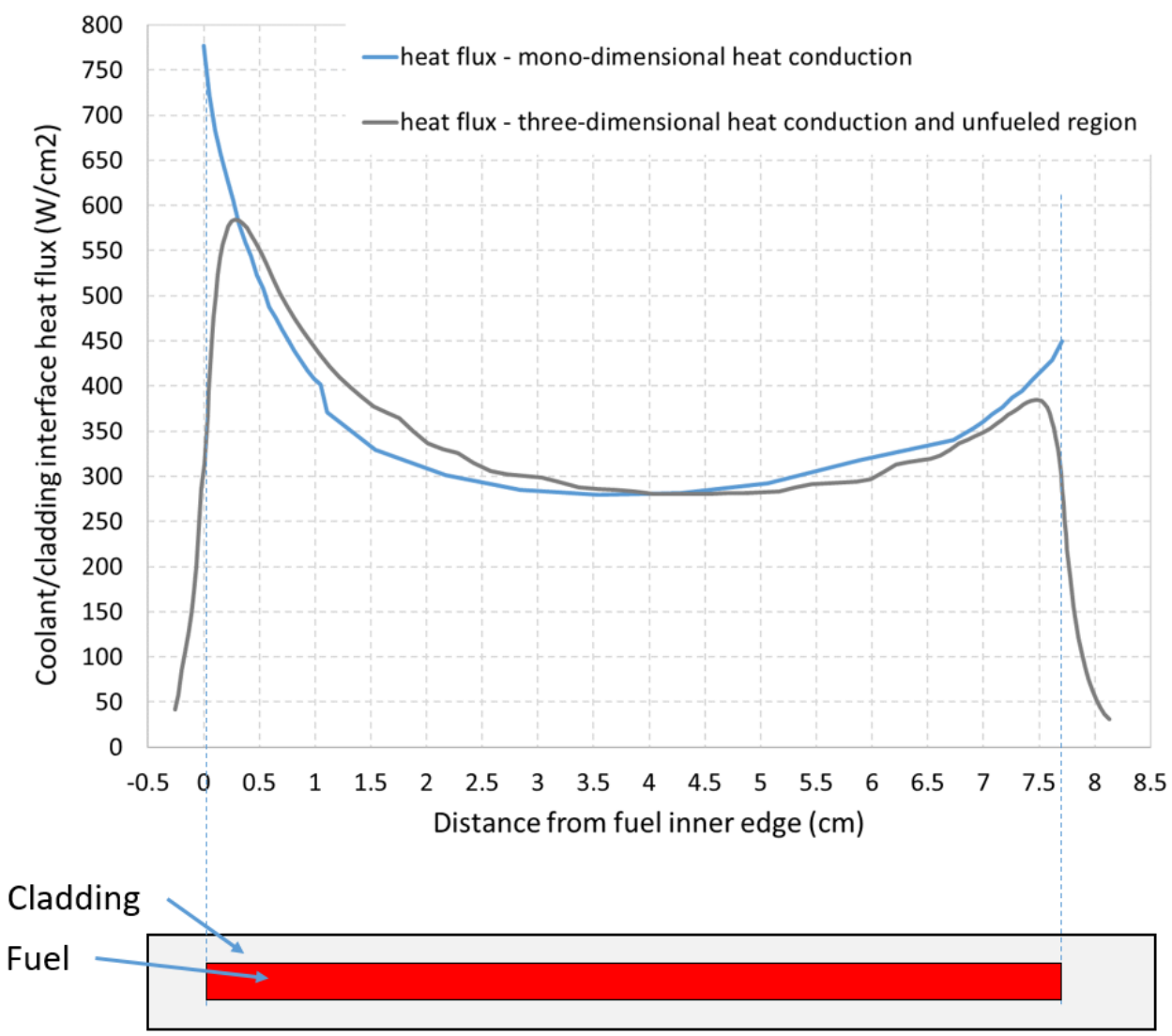

Figure 3-2 - illustration of the effect of modeling heat conduction in one (blue curve) or three dimensions in conjunction with the unfueled regions (dark gray curve) on the heat flux at the coolant/cladding interface. Based on data from [Bojanowski, 2018B]. 


\section{The Gambill and Bundy Experiments}

In 1961, W. R. Gambill and R. D. Bundy designed and performed a relatively large number of experiments to support the thermal-hydraulic design of the involute-plate reactor HFIR [Gambill, 1961]. The experiments aimed at evaluating friction factors, burnout heat fluxes, and average and local non-boiling heat transfer coefficients for flows of water through thin aluminum and nickel channels. Experimental data were compared to existing correlations and recommendations on which correlations to use for HFIR analysis were provided. The work they performed carried a significant importance as the heat transfer correlations they recommended is still used today in HFIR thermalhydraulic analysis [McLain, 1967]. The experimental setup and the key results they obtained are described in this section. Gambill and Bundy made use of various unit systems. The authors of the present work are using the SI system but had still to refer to the unit system used by Gambill and Bundy where deemed necessary.

\subsection{Experimental Setup}

The experimental system developed by W. R. Gambill and R. D. Bundy consisted of a flow loop which circulated distilled water through a heated section representative of the HFIR coolant channel geometry. A schematic representation of the loop is provided in Figure 4-1.

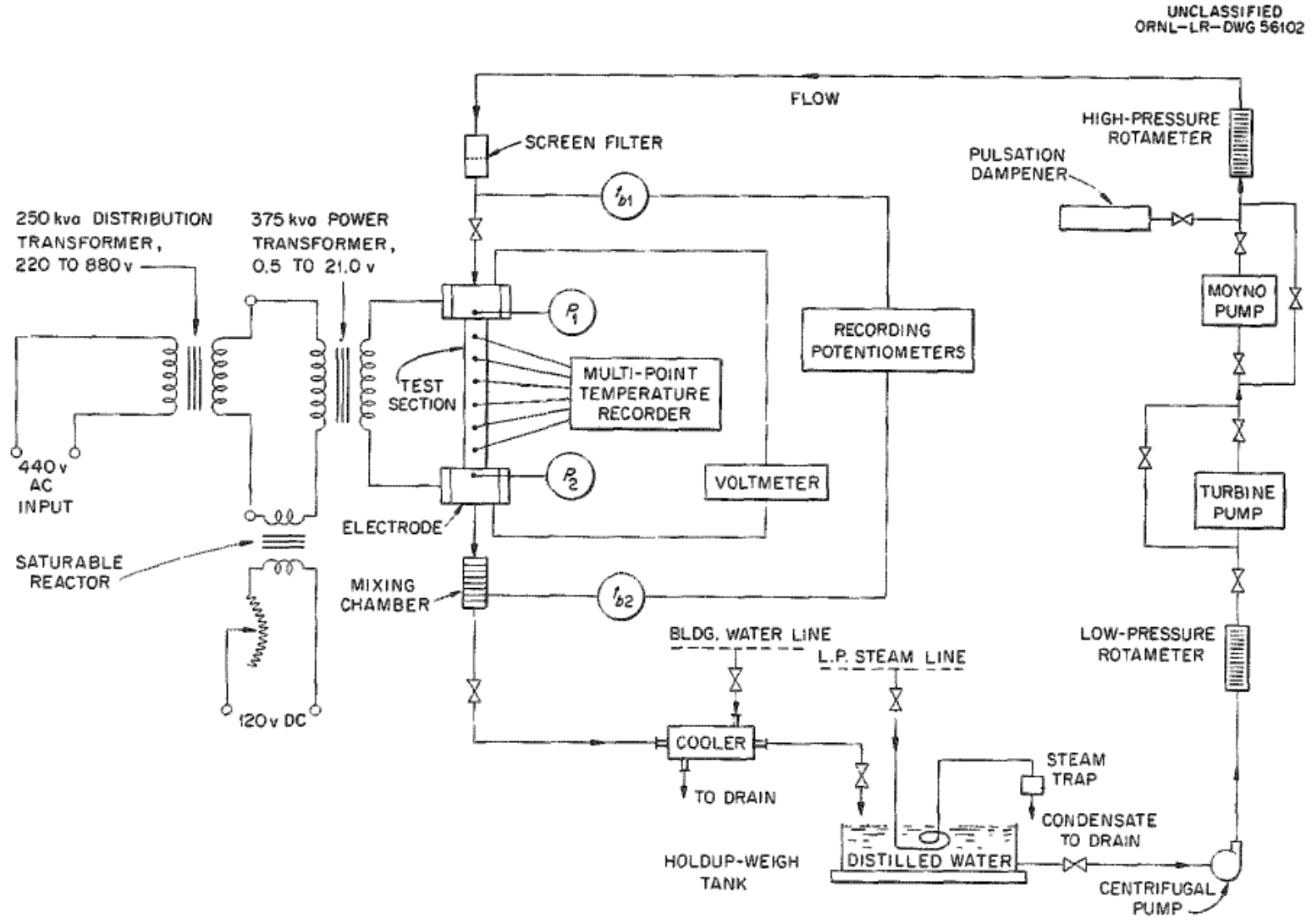

Figure 4-1 - Schematic of the heat transfer system used by Gambill \& Bundy. Source: Reproduction of [Gambill, 1961], Figure 1. 
The test section contained a single instrumented coolant channel of thickness representative of the HFIR coolant channel. The section was electrically heated and designed to generate a heat flux as constant as possible at any given location. Several thermocouples were located in the test section to evaluate the temperature at the wall (e.g. coolant/cladding interface). A cross-section schematic of the test section is shown on Figure 4-2. The actual test section is shown on Figure 4-3 (section disassembled), Figure 4-4 (section assembled) and Figure 4-5 (section installed).

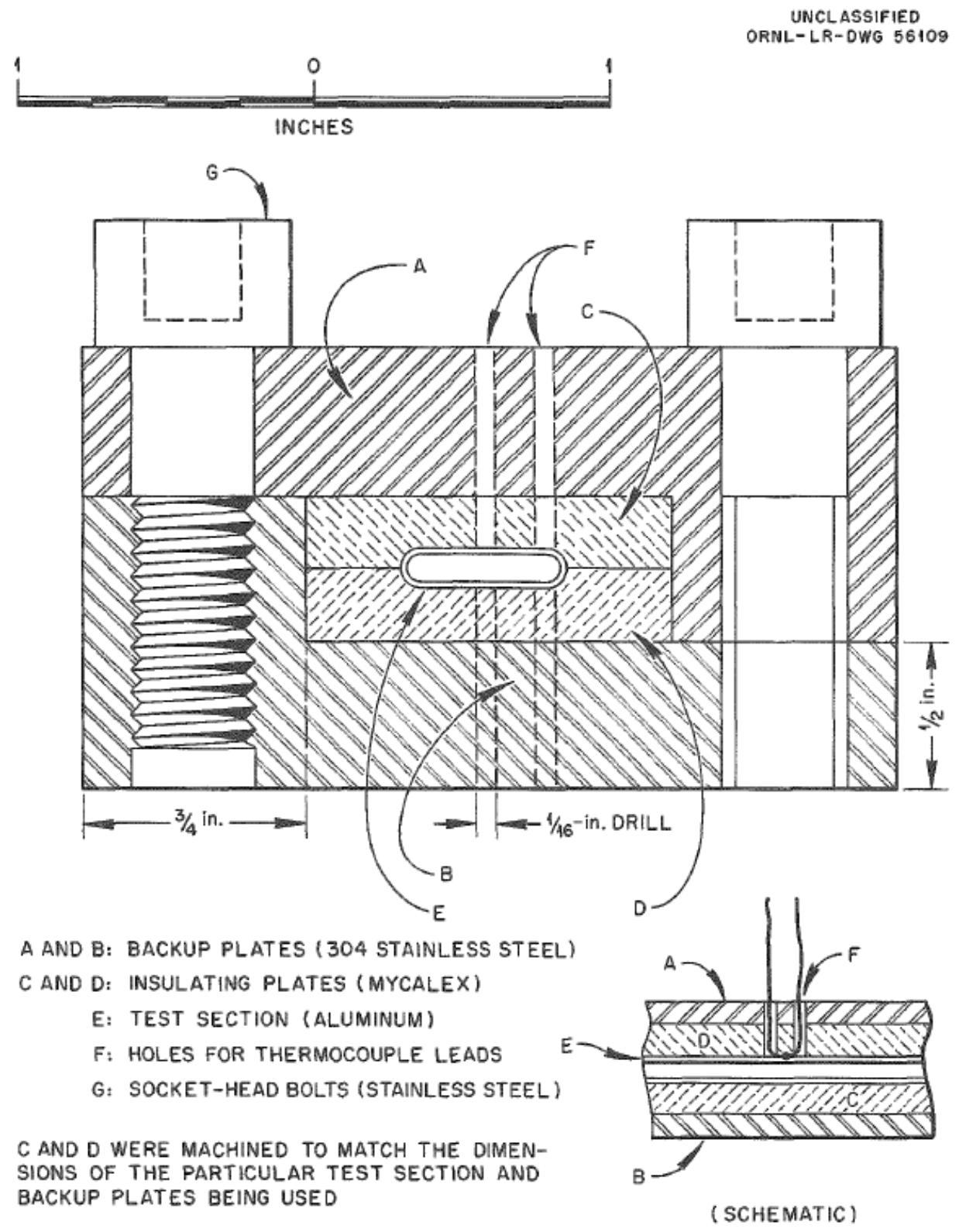

Figure 4-2 - Cross-section of the aluminum test-section assembly. Source: Reproduction of [Gambill, 1961], Figure 8. 


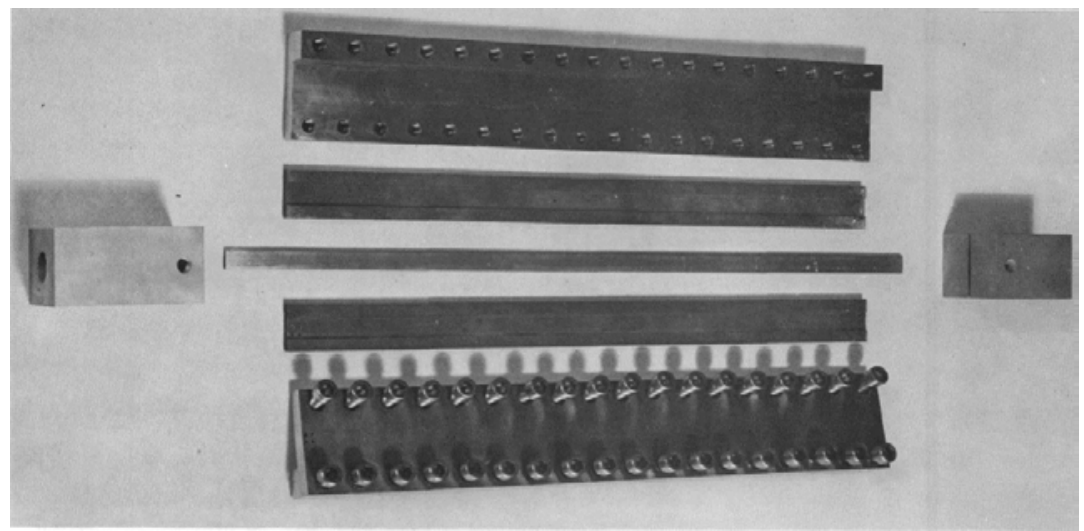

Figure 4-3 - Aluminum test section (disassembled). Top to bottom: backup plate, Mycalex insulator, test section and end blocks, Mycalex insulator, and backup plate. Source: Reproduction of [Gambill, 1961], Figure 9.

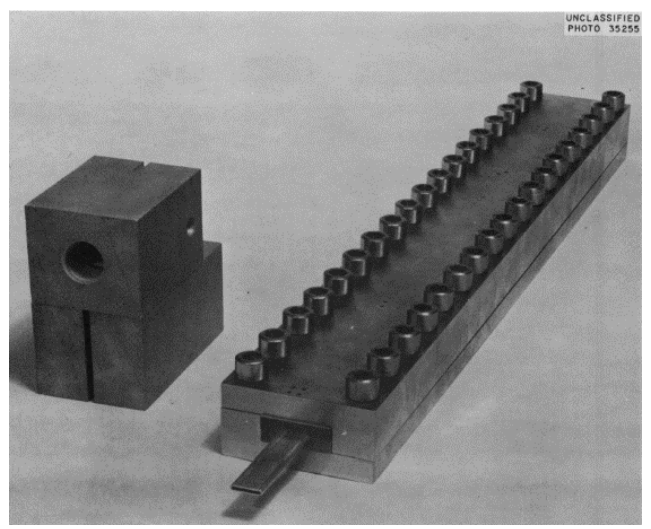

Figure 4-4 - Assembled aluminum test section. Source: Reproduction of [Gambill, 1961], Figure 11.

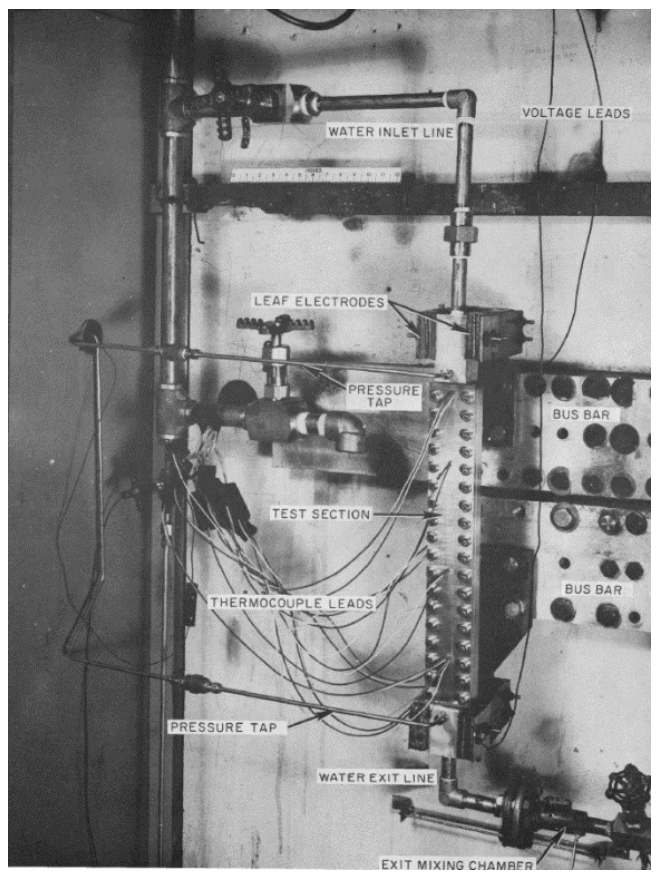

Figure 4-5 - Installed aluminum test section. Source: Reproduction of [Gambill, 1961], Figure 13. 


\subsection{Measured Heat Transfer Coefficients}

Gambill and Bundy carried out a series of eleven tests. For each, an attempt was made to measure friction factors, burnout heat fluxes and heat transfer coefficient. The tests had short duration to prevent the development of an oxide layer on the aluminum-coolant interface and a new test section was used at the beginning of a new test series. The range of conditions of these tests is provided in Table 4-1 below.

Table 4-1 - Range of conditions in Gambill and Bundy experiment

\begin{tabular}{|l|c|c|}
\hline \multicolumn{1}{|c|}{ parameter } & Min. value & Max. value \\
\hline Heat flux (Btu/hr.ft2 / W/cm ${ }^{2}$ ) & $1.000 \mathrm{E}+6 / 315.5$ & $7.400 \mathrm{E}+6 / 2,334$ \\
\hline Exit coolant pressure (atm. abs. / bar abs.) & $1.100 / 1.115$ & $38.60 / 39.11$ \\
\hline Heated length (inch / cm) & $12.00 / 30.48$ & $18.80 / 47.752$ \\
\hline Hydraulic diameter (inch / cm) & $0.075 / 0.1905$ & $0.105 / 0.2667$ \\
\hline Velocities (fps / m/s) & $10.20 / 3.110$ & $85.40 / 26.03$ \\
\hline Local Reynolds number & 9,000 & 275,000 \\
\hline Heat transfer coefficient (Btu/hr.ft $\left.{ }^{2} . \mathrm{F} / \mathrm{W} / \mathrm{m}^{2} / \mathrm{K}\right)$ & $3.120 \mathrm{E}+3 / 17.70 \mathrm{E}+3$ & $7.360 \mathrm{E}+6 / 41.76 \mathrm{E}+6$ \\
\hline
\end{tabular}

For the heat transfer coefficient, only results from test \#4 to \#7 were reported. The exact range of conditions for these specific tests was not provided, except for test \#7.

The local heat transfer coefficient $h_{x}$ was calculated as:

$$
h_{x}=\frac{\phi_{x}}{\left(t_{w}-t_{b}\right)_{x}}
$$

Where:

- $\quad h_{x}$ : heat transfer coefficient at position $\mathrm{x}$

- $\Phi_{x}$ : heat flux at position x

- $t_{w}$ : wall temperature at position $\mathrm{x}$

- $\quad t_{b}$ : bulk temperature at position $\mathrm{x}$

The coolant bulk temperature was assumed to vary linearly along the test section. Gambill and Bundy noted that a more robust calculation showed that the error incurred by the linear assumption behavior was negligible. The procedure to evaluate the wall temperature was based on the temperature measured by the thermocouples, the local heat flux and the local thermo-physical properties of the aluminum. The procedure was estimated to produce an error of less than $5 \%$.

Gambill and Bundy are not discussing the error associated with their experimentally obtained heat transfer coefficient and their plots do not show any error bars. Based on engineering judgement and the information available, we estimate the error on the heat flux, wall and bulk temperature to be less than $5 \%, 5 \%$ and $2 \%$, respectively. Using the classic error propagation equation (i.e. square root of the sum of squares), we estimate the error on the reported local heat transfer coefficient to be less than $7.5 \%$.

For each test, a plot showing the heat transfer coefficient as well as the bulk and wall temperature was created. One of these plots is reproduced in Figure 4-6 below. It corresponds to the steady state \#8 of test \#7. It is unclear how many steady states were obtained for each test. Gambill and Bundy 
noted that the scatter of the measured wall temperature in this figure is particularly large. This is however the only case for which the flow conditions are explicitly reported.

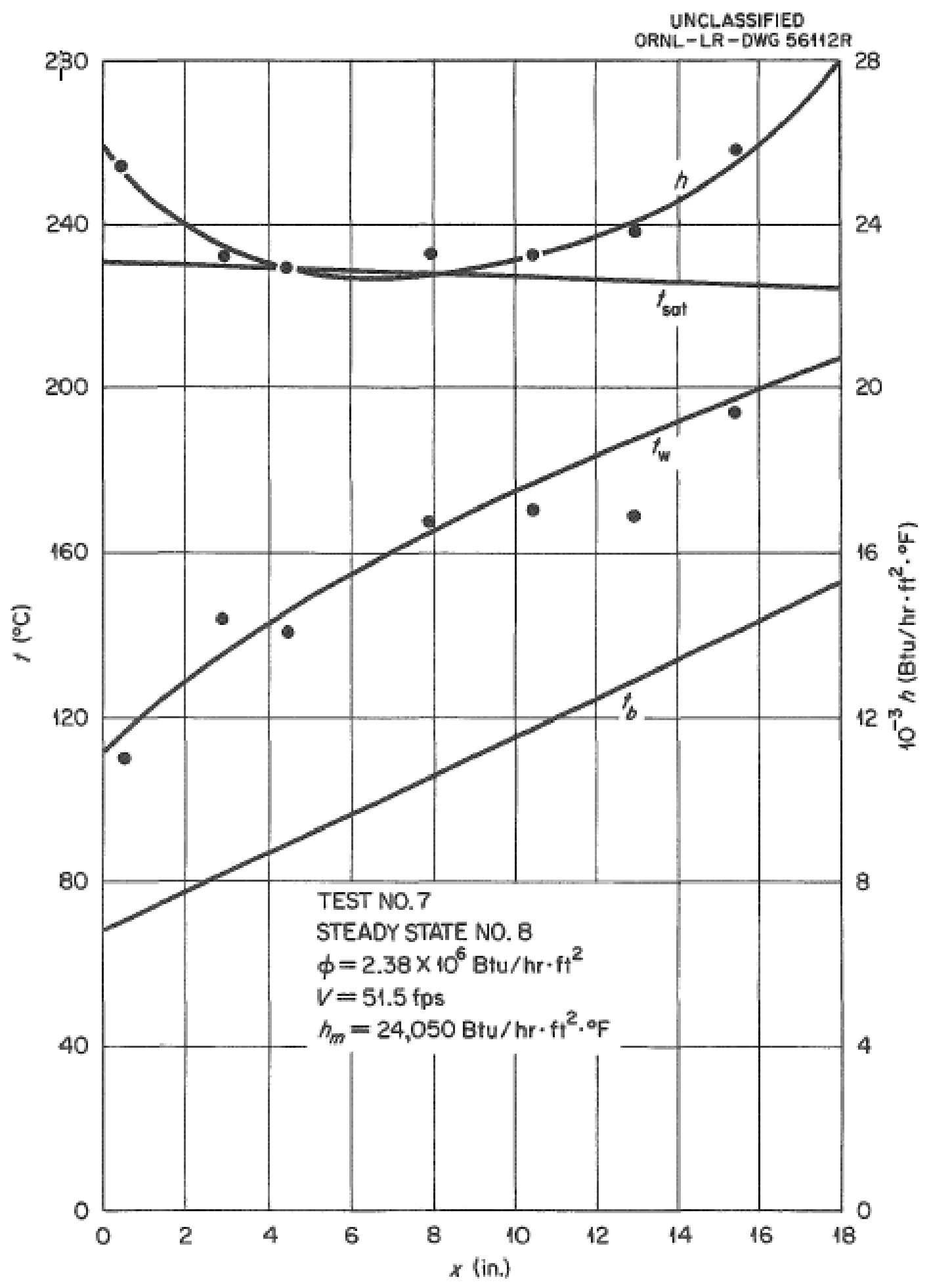

Figure 4-6 - Typical plot of variation of pertinent temperatures and of heat transfer coefficient with heated length. Source: reproduction of [Gambill, 1961], Figure 16. 
On Figure 4-6, one can find surprising that the heat transfer coefficient first decreases along the axial direction and then, increases again. Gambill and Bundy explained this behavior by the development of the thermal boundary layer near the entrance. They noted that this behavior was sometimes observed but not always.

The obtained local heat transfer coefficient curve was then integrated to obtain an average value for the test section. To simplify the reading, the local and average heat transfer coefficient will simply be referred to as $h_{x}$ and $h_{m}$, respectively, in the remaining part of this report.

One objective of the Gambill and Bundy experiment was to identify a correlation suitable for HFIR steady-state heat transfer analysis. Since these correlations provide the Nusselt number $\mathrm{Nu}$ and not the heat transfer coefficient directly, most experimental results provided by Gambill and Bundy were also expressed as Nusselt numbers. Local or average Nusselt numbers, will be noted $N u_{x}$ and $N u_{m}$, respectively. Recall that the relation between the Nusselt number and the heat transfer coefficient is given by:

$$
N u_{x}=\frac{h_{x} \cdot D_{e}}{k_{x}}
$$

Where:

- $\quad N u_{x}$ : Nusselt number at position $\mathrm{x}$

- $\quad h_{x}$ : heat transfer coefficient at position $\mathrm{x}$

- $k_{x}$ : coolant thermal conductivity at position $\mathrm{x}$

- $\quad D_{e}$ : hydraulic diameter

Experimental Nusselt numbers were compared to the ones obtained with the Sieder-Tate correlation [Sieder, 1936] and the Hausen correlation [Hausen, 1959]. Gambill and Bundy did not provide any justification for the selection of these two particular correlations.

The Sieder-Tate correlation is given by:

$$
N u=0.027 \operatorname{Re}^{0.8} \operatorname{Pr}^{1 / 3}\left(\frac{\mu_{b}}{\mu_{w}}\right)^{0.14}
$$

The Hausen correlation is given by:

$$
N u_{b}=0.116\left[(\operatorname{Re})_{b}^{2 / 3}-125\right](\operatorname{Pr})_{b}^{1 / 3}\left[1+\left(\frac{D_{e}}{L_{h}}\right)^{2 / 3}\right]\left(\frac{\mu_{b}}{\mu_{w}}\right)^{0.14}
$$

From (Equation 4), Gambill and Bundy derived a local form of the Hausen equation:

$$
N u_{x}=0.116\left[(\operatorname{Re})_{x}^{2 / 3}-125\right](\operatorname{Pr})_{x}^{1 / 3}\left[1+\frac{1}{3}\left(\frac{D_{e}}{x}\right)^{2 / 3}\right]\left(\frac{\mu_{b}}{\mu_{w}}\right)_{x}^{0.14}
$$

Where:

- Re : Reynolds number

- Pr: Prandtl number

- $\quad D_{e}$ : hydraulic diameter

- $\quad L_{h}:$ characteristic length

- $\quad \mu$ : dynamic viscosity

Indices $b, x$, and $w$ indicate if parameters are evaluated using, the average bulk, local bulk and local wall properties respectively. 
Figure 4-7 to Figure 4-9 present a comparison of the experimental data with the Sieder-Tate and Hausen correlations. Note that in these figures, the normalization of the abscissa and ordinate differ, depending if local or average Nusselt numbers are considered and depending to what correlation the experimental data are compared to. The $\mathrm{Nu}$ Normalized $^{*}$ (average) and Nu Normalized ${ }^{* *}$ (local) used in these figures are defined as:

$$
\begin{gathered}
\text { Nu Normalized } *=\frac{(N u)_{b}\left(\frac{\mu_{w}}{\mu_{b}}\right)^{0.14}}{(\operatorname{Pr})_{b}^{1 / 3}\left[1+\left(\frac{D_{e}}{L_{h}}\right)^{2 / 3}\right]} \\
N u \text { Normalized }^{* *}=\frac{(N u)_{x}\left(\frac{\mu_{w}}{\mu_{b}}\right)_{x}^{0.14}}{(\operatorname{Pr})_{x}^{1 / 3}\left[1+\frac{1}{3}\left(\frac{D_{e}}{x}\right)^{2 / 3}\right]}
\end{gathered}
$$

In Figure 4-8 and Figure 4-9 (comparison with the Hausen correlation) the Re Normalized* is defined as:

$$
\text { Re Normalized }^{*}=\operatorname{Re}^{2 / 3}-125
$$

Where, depending on the case, $R e$ is calculated as either a bulk or local quantity for a specific cross section.

In Figure 4-7 (comparison with Sieder-Tate correlation), the $\mathrm{Nu}$ Normalized ${ }^{* * *}$ is defined as:

$$
\text { Nu Normalized } \text { N** }^{*}=\frac{(N u)_{b}}{(\operatorname{Pr})_{b}^{1 / 3}}\left(\frac{\mu_{w}}{\mu_{b}}\right)^{0.14}
$$

Figure 4-7 and Figure 4-8 present approximately 30 averaged experimental Nusselt numbers which are compared to the Sieder-Tate and Hausen correlations. The experimental Reynolds numbers vary in a relatively large range $\left(1.0 \times 10^{4}\right.$ to $\left.2.5 \times 10^{5}\right)$ and based on the information provided in Table $2-2$, cover the range of interest of all three involute-plate reactors (i.e. Reynolds number $\sim 1.0 \times 10^{5}$ ). Based on these figures, it appears clearly that both the Sieder-Tate and Hausen correlations are estimating reasonably well the Nusselt number. A large majority of the experimental data points are above the correlations (even after inclusion of error bars) which means that, in this particular experiment, both correlations tend to provide conservative results.

On Figure 4-9, approximately 140 local Nusselt numbers are presented and compared to the local derivation of the Hausen correlation (see Equation 5). The experimental Reynolds numbers vary in a slightly larger range than previously and is therefore also highly relevant for involute-plate reactors. As observed for the averaged Nusselt number, a large majority of the experimental data points fall above the correlation (i.e. the correlation predicts lower Nusselt number) which indicate a certain degree of conservatism of the Hausen correlation. Based on this work, Gambill and Bundy recommended the use of the Hausen correlation for the HFIR reactor. This correlation has been integrated in the HFIR safety basis [McLain, 1967] which is still used today. 


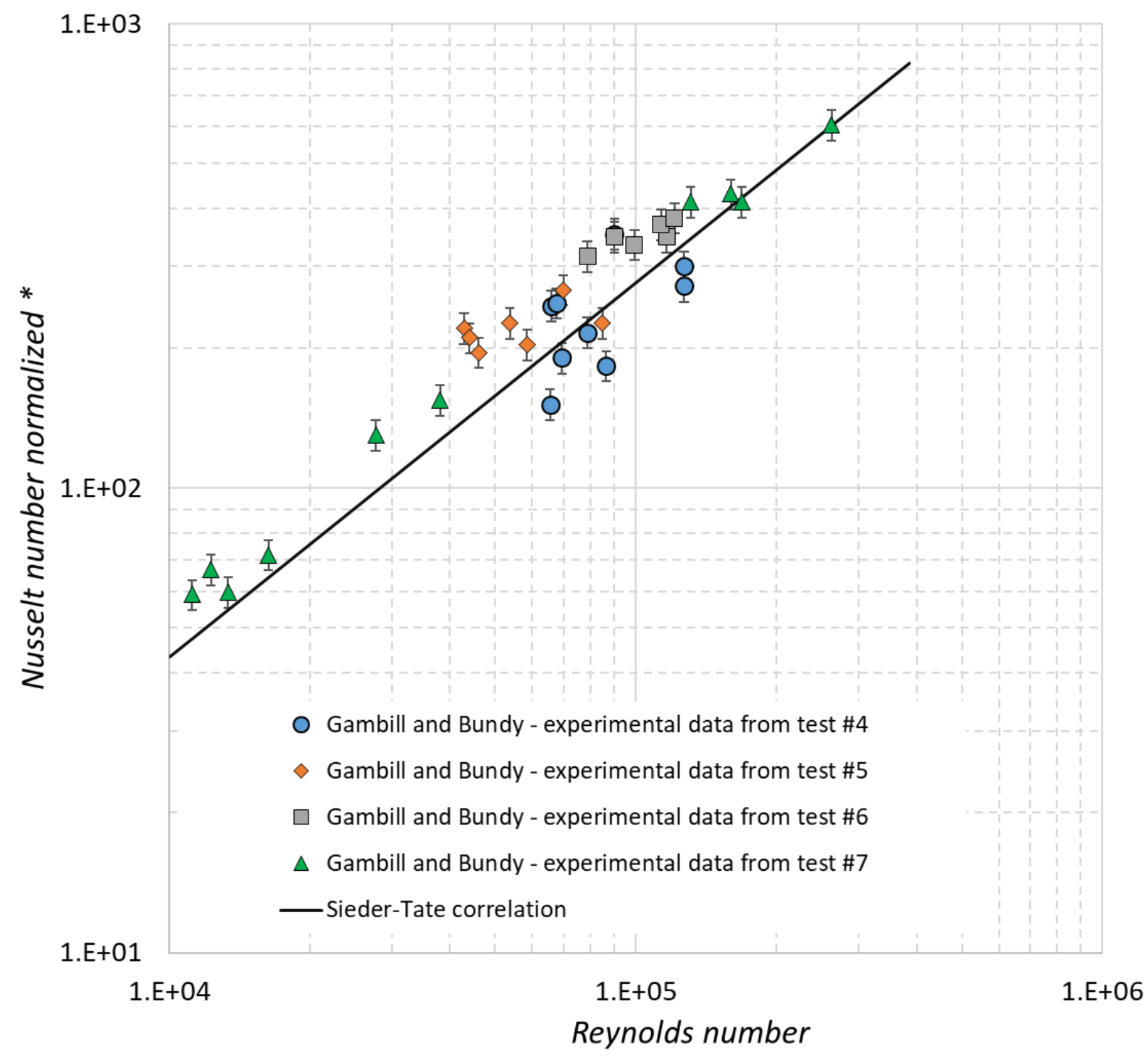

Figure 4-7 - Gambill and Bundy experimentally obtained average Nusselt number (normalized using Equation 9) and comparison with the Sieder-Tate correlation. Source: digitization of [Gambill, 1961], Figure 17. Error bars are not from original work, estimated by present authors. 


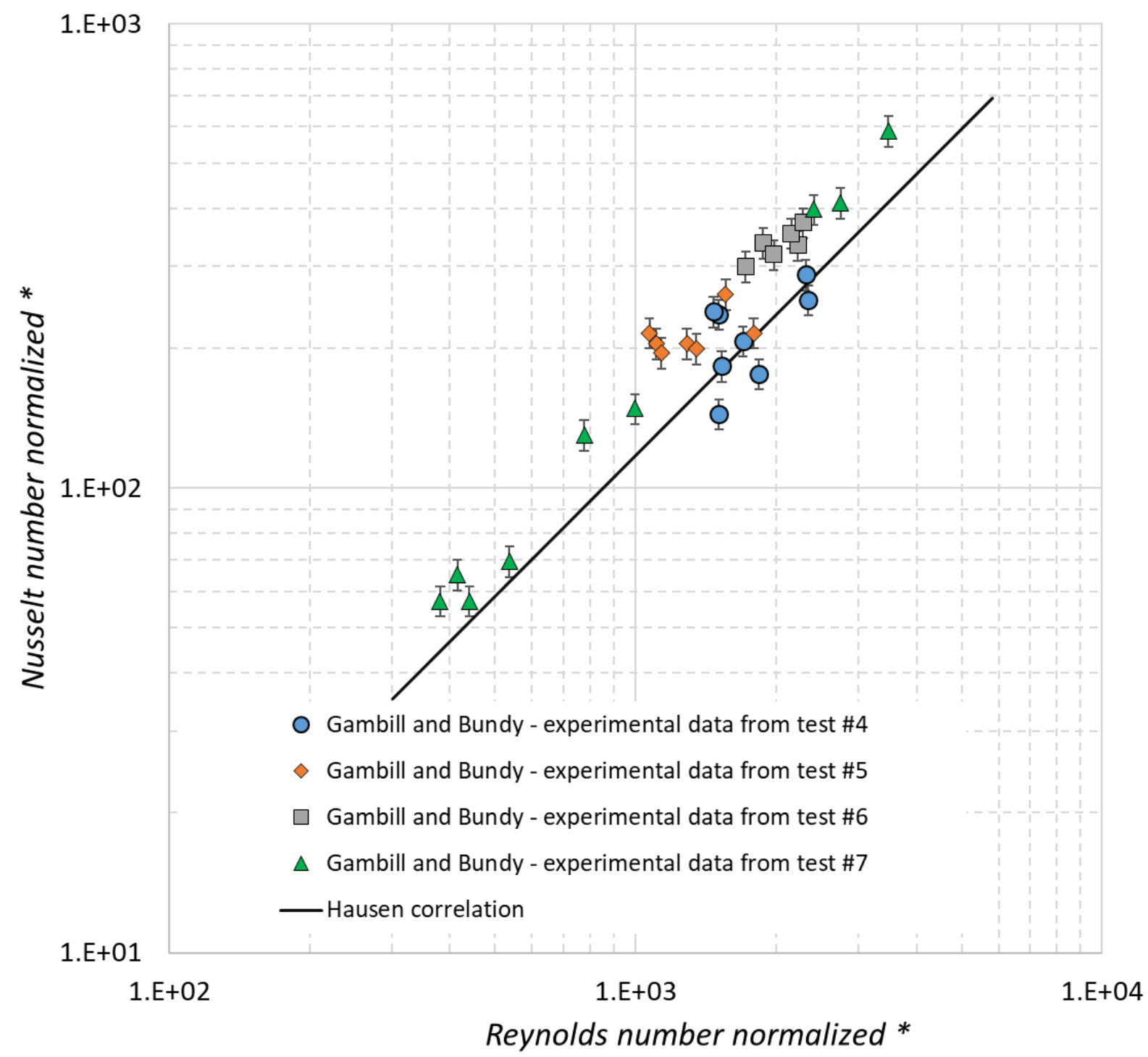

Figure 4-8 - Gambill and Bundy experimentally obtained average Nusselt number (normalized using Equation 6) and comparison with the Hausen correlation. Source: digitization of [Gambill, 1961], Figure 18. Error bars are not from original work, estimated by present authors. 


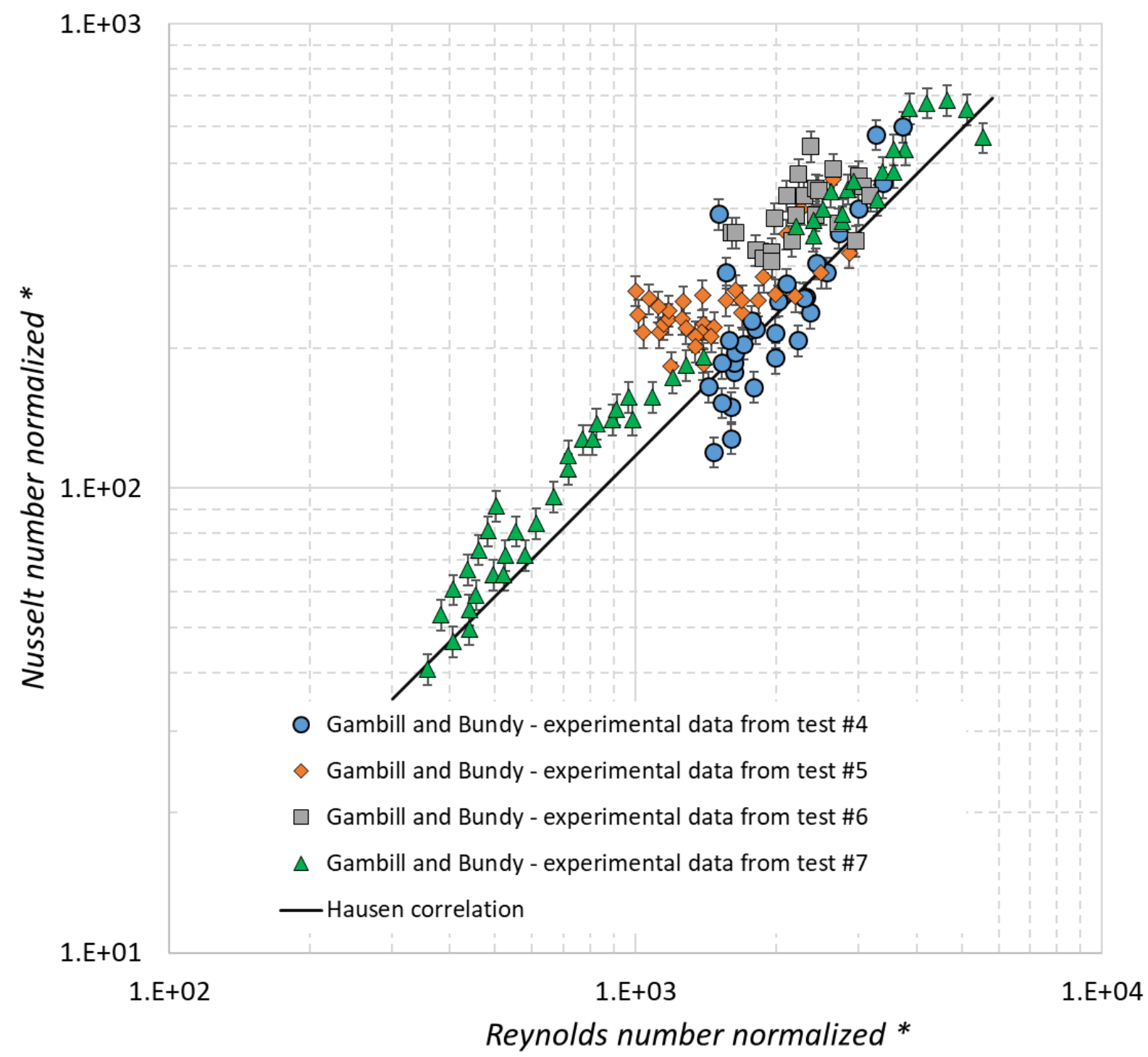

Figure 4-9 - Gambill and Bundy experimentally obtained local Nusselt number (normalized using Equation 7) and comparison with the Hausen correlation. Source: digitization of [Gambill, 1961], Figure 19. Error bars are not from original work, estimated by present authors. Data shown respects a double condition: film temperature drop $\Delta$ tf $\geq 150 \mathrm{C}$ and $\mathrm{x} / \mathrm{De} \geq 30$. 


\section{CFD Modeling of the Gambill and Bundy Experiment}

As explained earlier, the Involute Working Group (IWG) is aiming at qualifying CFD tools for performing steady-state safety analysis for all three involute-plate reactors: RHF, HFIR and FRM II. A critical part of CFD modeling for this kind of application is to demonstrate the ability to model correctly the heat transfer between the fuel plates and the coolant channels. Modeling heat transfer requires selecting a turbulence model that capture adequately the phenomena involved. It also requires adequate meshing that is consistent with the requirements of the selected turbulence models.

In this section, CFD models of the Gambill and Bundy experiments are discussed that make use of widely used turbulence models:

- $\quad$ K-Epsilon (Realizable K-Epsilon model with two layer all y+ wall treatment)

- K-Omega (Menter's K-Omega SST with all y+ wall treatment)

- Reynolds-Stress (with all y+ wall treatment)

The goal was to assess how well these well-known turbulence models perform in reproducing the experimental data. Recall that the geometry of the test section and the operating conditions are highly relevant for the involute-plate reactors.

With modern CFD packages, in addition to wide selection of various turbulence models, users have the possibility to set many parameters that may affect the solution. Here, for simplicity, the authors focused on simple smooth wall functions and were targeting, when possible, $\mathrm{Y}+$ in the range 30 to 100 (so called high Y+ range). More information on the turbulence models used in this study is provided in Appendix B.

Authors of this report could not access the raw experimental data and had to rely solely on the results presented in the Gambill and Bundy report [Gambill, 1961]. Unfortunately, this report does not provide the exact flow conditions used for specific tests. An exception to this description was the steady-state \#8 of Test \#7. For this test, enough information was provided to build an equivalent CFD model with minimal assumptions.

Based on the information available, using the commercial software STAR-CCM+ [Siemens, 2018], a CFD model of the test section used in test \#7 was created. In the experiment, some components of the flow loop (sizeable electrode plates, mounting extensions of the testing specimen...) certainly help flow and thermal boundary layers to develop. Not enough information was provided to model explicitly these components. Instead, an artificial inlet extension was added to the CFD model to allow for the flow boundary layer development. However, the development of the thermal boundary layer could not be easily implemented in the CFD model, as the distribution of the temperature within the electrode plates was not provided. 


\subsection{Test Section Geometry}

As presented in Figure 5-1, the inner channel in Test \#7 had rounded shorter edges. The channel gap was 0.501 -inch-wide $(1.273 \mathrm{~cm})$ and 0.057 -inch-thick $(0.1448 \mathrm{~cm})$. The metal thickness in the flat section was equal to $0.035 \mathrm{inch}(0.089 \mathrm{~cm})$, while in the curved section it was 0.027 -inch-thick $(\sim 0.069$ $\mathrm{cm})$. That difference in the thicknesses was designed to produce approximately the same boundary heat flux on both, the flat and the curved, parts. The heated length of the specimen in Test \#7 was 18.28 inch $(46.43 \mathrm{~cm})$.

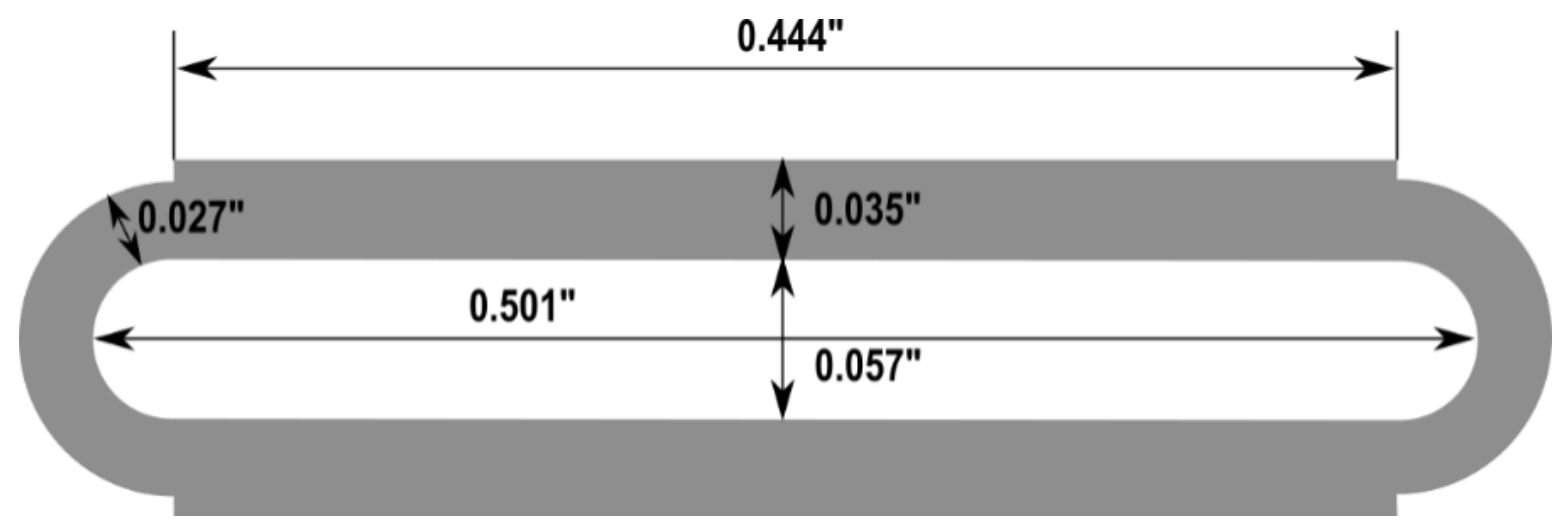

Figure 5-1 - The cross section of the specimen in Gambill's experiment set \#7 (units: inch)

\subsection{Material Properties}

Constant density, specific heat and thermal conductivity for the aluminum alloy 1100 (test section material) were assumed in the simulations as listed in Table 5-1. Variation in density and thermal conductivity of aluminum within the reported range of temperatures was considered negligible. Variation in specific heat within the range of expected temperatures $300-550^{\circ} \mathrm{F}\left(149-288^{\circ} \mathrm{C}\right)$ is less than $5 \%$ and has no effect on the results.

Table 5-1 - Material constants for the solid parts (aluminum alloy 1100)

\begin{tabular}{|l|c|}
\hline \multicolumn{1}{|c|}{ Material constant } & Aluminum $\mathbf{1 1 0 0}$ \\
\hline Density $\left(\mathrm{kg} / \mathrm{m}^{3}\right)$ & $2,710.0$ \\
\hline Specific heat $(\mathrm{J} / \mathrm{kg}-\mathrm{K})$ & 903.0 \\
\hline Thermal conductivity $(\mathrm{W} / \mathrm{m}-\mathrm{K})$ & 218.0 \\
\hline
\end{tabular}

For the coolant (water), the density, dynamic viscosity, specific heat as well as thermal conductivity of water were defined as polynomial functions of temperature of various orders. The water properties at pressure of 30 bar (3 MPa) were obtained from [NIST, 2018] in a tabular format. Figure 5-2 and Figure 5-3 show plots of these properties. Equations of fitted polynomials used for each of these material properties in STAR-CCM+ simulations are displayed in these plots as well. The same water properties were used throughout all the simulations presented in this report because in the range of pressures considered - 10 to 40 Bar - water properties (always single phase and liquid) can be reasonably considered to be pressure-independent. 

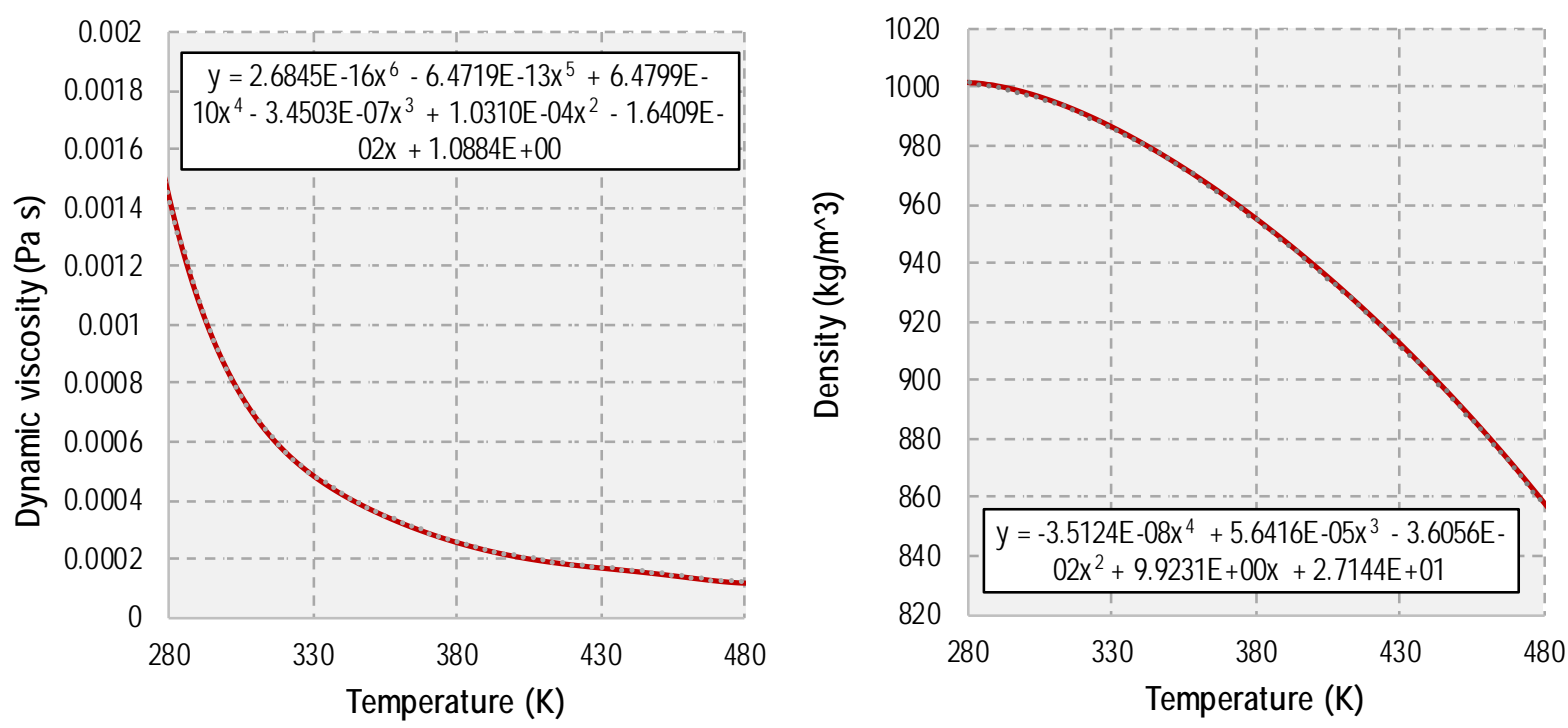

Figure 5-2 - (left) Dynamic viscosity as a function of temperature at 30 bar; (right) Density of water as a function of temperature at $30 \mathrm{bar}$
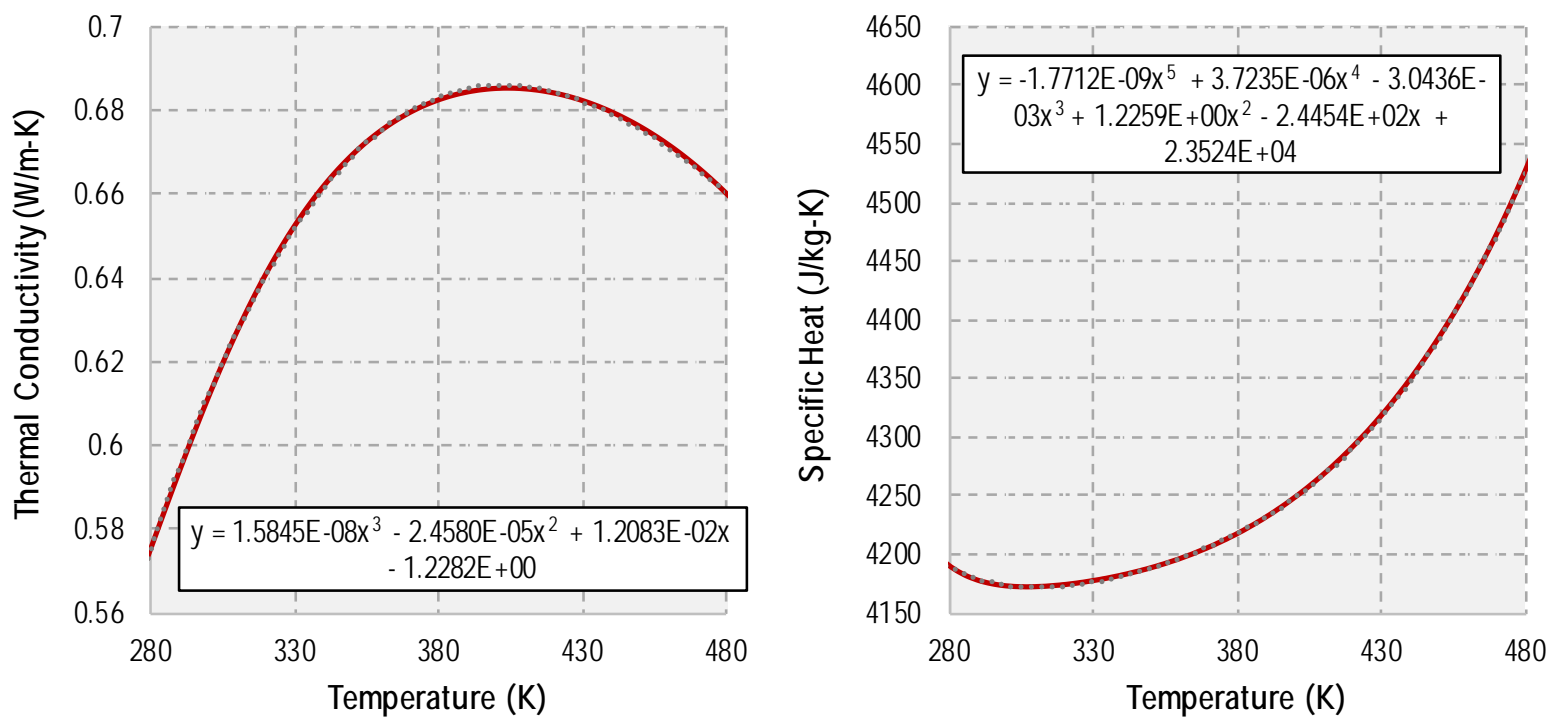

Figure 5-3 - (left) Thermal conductivity of water as a function of temperature at 30 bar; (right) Specific heat of water as a function of temperature at $30 \mathrm{bar}(3 \mathrm{MPa})$

\subsection{Heat Source Modeling}

Heat generation within the specimen can be simulated in STAR-CCM+ with the use of several methods, including: total heat source, volumetric heat source and Joule heating. It was decided that the volumetric heat source is the most appropriate method for the purpose of this study. The volumetric heat source can be defined to be dependent on resistivity of the aluminum, which varies with the 
temperature. At the same time, it does not increase modeling complexity by adding further physics to the simulation (as would be the case for Joule heating).

The total power generated by the flowing current is defined as:

$$
P=I^{2} R=I^{2} \frac{\rho(T)}{A} l
$$

Thus, the volumetric heat source is defined as:

$$
\frac{P}{V}=\frac{I^{2} R}{V}=\frac{I^{2} \frac{\rho(T)}{A} l}{A l}=\frac{I^{2}}{A^{2}} \rho(T)
$$

Where:

- $\quad$ P: power $(W)$

- I: current (A)

- $\quad$ R: resistance $(\mathrm{Ohm})$

- $\quad \rho(T)$ : resistivity $(\mathrm{Ohm} \cdot \mathrm{m})$

- $\quad A, l$ : cross section area and length of the heated specimen, respectively (m)

The resistivity of aluminum alloy $1100, \rho$, was defined as a linear function of temperature by an empirical formula based on $(\mathrm{Du}, 2014)$ :

$$
\rho=\rho_{0}\left(1+\alpha \cdot\left(T-T_{0}\right)\right)
$$

Where:

- $\rho_{0}$ : resistivity at a reference temperature $\mathrm{T}_{0}$

- $\quad \alpha-$ : material specific temperature coefficient of resistance.

Assuming $\rho_{0}=2.99 \cdot 10^{-8}$ at $\mathrm{T}_{0}=293.15 \mathrm{~K}$ [MatWeb, 2018] and $\alpha=0.004308[\mathrm{Du}, 2014]$ the equation used in the model took the form:

$$
\rho=2.99 \cdot 10^{-8}(1+0.004308 \cdot(T-293.15 K))
$$

\subsection{Simulation of Test \#7 Steady-State \#8}

In this test, the coolant was flowing into the channel at a velocity of $51.5 \mathrm{ft} / \mathrm{s}(15.7 \mathrm{~m} / \mathrm{s})$. The bulk temperature of the coolant at the inlet was about $155.3^{\circ} \mathrm{F}\left(68.5^{\circ} \mathrm{C}\right)$ and at the outlet was about $310.1^{\circ} \mathrm{F}$ $\left(154.5^{\circ} \mathrm{C}\right)$. The outlet pressure was measured to be 355 psig $(2.45 \mathrm{MPa})$. The reported average heat flux was estimated at 7,508 $\mathrm{kW} / \mathrm{m}^{2}$. As presented in Table 2-1, the operating conditions of Test \#7 steady-state \#8 are particularly relevant for involute-plate reactors.

The total power supplied was estimated from the change in the bulk temperature from the inlet to the outlet (assuming its linear growth with the growth of the distance from the inlet and constant value of heat capacity) to be around $100 \mathrm{~kW}$. Because water and aluminum properties (resistivity) are temperature dependent, this value is only an estimate. In the simulations, the power was 
minimally adjusted (less than $2 \%$ ) so the bulk temperature on the outlet matched the reported outlet bulk temperature.

Although in the experiments the temperature was measured on the outside walls of the specimen, this quantity was not specified directly by Gambill \& Bundy. Instead, the wall temperature on the interface between the aluminum specimen and the coolant was provided (Figure 16 of Gambill and Bundy report, reproduced for convenience as Figure 4-6 in this report) and was used here as a primary validation data for the simulations.

The computational mesh in the STAR-CCM+ model was built with the use of STAR-CCM+ Directed Mesher. The base model was built with conformal hexahedral mesh with the smallest element edge size of about $\sim 0.0012$ inch $(0.03 \mathrm{~mm})$. The mesh in the cross section through the specimen and the channel is shown in Figure 5-4. The largest size of the element edge, in the axial (flow) direction, was $\sim 0.04$ inch $(1 \mathrm{~mm})$. Altogether 300 layers of elements were used in the axial direction. As a result, the base model had around 3.3 million hexahedral cells with about 1.6 million in the aluminum region and about 1.5 million in the coolant region. The water channel part was extended by the length 11.5 $\mathrm{cm}$ long what is equivalent to about 43 hydraulic diameters of the channel. Usually 40 hydraulic diameters are more than enough for a turbulent flow to fully develop. That section was built of approximately 200,000 elements. In the experiment, other elements of the flow loop existed that allowed for flow development. Not enough information was provided to model these elements explicitly.

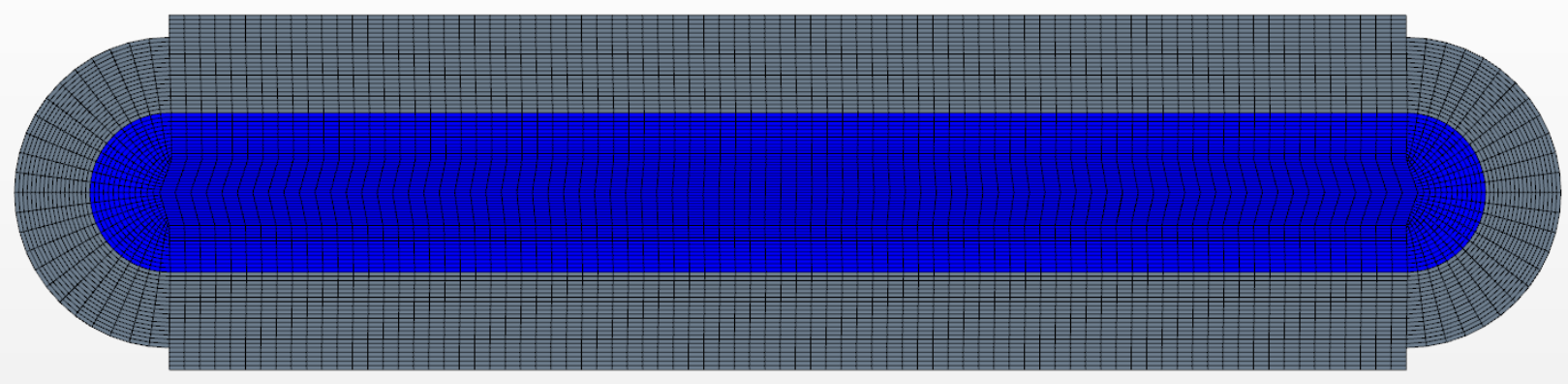

Figure 5-4 - Cross section of Gambill's experiment test \#7 CFD Model with mesh visible (gray: aluminum test section; blue: water)

The near wall mesh in the base model went through several updates to satisfy the requirement of wall Y+ parameter being between 30 and 100, which assures the correctness of the approximations of near-wall turbulent flows per STAR-CCM+ manual. Certain turbulence models are implemented for low (1 to 5) and high (above 30) Y+ values while some of them are only implemented for one of the two regions. In these simulations the focus was on high $\mathrm{Y}+$ meshes as these are most efficient and appropriate for highly turbulent flows. Nonetheless, the turbulence models selected in this study were implemented for low and high Y+ values. The wall Y+ distribution on the coolant wall for the base model is shown in Figure 5-5. It starts around 35 near the inlet and grows to about 80 near the outlet. Relatively large gradients of temperature are expected in both the liquid and solid domains. The chosen mesh density is expected to provide a smooth distribution of the temperatures without noticeable jumps between the neighboring layers of cells. For the cases with very low Reynolds number (introduced later in section 5.5 of this report), the mesh has been adjusted so the $Y+<1$ (the first cell center placed in the viscous sublayer). Otherwise, the near wall cell would have occupied a significant part of the channel thickness. 
Adiabatic boundary conditions were assumed on the external boundaries of the aluminum specimen. The water temperature at the inlet was set to be the same as in the experiment at $155.3^{\circ} \mathrm{F}\left(68.5^{\circ} \mathrm{C}\right)$. The bulk water temperature at the outlet of the base model was calculated to be $309.9^{\circ} \mathrm{F}\left(154.4^{\circ} \mathrm{C}\right)$ while in the experiment it was measured to be $310.1^{\circ} \mathrm{F}\left(154.5^{\circ} \mathrm{C}\right)$. The distribution of the temperature in the longitudinal cross-section through the coolant channel is shown in Figure 5-6. The temperature distribution at the axial midplane of the specimen is shown in Figure 5-7.

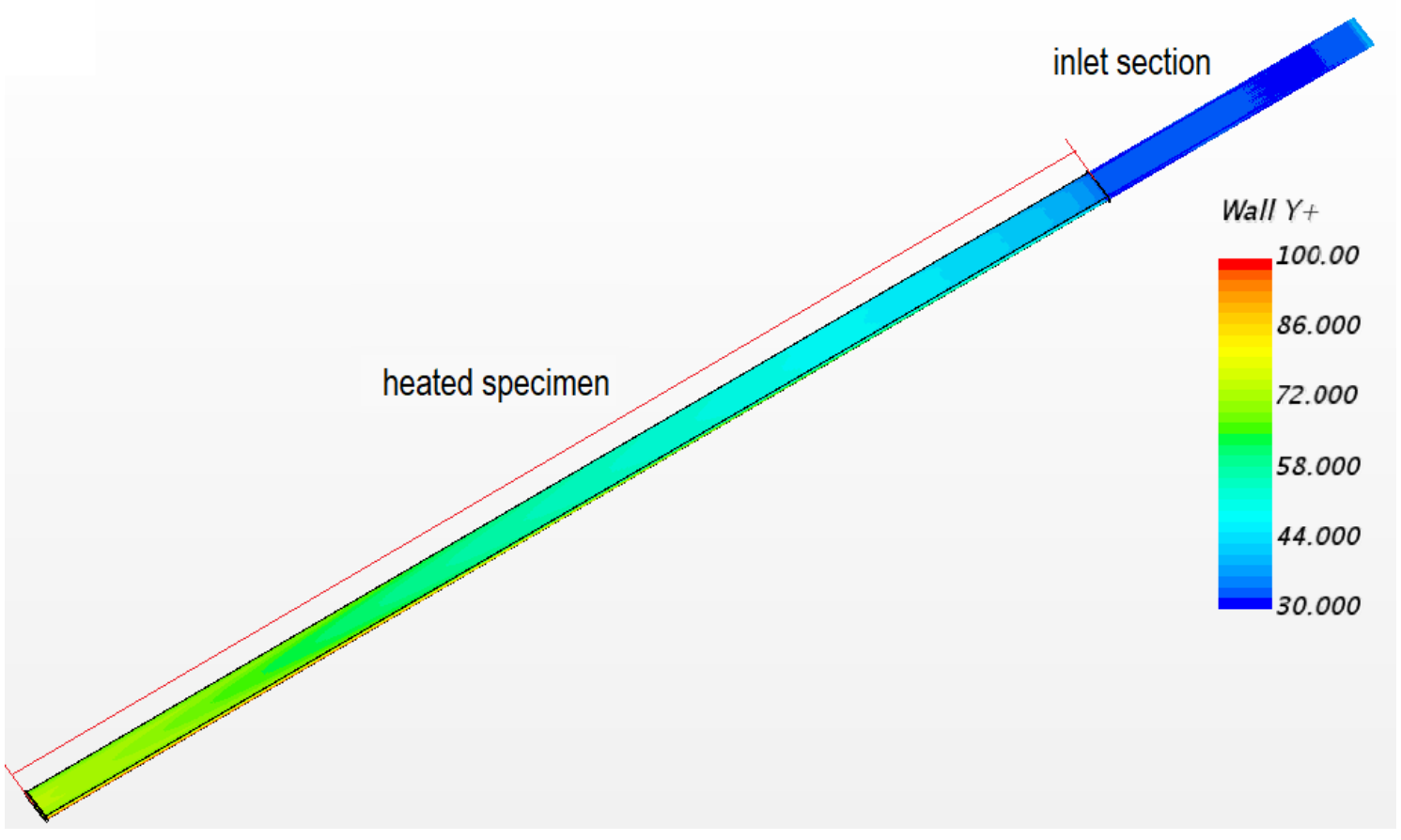

Figure 5-5 - Wall Y+ in the steady-state \#8 Test \#7 model 


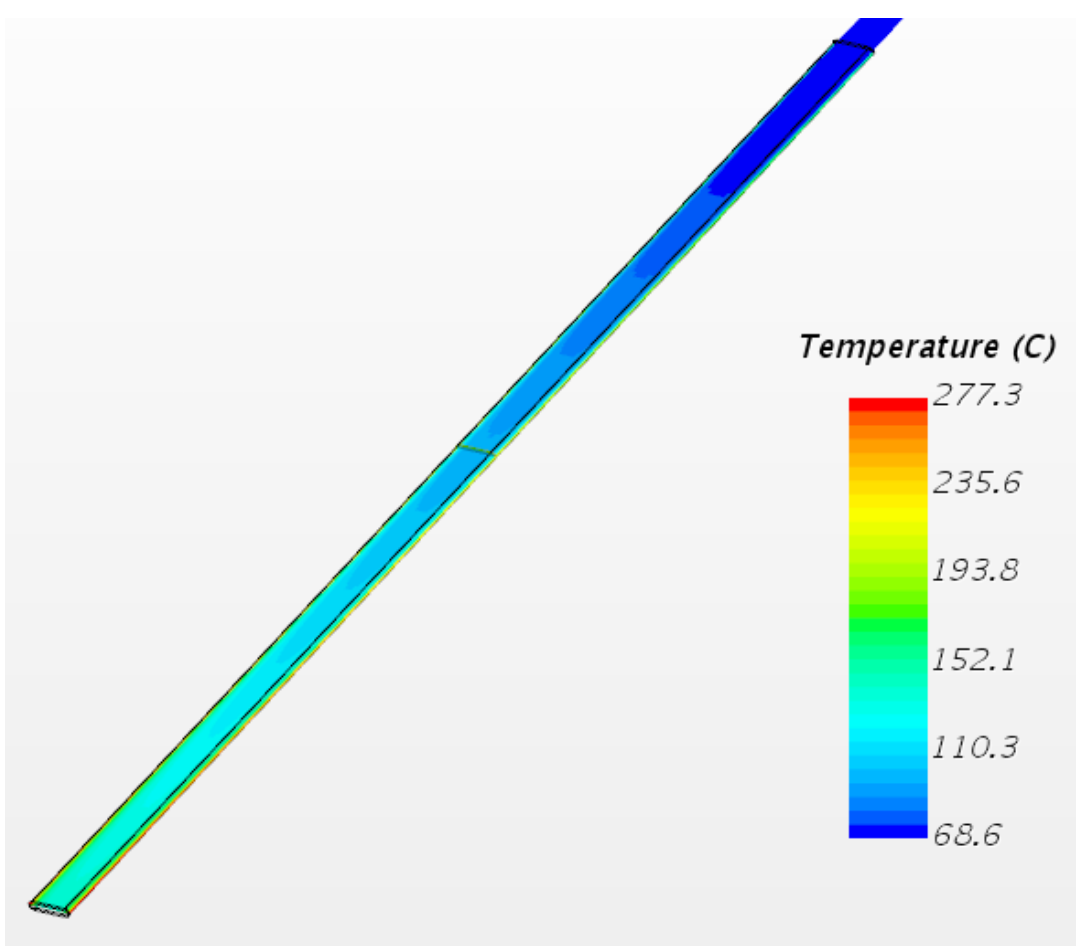

Figure 5-6 - Temperature distribution in the cut through the coolant channel in the steady-state \#8 Test \#7 model (obtained with K-Epsilon turbulence model)

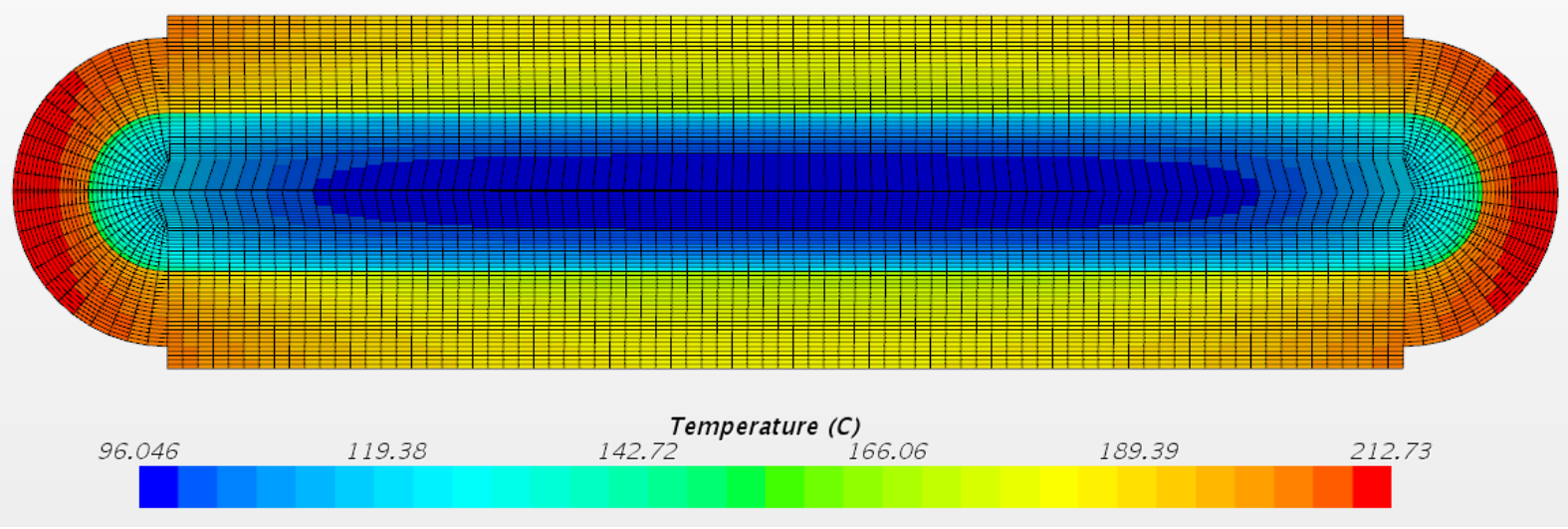

Figure 5-7 - Temperature distribution in the center of the specimen and the coolant channel in the steady-state \#8 Test \#7 model (obtained with K-Epsilon turbulence model)

As mentioned earlier, the wall temperature on the interface between the specimen and the coolant was reported only for the steady-state \#8 of Test \#7. Experimental results obtained from this test have been presented previously in section 4.2, Figure 4-6. Seven discrete measurement locations were considered along the wall. Figure 5-8, Figure 5-9 and Figure 5-10 present the experimental data obtained for this test together with the results obtained from the CFD model run with K-Epsilon (k$\varepsilon$ ), K-Omega (k- $\omega$ ) and Reynolds-Stress (R-S) turbulence models, respectively.

These figures show the bulk and wall temperature profiles along the test section as well as the local heat transfer coefficient (right axis). As shown in Figure 5-8 to Figure 5-10, the bulk temperature 
profiles calculated with the three CFD models match the experimental data very well (the heat source has been calibrated for that).

Regarding the wall temperature profile, there is a visible discrepancy between the predicted temperature and the experimental data near the inlet to the specimen. It was the largest for $\mathrm{k}-\omega$ model followed by k- $\varepsilon$ model, and smallest for the R-S turbulence model. Passed a quarter of the specimen's length downstream from the inlet, the discrepancy is reduced significantly. In the downstream half of the sample (zone with higher temperatures on the walls) all three models seem to capture relatively well the evolution of the wall temperature: the curve obtained with all three CFD models fall within most of the experimental data points.

It was concluded that the discrepancy near the inlet could be attributable to the fact that in the simulation, only the heated portion of the specimen is modeled while in reality there are more metal parts in contact with the specimen that conduct the heat away from the inlet of the heated section (i.e. nozzle, piping, and electrodes). Recall that these components could not be modeled as not enough information was provided. As a result, the temperature measured in the experiment near the inlet is lower than the simulated temperature. Good agreement between the simulated and experimental data for most of the investigated locations justified not exploring further the discrepancies observed at the inlet.

Figure 5-8, Figure 5-9 and Figure 5-10 also show the local heat transfer coefficients obtained experimentally and the ones obtained with CFD. Qualitatively, the CFD models capture the same trend as the one obtained experimentally: a sharp decrease of the heat transfer coefficient near the entrance followed by a continuous increase further along the channel. As mentioned by Gambill and Bundy, the development of the thermal boundary layer is probably responsible for the sharp decrease observed near the inlet. The simplification made in the CFD model at the inlet probably exacerbate this phenomenon. Further along the channel, the rise of the heat transfer coefficient is very strong with the $\mathrm{k}-\varepsilon$ model and far more modest with the k- $\omega$ and R-S models.

As a result, despite the fact that the heat transfer coefficients calculated with the three CFD models fall within most of the experimental data points, the $k-\varepsilon$ model tends to predict values slightly above the experimental ones while the opposite is observed with k- $\omega$ and R-S models. Overall, the CFD models seem to be able to capture correctly the experimental observations. 


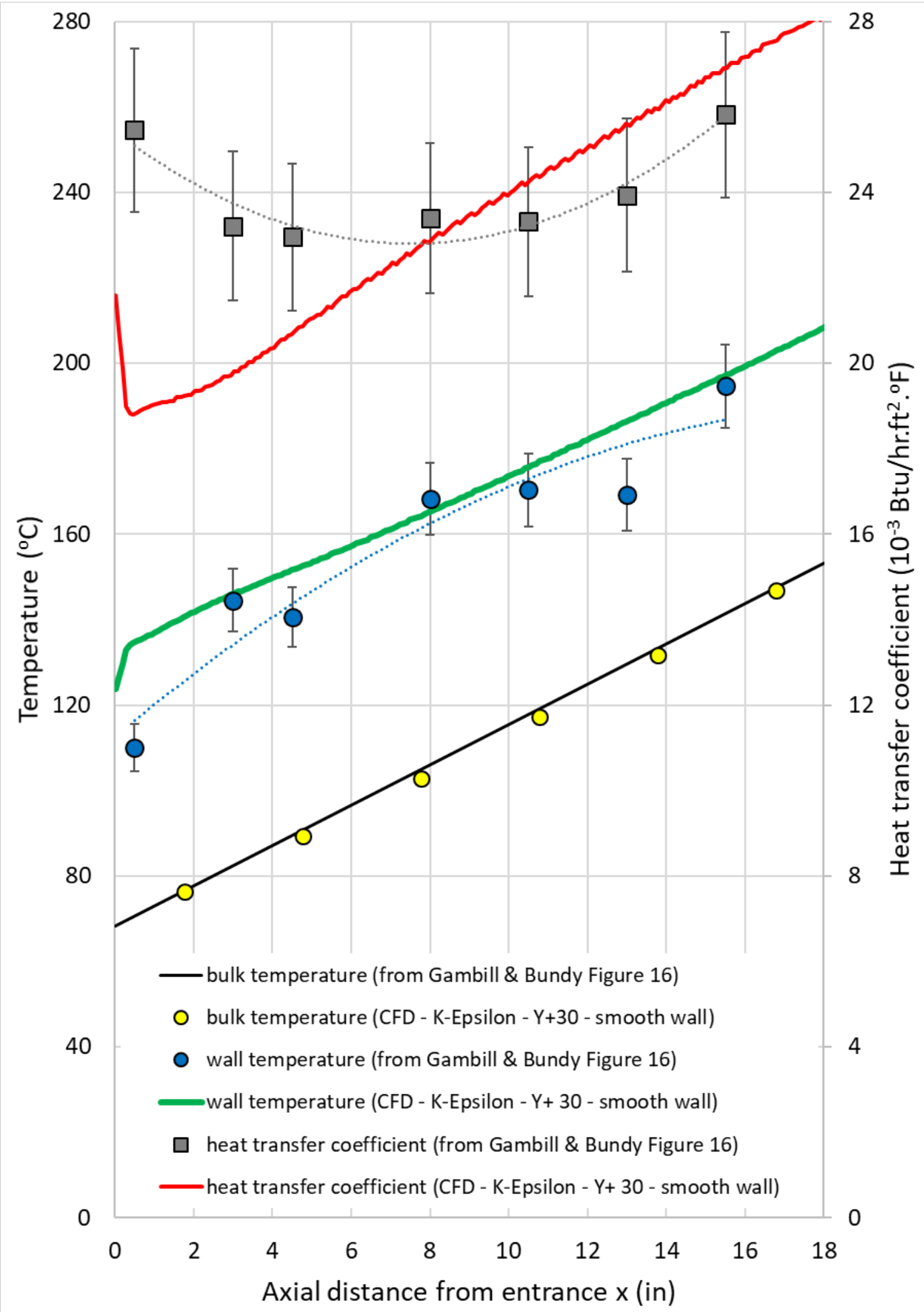

Figure 5-8 - Temperature and heat transfer coefficient obtained by Gambill and Bundy in Test \#7 steady-state \#8 and comparison with CFD using K-Epsilon model 


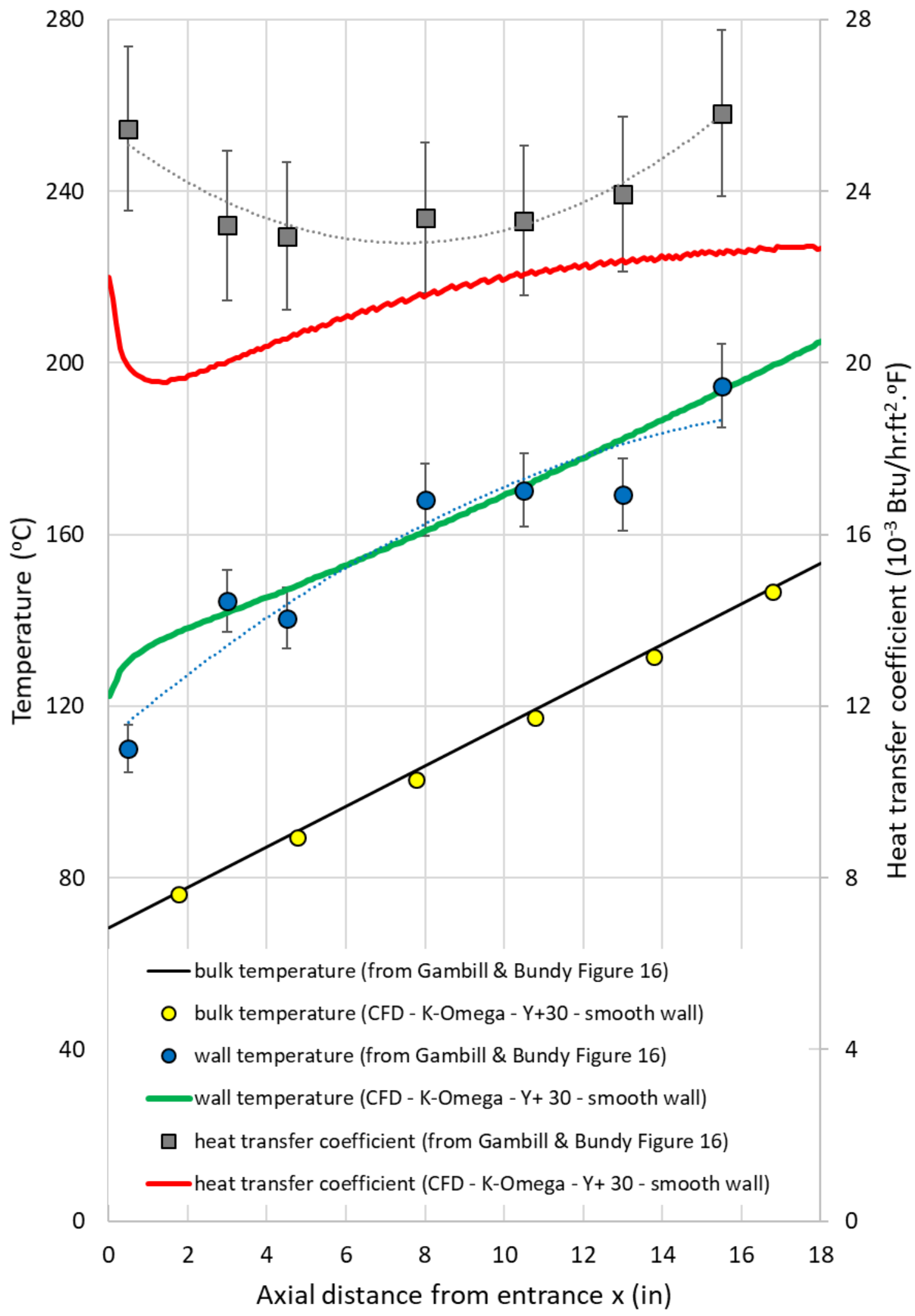

Figure 5-9 - Temperature and heat transfer coefficient obtained by Gambill and Bundy in Test \#7 steady-state \#8 and comparison with CFD using K-Omega model 


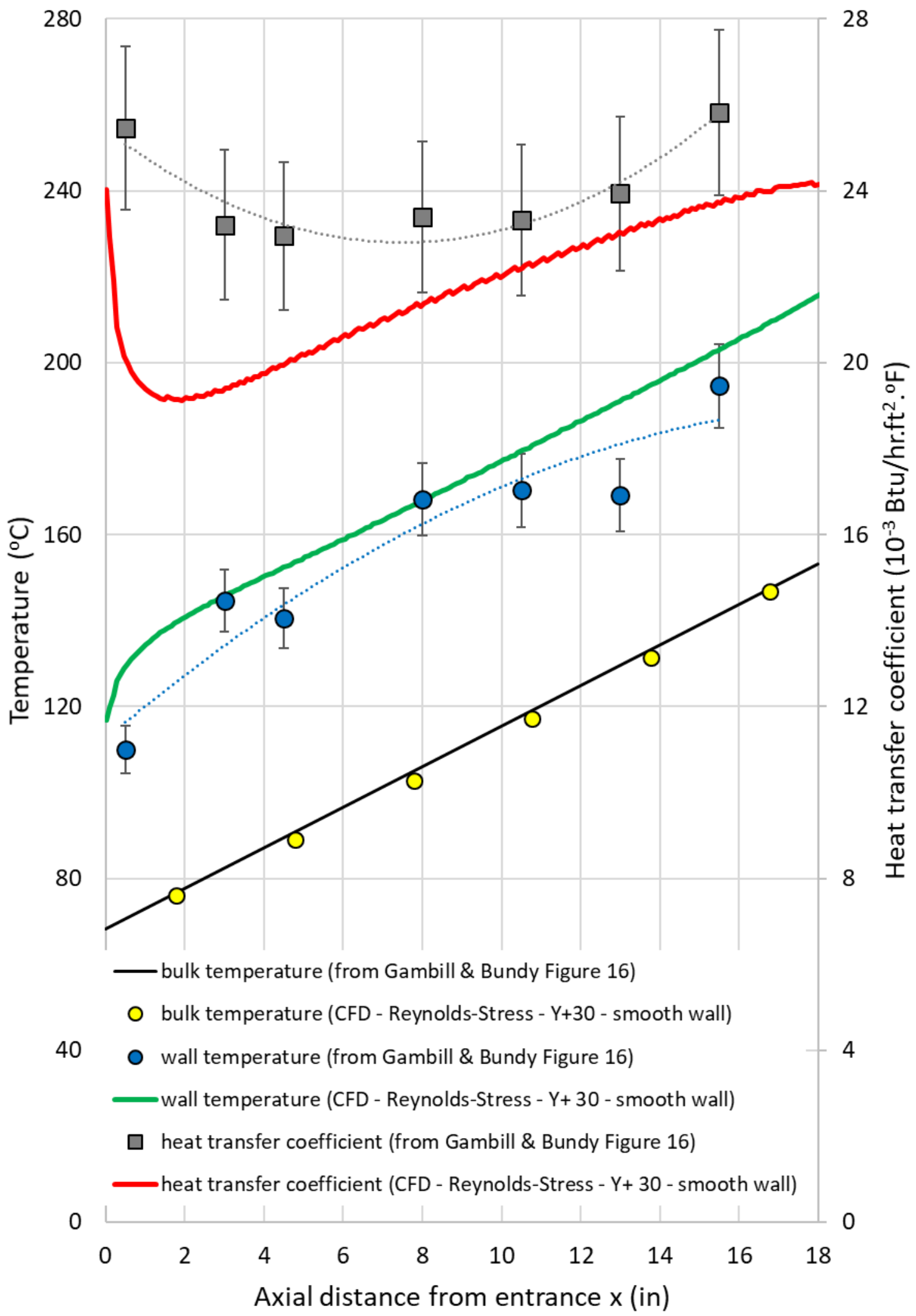

Figure 5-10 - Temperature and heat transfer coefficient obtained by Gambill and Bundy in Test \#7 steady-state \#8 and comparison with CFD using Reynolds-Stress model 


\subsection{Simulations for an Extended Range of Reynolds Number}

As explained earlier, the conditions from Test \#7 steady-state \#8 were the only ones that were provided explicitly. The exact conditions of the tests used to generate the data points presented in Figure 4-7, Figure 4-8 and Figure 4-9 were not available. Only the range of operating conditions was given (see Table 4-1).

The experimental results of tests \#4 through \#7 are functions of the Reynolds number only. The range of Reynolds and Nusselt numbers covered in the experiment can be replicated in the simulations based on their non-dimensional character. Thus, in the subsequent set of simulations, the inlet velocity and the power provided through the heating in the channel walls were modified to create several other cases, covering broader ranges of Reynolds number. These two input parameters are obviously not the only ones that can vary to achieve this goal. Thus, a more general sensitivity study is presented in Section 6 with five varying input parameters on a smaller, fast converging CFD model.

The cases considered in this Section are listed in Table 5-2. The heat flux was not the direct input to these simulations, instead, as explained earlier, the volumetric heat source was used. However, in the table, the resultant average heat flux is used as a quantity that is easier to compare between different cases.

Table 5-2 - Analyzed cases based on Gambill experiment geometry

\begin{tabular}{|c|c|c|c|}
\hline Case ID & Bulk velocity & Average heat flux & Turbulence model \\
\hline \#A (nominal) & $16.5 \mathrm{~m} / \mathrm{s}$ & $7.8^{*} 10^{6} \mathrm{~W} / \mathrm{m}^{2}$ & $\mathrm{k}-\varepsilon, \mathrm{k}-\omega$, Reynolds stress \\
\hline \#B & $8.25 \mathrm{~m} / \mathrm{s}$ & $3.8^{*} 10^{6} \mathrm{~W} / \mathrm{m}^{2}$ & $\mathrm{k}-\varepsilon, \mathrm{k}-\omega$, Reynolds stress \\
\hline \#C & $4.08 \mathrm{~m} / \mathrm{s}$ & $1.2^{*} 10^{6} \mathrm{~W} / \mathrm{m}^{2}$ & $\mathrm{k}-\varepsilon, \mathrm{k}-\omega$, Reynolds stress \\
\hline \#D & $2.1 \mathrm{~m} / \mathrm{s}$ & $1.4^{*} 10^{6} \mathrm{~W} / \mathrm{m}^{2}$ & $\mathrm{k}-\varepsilon, \mathrm{k}-\omega$, Reynolds stress \\
\hline
\end{tabular}

In all of the analyzed cases, the Reynolds number spans from about 5,500 to about 250,000, which covers almost exactly the range covered by Gambill and Bundy in their Test \#4 to \#7 (see Figure 4-7, Figure 4-8 and Figure 4-9 for a reproduction of the results obtained by Gambill and Bundy).

A comparison of the experimental Nusselt number along with the CFD results obtained with the cases \#A to \#D is shown in Figure 5-11 to Figure 5-13. To simplify the figures, fit functions of all CFD data points obtained for all four cases are shown instead of the actual data points. The discrete CFD data points and their corresponding fit functions are provided in full in Appendix C. The fits have an $\mathrm{R}^{2}$ above 0.995 which means that the deviation between the data points and the fit functions is in all cases very small.

Figure 5-11 shows the experimental averaged Nusselt numbers along with the ones obtained using the Sieder-Tate correlation and the CFD results. Based on this figure it can be concluded that the three CFD models (k- $\omega, \mathrm{k}-\varepsilon$ and R-S) perform relatively well as the calculated Nusselt numbers fall well within the cluster of experimental data points. This is particularly true in the range of interest of the involute-plate reactors (e.g. Re $\sim 100,000$ ). There are, however, differences between the CFD turbulence models: $k-\omega$ tends to calculate higher Nusselt number, followed by k- $\varepsilon$ and the most conservative results (prediction of lowest Nusselt number) are provided by R-S. Quantitatively, about 75, 69 and 78\% of the experimental data points fall above the k- $\varepsilon$, k- $\omega$ and R-S model respectively. This indicates a tendency toward conservatism. Both the k- $\varepsilon, \mathrm{k}-\omega$ tend to predict higher Nusselt 
numbers than Sieder-Tate correlation. The R-S model tends to predict higher Nusselt numbers than Sieder-Tate correlation up to Reynold numbers of 200,000 and then tends to predict lower values.

Figure 5-12 presents the experimental averaged Nusselt numbers along with the ones obtained using the Hausen correlation and the CFD results. Since the same data points as presented in Figure 5-11 are shown (only with a different normalization), the same observations described in the previous paragraph apply. Like for Sieder-Tate, the CFD results tend to predict higher Nusselt numbers than the Hausen correlation. In this case, it is true for all three turbulence models and for the entire range of considered Reynolds numbers.

Figure 5-13 presents the experimental local Nusselt numbers along with the ones obtained using the Hausen correlation and the CFD simulations. Since local values are considered here, the number of experimental data points to compare with increases from 31 to almost 140. Despite the number of data points, it can still be observed that the Nusselt numbers calculated with CFD fit very well within the experimental data points as most of them cluster around the fits to the Nusselt numbers predicted by CFD.

Quantitatively, about 72, 64 and 74\% of the experimental data points fall above the k- $\varepsilon$, k- $\omega$ and R-S model respectively, confirming the tendency toward conservatism of the CFD models. To better describe this pattern, a distribution of the deviation of the calculation relative to the experiment (i.e [Calculated value -Experimental value]/Experimental value or (C-E)/E) is shown in Figure 5-14 (data bins have a width of $10 \%$ ). The mean (C-E)/E is $-10.1,-3.6$ and $-10.1 \%$ for the $\mathrm{k}-\varepsilon, \mathrm{k}-\omega$ and R-S model respectively. Encouraged by the skewness and kurtosis factors that are found to be between -2 and 2 for all three (C-E)/E distributions, additional statistical tests (p-tests) have been carried out to test if these distributions were following a normal distribution. These tests indicated that the data are not normally distributed and therefore, the mathematical tools characterizing them cannot be employed here.

Nonetheless, it can be concluded that the three turbulence models capture relatively well the experimental results. However, there are differences between models and $k-\omega$ is found to fit the best the experimental results, followed closely by k- $\varepsilon$ and then R-S. In addition, these models are found to be in very good agreement with the Sieder-Tate correlation. Both the k- $\varepsilon$ and the R-S models are calculating values within $10 \%$ of what is obtained with the Sieder-Tate correlation. Since the final application of this work is to carry steady-state safety analysis, one would likely prefer to use a turbulence model that leans toward conservatism. In this particular case, the R-S model would likely be the one to select.

At this point of the analysis, it has been shown that CFD tools are able to provide satisfactory results in a range of conditions that is highly relevant for the involute-plate reactors: bulk and wall temperatures, heat flux and coolant velocity. The test-section used by Gambill and Bundy was prototypic of the HFIR coolant channel geometry. The two other involute-plate reactors, namely RHF and FRM II have however thicker channels. Based on the encouraging results obtained so far, in the next section, a comparison of CFD versus Sieder-Tate and Hausen correlation is made for an abstract geometry that cover completely the parameters of interest of the three involute-plate reactors. 


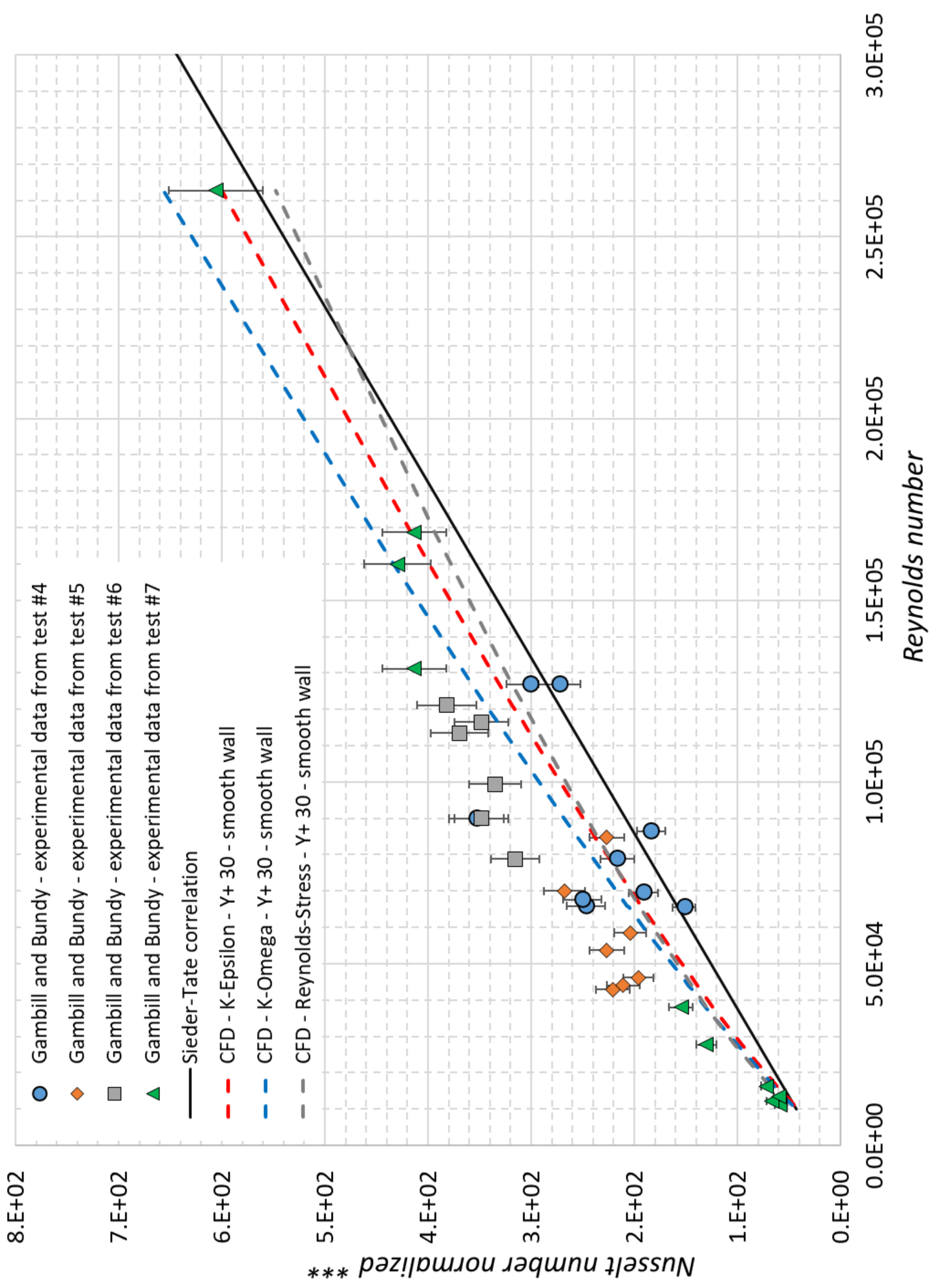

Figure 5-11 - Comparison of experimental averaged Nusselt number with the ones obtained with the K-Epsilon, KOmega and Reynold-Stress CFD models and with the Sieder-Tate correlation 


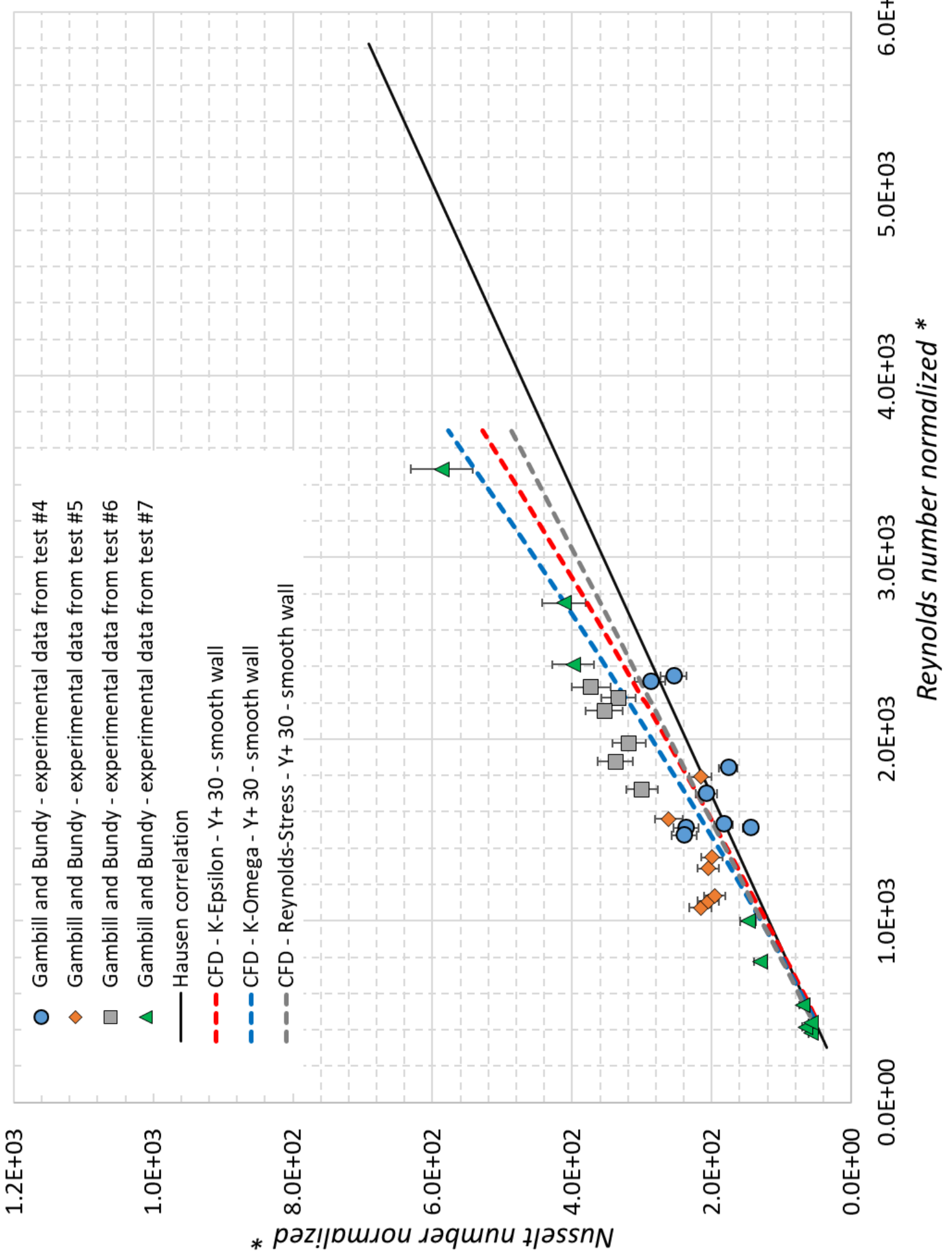

Figure 5-12 - Comparison of experimental averaged Nusselt number with the ones obtained with the K-Epsilon, KOmega and Reynold-Stress CFD models and with the Hausen correlation 


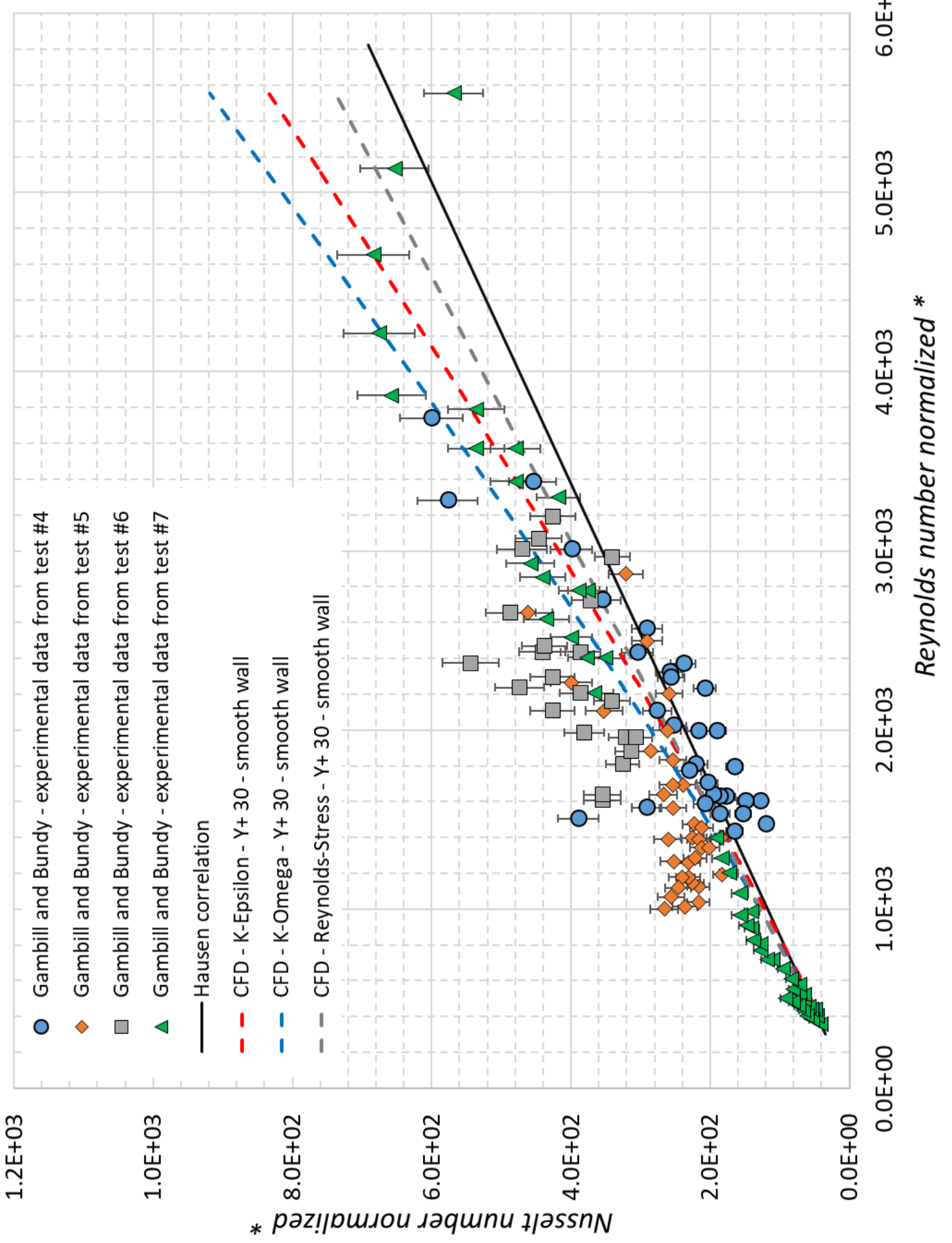

Figure 5-13 - Comparison of experimental local heat Nusselt number with the ones obtained with the K-Epsilon, K-Omega and Reynold-Stress CFD models and with the Hausen correlation 


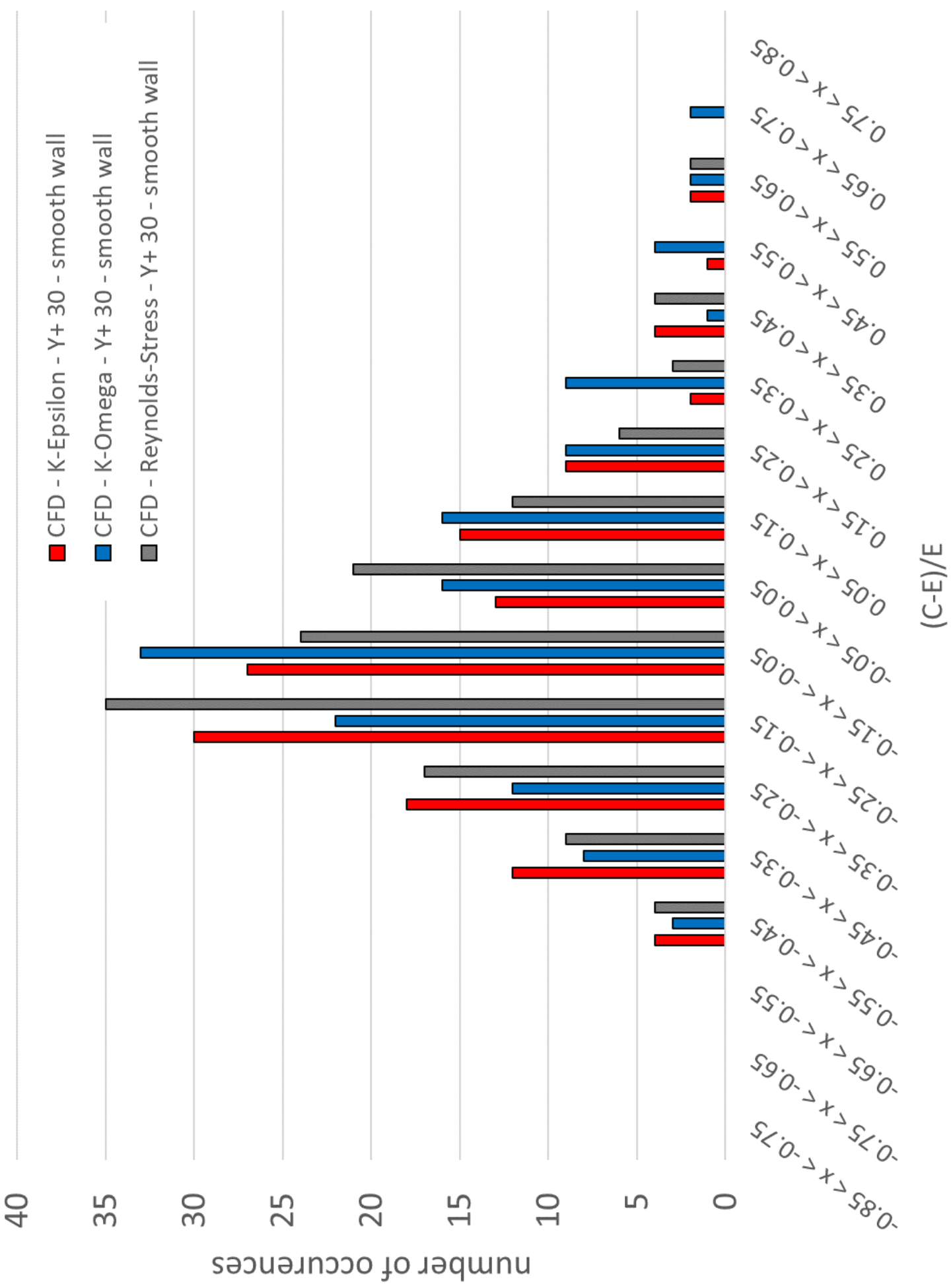

Figure 5-14 - Distribution of the deviation between CFD calculations (marked C) relative the experimental results (marked E) for the local Nusselt number case 


\section{Comparison of CFD and Empirical Correlations for an Abstract Geometry}

It has been shown in the previous section that the CFD k- $\varepsilon, \mathrm{k}-\omega$ and R-S turbulence models were able to reproduce relatively well the results obtained by Gambill and Bundy in their experiment. In addition, it has been shown that the CFD results were relatively close to the Sieder-Tate and Hausen correlations. In order to cover a broader range of geometry, flow and thermal conditions relevant for involute-plate reactors, a study was conducted on a reduced, yet representative model. In this simulation, only a small portion of the water channel was modeled and CFD results were compared to the ones obtained with the Sieder-Tate and Hausen correlations. A description of the model and key results are discussed in this section.

\subsection{CFD Model Description}

The heating of the coolant was represented by a constant heat flux on the boundary wall and no aluminum part was modeled. The model used cyclic boundary conditions on inlet and outlet, allowing for reaching the conditions of a fully developed flow present in a long-heated channel away from the inlet (and outlet) within a few computational cells. On its sides, the model had symmetry boundary conditions, which is equivalent to a wide, thin channel. On the surface opposite to the heated wall a symmetry boundary condition was also enforced, representing the middle of the channel. Figure 6-1 illustrates the reduced model used in this study (the heated wall is marked with grey color, blue is the symmetry plane and purple is the velocity inlet of the cyclic boundary). The total number of cells in the model was $3 \times 3 \times 11=99$. This size of the model assures minimal computational burden of each simulation and dozens of them can be performed within hours.

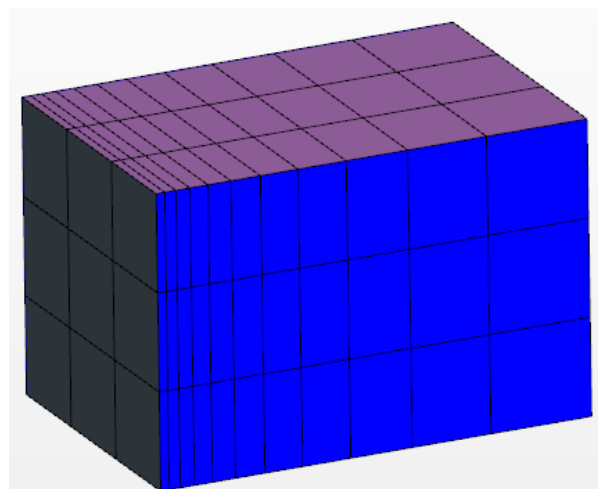

Figure 6-1 - Simplified model used in the sensitivity study

The study was performed with five varying parameters in the CFD model:

- hydraulic diameter (determining the channel thickness in the simulation),

- coolant bulk velocity (determining the flow rate),

- coolant bulk temperature,

- onset nucleate boiling ratio - ONBR,

- that together with the varying pressure defined the wall heat flux in the simulation. 
Three different values of hydraulic diameter, bulk velocity, coolant temperature, pressure, and four different values of ONBR defined altogether 648 distinct cases (per each tested turbulence model, 1944 total). Table 6-1 lists all the varying parameters and their range of values in the simulations.

Table 6-1 - Input variables and their values in the sensitivity analysis

\begin{tabular}{|l|c|}
\hline \multicolumn{1}{|c|}{ Quantity } & Values \\
\hline Hydraulic diameter $(\mathrm{m})$ & $0.00254,0.00376,0.0044$ \\
\hline Bulk coolant velocity $(\mathrm{m} / \mathrm{s})$ & $5,10,18$ \\
\hline Bulk coolant temperature $\left({ }^{\circ} \mathrm{C}\right)$ & $10,30,50,70,90,110$ \\
\hline Pressure $(\mathrm{MPa})$ & $0.4,2.0,4.0$ \\
\hline ONBR $(-)$ & $1.05,1.2,2.0,5.0$ \\
\hline
\end{tabular}

\subsection{Onset of Nucleate Boiling Heat Flux}

The onset of nucleate boiling (ONB) occurs when the wall temperature is slightly higher than the saturated fluid temperature, sufficiently so to see the apparition of isolated bubbles forming at nucleation sites. In these conditions the fluid can still be considered single-phase liquid. ONB is obviously strongly correlated to the local wall temperature and saturation temperature of the coolant, which itself is strongly dependent on the local pressure.

The onset nucleate boiling ratio (ONBR) is the ratio between the heat flux leading to ONB and the local wall heat flux. A value slightly above one means that the wall heat flux is close to ONB while a large value means that the local wall heat flux is far below the ONB heat flux.

The reason for defining the wall heat flux via the ONBR and pressure is that it is a convenient way of defining the heat flux close to safety parameters widely used by research reactors while guaranteeing that the problem will remain single-phase. It should be noted that the authors are not using the ONBR as a recommendation for involute-plate reactors safety application. Depending on the reactor design and the definition of the safety basis, reactors may consider phenomena other than ONB.

The boundary heat flux for a specific ONBR was calculated using Bergles-Rosenhow correlation [Bergles, 1964], defined as:

$$
q_{O N B}^{\prime \prime}=1083 p^{1.156}\left[1.8\left(T_{w}-T_{s a t}\right)\right]^{2.16 / p^{0.0234}}
$$

Where:

- $\quad q^{\prime \prime}{ }_{\text {ONB }}$ : heat flux leading to ONB $\left(\mathrm{W} / \mathrm{m}^{2}\right)$

- $\quad p$ : local pressure (bar abs.)

- $\quad T_{w}$ : local wall temperature (K)

- $\quad T_{\text {sat }}$ : local saturation temperature (K)

The Bergles and Rohsenow ONB correlation predicts the wall superheat at which boiling occurs as a function of heat flux and pressure. As stated in Appendix A of [IAEA, 1980] in section A.1.3.4:

"This (the Bergles and Rohsenow) correlation is widely used and is applicable down to the low pressures characteristic of research and test reactors." 
Additionally in Section A.1.3.5 of the same reference, Figures A3 and A4 show that the Bergles and Rohsenow correlation closely predicts data measured at the Oak Ridge Research Reactor, which has aluminum-clad fuel plates, like the involute-plate reactors. Likewise, [Sudo, 1986] found extremely good agreement between their experimental results (representing the JRR-3 reactor conditions) and the Bergles-Rohsenow correlation.

\subsection{Automatic CFD Model Generation}

Interaction of a user with STAR-CCM+ solver can happen via Graphical User Interface (GUI), or a Java macro (a script written in Java programming language) that contains a list of commands for STAR$\mathrm{CCM}+$ equivalent to the GUI operations. Such Java macro can be recorded when commands are executed in the GUI and subsequently it can be "replayed" multiple times to perform these commands on the same or a different STAR-CCM+ simulation file. An external Python script was developed to automatically start the STAR-CCM+ simulations. While reading an input table from a CSV file, the Python script modified also the Java macro for each simulation case based on that table automatically.

Based on the hydraulic diameter (channel thickness), the geometry of the model was also changed. The mesh in the model was automatically generated for each of these cases to meet the requirement of $\mathrm{Y}+>30$ for the turbulence models used in the study (k- $\varepsilon, \mathrm{k}-\omega$, and R-S models). For low bulk velocity cases, the first near-wall layer of the mesh was occupying a substantial fraction of the channel thickness $(\sim 1 / 3$ of the width). For these cases the number of cells in the model across the channel thickness was reduced to 5 (from default 11), so the difference between the thinnest and thickest mesh layer is not too pronounced. Selectively, a small number of these simulations was repeated manually with the mesh near the wall satisfying the condition of $Y+<1$, and 15 layers of cells yielding similar results to the $\mathrm{Y}+>30$ simulations. The difference between these simulations was negligible.

Each simulation was well converged within 1,500 iterations taking about a minute of computation time on 16 core high performance computational node. All 648 simulations took about 20 hours to complete for k- $\varepsilon$ and k- $\omega$ models and about 30 hours for Reynolds stress turbulence model (more equations to solve per each cell than in two-equation turbulence $\mathrm{k}-\varepsilon$ and $\mathrm{k}-\omega$ models). The data of interest was extracted from each case automatically with the Java macro to a text file. The external Python script was used to build a result table out of that data.

\subsection{CFD Fit Functions compared to Empirical Correlations}

Like previously, the amount of data points generated with the CFD models is substantial and visualization and qualitative assessment becomes difficult. Therefore, fit functions have been generated and used to perform the comparison with the empirical correlations in the abstract geometry. The actual CFD data points and their corresponding fits are shown in Appendix C. The fits have a $\mathrm{R}^{2}$ above 0.987 which means that the deviation between the data points and the fit functions is in all cases small (it should be noted that the dispersion is slightly larger than obtained previously in the Gambill and Bundy experiment model).

As a first step, a comparison of the CFD fits generated from the Gambill and Bundy experiment model and the abstract geometry model is performed to understand how generic these CFD results are.

The CFD fits comparison is shown in Figure 6-2 and Figure 6-3. Figure 6-2 shows the results expressed in units used to compare with the Sieder-Tate correlation and in Figure 6-3, the results are 
expressed in units used to compare with the Hausen correlation. In each figure, fits obtained with the three turbulent models are shown. The dashed lines correspond to the data obtained in the Gambill experiment simulations and the solid ones correspond to the data obtained in the abstract geometry simulations.

In all cases, it is apparent that the fits obtained modeling the Gambill and Bundy experiment and the abstract geometry are very close to each other. In the abstract geometry, the fits obtained with both, the K-Epsilon and the K-Omega, models tend to predict lower Nusselt number than the ones obtained with the Gambill and Bundy experiment simulations. The deviation tends to increase modestly with the growing Reynolds number: from almost 0 at Reynolds equal to 10,000 to about $2 \%$ when the Reynolds is equal to 250,000 . The fits obtained with the Reynolds-Stress turbulence model are however much closer, the deviation is about $1 \%$ only. In this case, the fit obtained with the abstract geometry predicts higher Nusselt number than the one obtained modeling the Gambill and Bundy experiment.

Despite the drastic difference in the CFD models (complex geometry in Gambill and Bundy versus as simple as possible abstract geometry), the close proximity of these fit functions indicates the relevance of the approach used in the abstract geometry. Like an empirical correlation, these results show that the selected CFD turbulence models are geometry independent (granted meshing and other modeling best-practices such as convergence checks are carefully addressed). Thus, it is anticipated that using these turbulence models for the analysis of an actual involute channel will likely provide very similar results.

Figure 6-4 and Figure 6-5 compare these fit functions with the Sieder-Tate and Hausen correlations, respectively. Like previously observed in the Gambill and Bundy/CFD comparison, both correlations tend to predict lower Nusselt number than the ones obtained with CFD. The results obtained with KEpsilon and Reynolds-Stress turbulence models are within +0 to $+10 \%$ of the Sieder-Tate correlation and within +10 to $+20 \%$ of the Hausen correlation. K-Omega is further away from these correlations: within +10 to $+20 \%$ of Sieder-Tate and beyond $+20 \%$ for Hausen. In the Gambill and Bundy experiment, recall that both correlations were found to be in a relatively good agreement with the experimental results and leaning towards conservatism, especially Hausen. CFD models using KOmega were shown to be in excellent agreement with the experimental results and therefore the furthest away from the empirical correlations. The very same observations can be made here.

Overall, the CFD results obtained in the simulations with the abstract geometry demonstrate a high degree of consistency between CFD models and validate the chosen approach. The parametrized abstract geometry simulations have been designed to cover the range of interest of the involute reactors and the three selected turbulence models provide reasonable results. The comparison of the CFD results to the empirical correlations of Sieder-Tate and Hausen strengthen this argument. 


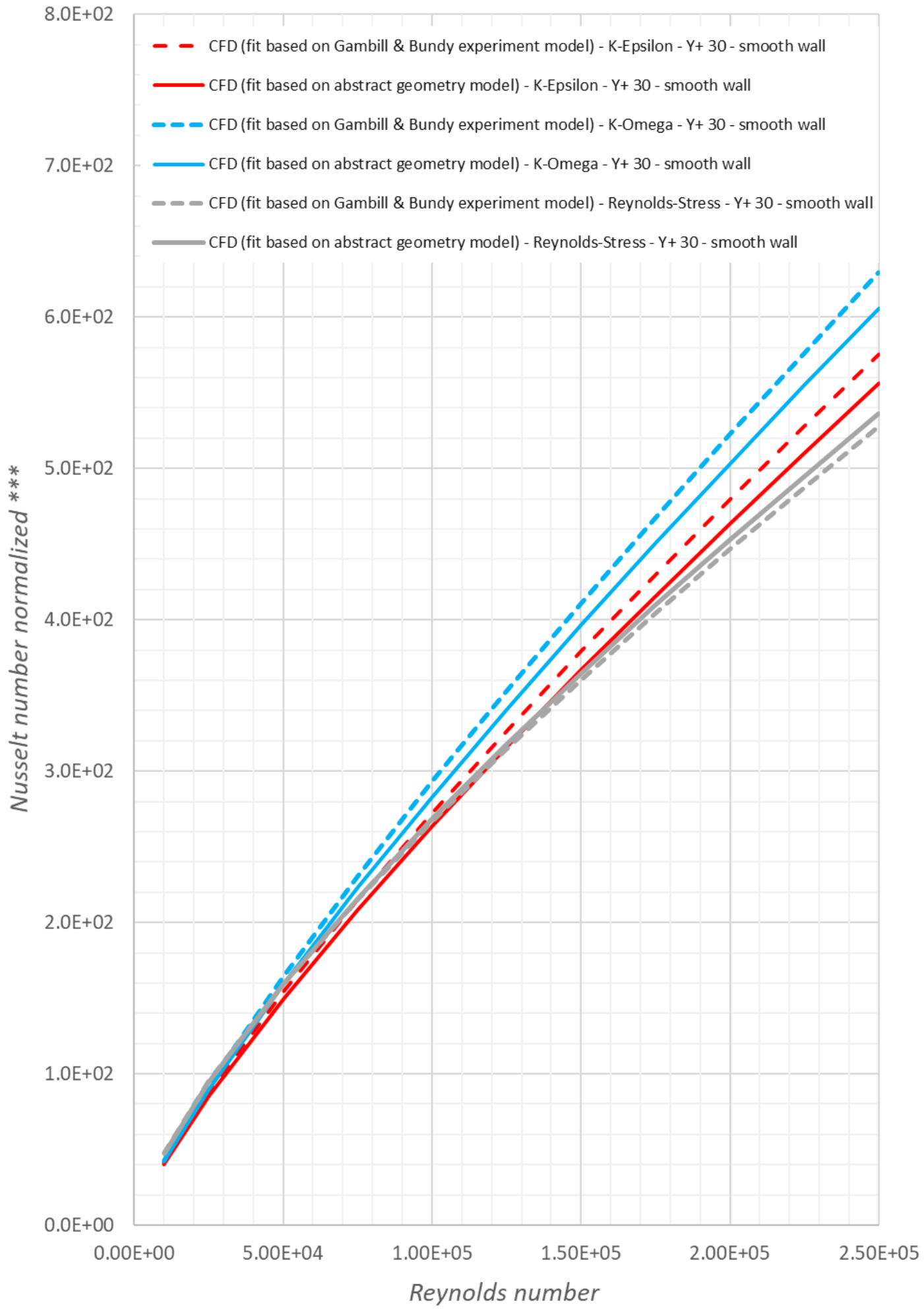

Figure 6-2 - Comparison of CFD fit functions obtained with the Gambill and Bundy experiment model and the abstract geometry model used for comparison with the Sieder-Tate correlation 


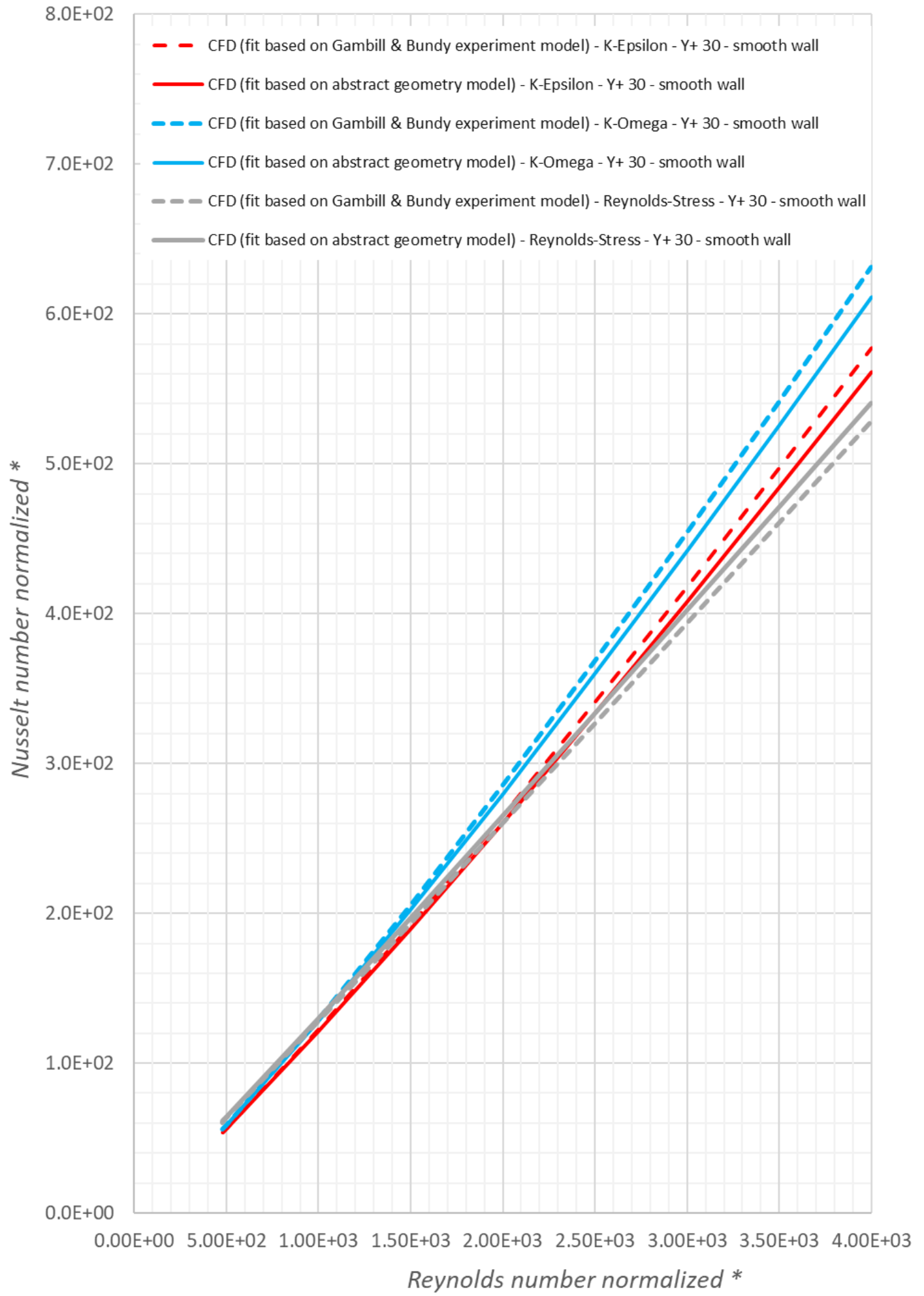

Figure 6-3 - Comparison of CFD fit functions obtained with the Gambill and Bundy experiment models and the abstract geometry models used for comparison with the Hausen correlation 


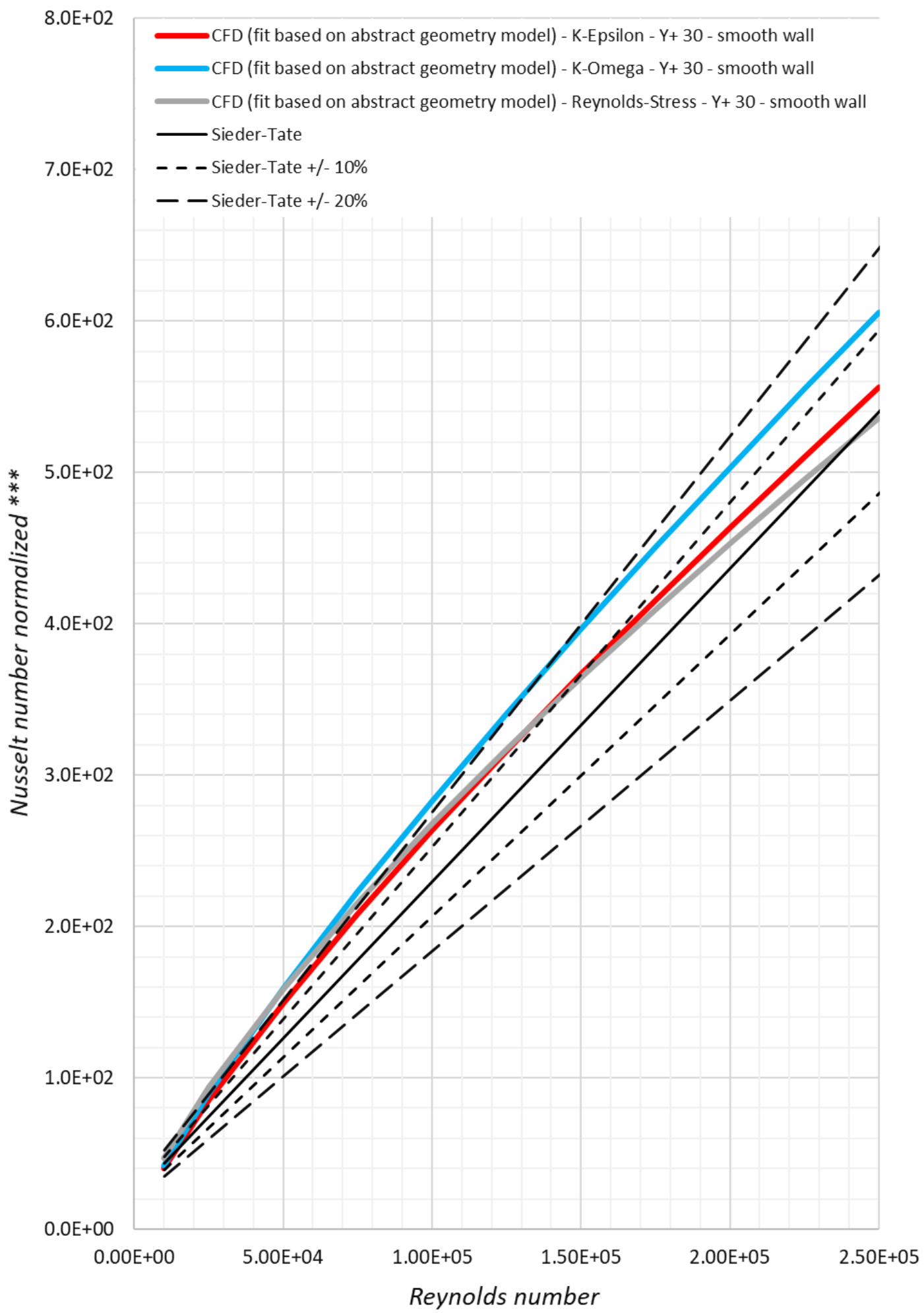

Figure 6-4 - Comparison of CFD fit functions obtained with the abstract geometry models and comparison with the Sieder-Tate correlation 


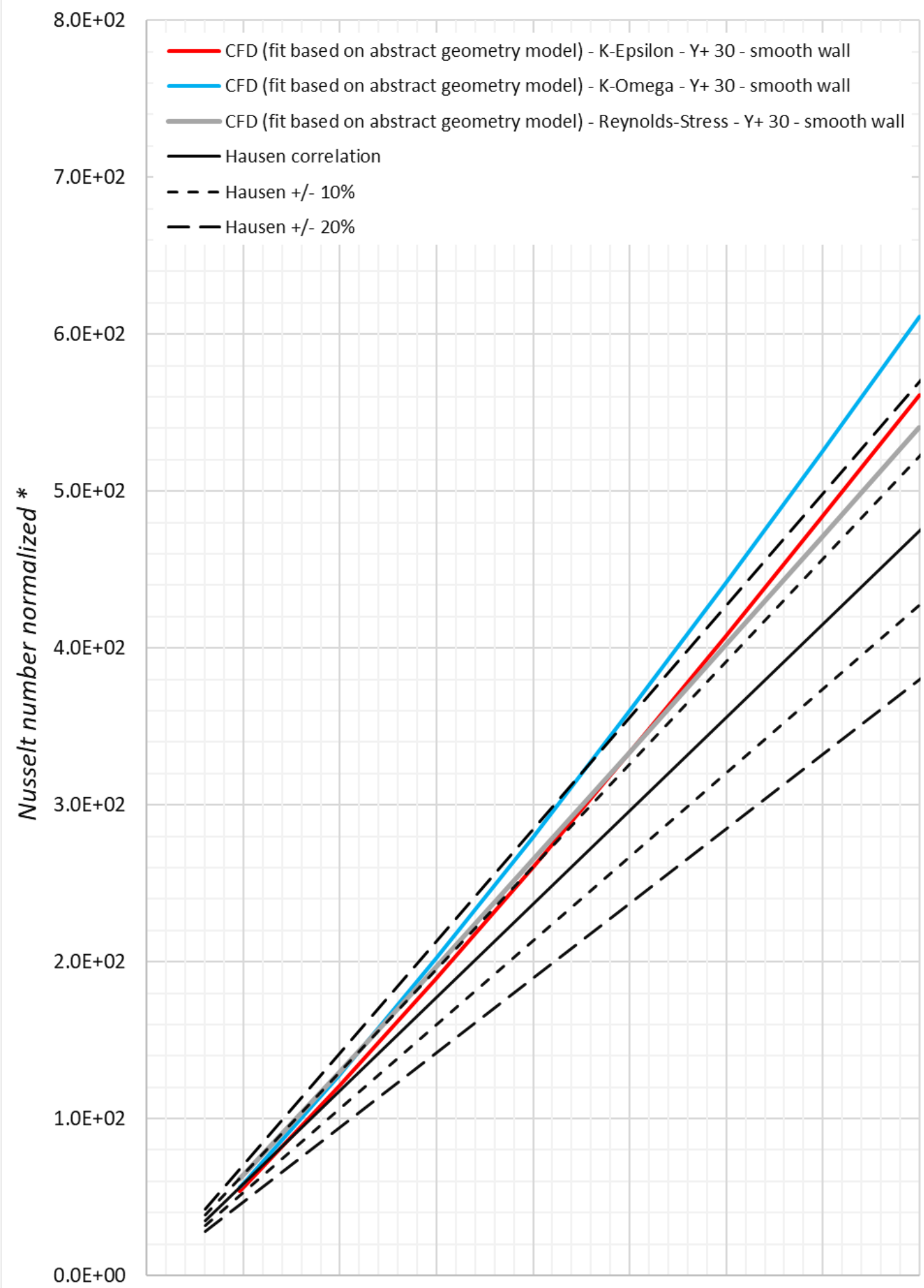

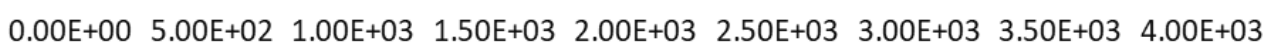

Reynolds number normalized *

Figure 6-5 - Comparison of CFD fit functions obtained with the abstract geometry models and comparison with the Hausen correlation 


\section{Conclusions}

The three involute plate research reactors RHF, HFIR and FRM II have expressed an interest in using Computational Fluid Dynamics (CFD) software to carry their steady-state safety analysis. Since these tools represent a significant departure from the methods used currently (one-dimensional), acceptability of CFD by regulators requires thorough verification and validation (V\&V). This is why Argonne National Laboratory and the three involute-plate reactors formed an informal group called the Involute Working Group (IWG) aiming at qualifying CFD tools to perform steady-state safety analysis. Qualification of CFD implies to validate and demonstrate the pertinence of all aspects of the CFD analysis.

The present report focused on selected turbulence models and their impact on heat transfer predictions. Three well-known and widely used turbulence models have been selected to perform these analysis:

- $\quad$ K-Epsilon (Realizable K-Epsilon model with two layer all y+ wall treatment),

- $\quad$ K-Omega (Menter's SST K-Omega with all y+ wall treatment),

- $\quad$ Reynolds-Stress (with all y+ wall treatment).

These turbulence models have been tested in a CFD model of the Gambill and Bundy experiment. The results show a good agreement between CFD, the experimental data and a close proximity with the well-known empirical correlation Sieder-Tate and Hausen. The model with the K-Omega turbulence matched particularly well the experimental results, followed by K-Epsilon and ReynoldsStress models. Both K-Epsilon and Reynolds-Stress models tended to predict more conservative results.

Based on this initial success, the turbulence models have been tested in an abstract geometry covering more completely the geometric and operating conditions of the three involute plate reactors. The CFD results obtained with this abstract geometry matched very well the ones obtained in the Gambill and Bundy experiment model and again were found to agree relatively well with the empirical correlation of Sieder-Tate and Hausen.

Overall, it can be concluded that the selected turbulence models are able to represent accurately the heat transfer of involute-plate reactors. Since the final application is safety, the authors would recommend the use of the Reynolds-Stress turbulence models because it is the one providing systematically the most conservative results. 


\section{References}

[Bergeron, 2012] A. Bergeron, "Review of the Oak Ridge National Laboratory (ORNL) Neutronic Calculations Regarding the Conversion of the High Flux Isotope Reactor (HFIR) to the Use of Low Enriched Uranium (LEU) Fuel", ANL/RERTR/TM-12/49, Argonne National Laboratory, 2012.

[Bergeron, 2014] A. Bergeron, "Neutronic Conversion Analyses of the Laue-Langevin Institute (ILL) High Flux Reactor (RHF)", ANL/GTRI/TM-14/15, Argonne National Laboratory, 2014.

[Bergeron, 2019] A. Bergeron et al., "Involute Working Group - Progress towards Validation of CFD for Involute-Plate Reactors Safety Analysis", RERTR 2019, 40 th International Meeting on Reduced Enrichment for Research and Test Reactors. Zagreb, Croatia, Oct. 6-10, 2019.

[Bergles, 1964] A. E. Bergles and W. M. Rohsenow, "The determination of Forced Convection Surface Boiling Heat transfer", Journal of heat transfer, vol. 86, pp. 365-372, August 1964

[Bojanowski, 2018] C. Bojanowski et al., "Influence of Multi-Dimension Heat Conduction on Heat Flux Calculation for HFIR LEU Analysis", ANL/RTR/TM-17/18, Argonne National Laboratory, 2018.

[Bojanowski, 2018B] C. Bojanowski et al., "Experimental Validation of CFD Turbulent Models Relevant for Involute-Plate Reactors", RERTR 2018, 39th International Meeting on Reduced Enrichment for Research and Test Reactors. Edinburgh, Scotland, Nov. 4-7, 2018.

[Du, 2014] W. Y. Du, "Resistive, Capacitive, Inductive, and Magnetic Sensor Technologies". Boca Raton, FL: CRC Press. 10.1201/b17685, 2014.

[Gambill, 1961] W. R. Gambill and R.D. Bundy, "HFIR Heat-Transfer Studies of Turbulent Water Flow in Thin Rectangular Channels", ORNL-3079, Oak Ridge National Laboratory, 1961.

[Hausen, 1959] H. Hausen, "Neue Gleichungen fur die Wärmeubertragung bei freier oder erzwungener Strömung", Allgemeine Wärmetechnic, 9(4/5), pp. 75-79, 1959.

[IAEA, 1980] "Research Reactor Core Conversion from the Use of Highly Enriched Uranium to the Use of Low Enriched Uranium Fuels Guidebook, A Technical Document Issued by the International Atomic Energy Agency", IAEA-TECDOC-233, Vienna, 1980,

Error! Hyperlink reference not valid.

[ILL, 2018] Institut Laue-Langevin, "The ILL High-Flux reactor". Website last accessed July 23, 2018. https://www.ill.eu/reactor-and-safety/high-flux-reactor/ 
[Jain, 2019]

[Jones, 1972]

[Kuphaldt, 2018]

[MatWeb, 2018]

[McLain, 1967]

[Menter, 1994]

[NIST, 2018]

[ORNL, 2018]

[Reiter, 2019]

[RERTR, 2019]

[Rodi, 1991]

[Röhrmoser, 2010]

[Sarkar, 1990]

[Sieder, 1936]
P. Jain (Oak Ridge National Laboratory), private communication. Email sent to A. Bergeron July 23, 2019.

W. P. Jones and B. E. Launder, "The Prediction of Laminarization with a TwoEquation Model of Turbulence", Int. J. Heat and Mass Transfer, 15, pp. 301-314., 1972.

T.R. Kuphaldt, “All About Circuits”. Website last accessed July 23, 2018. https://www.allaboutcircuits.com/textbook/.

"MatWeb - Material Property Data". Website last accessed September 05, 2018.

http://www.matweb.com/search/datasheet print.aspx?matguid=db030774 2df14c8f817bd8d62207368e

H. A. McLain, "HFIR Fuel Element Steady State Heat Transfer Analysis Revised Version”, ORNL-TM-1904, Oak Ridge National Laboratory, December 1967.

F. R. Menter, "Two-equation eddy-viscosity turbulence modeling for engineering applications", AIAA Journal, 32(8), pp. 1598-1605, 1994.

National Institute of Standards and Technology, "NIST Chemistry WebBook, SRD 69". Website last accessed July 23, 2018.

https://webbook.nist.gov/chemistry/fluid/

Oak Ridge National Laboratory, "High Flux Isotope Reactor". Website last accessed July 23, 2018.

https://neutrons.ornl.gov/hfir

C. Reiter (Technical University of Munich), private communication. Email sent to A. Bergeron July 24, 2019

Reduced Enrichment for Research and Test Reactor, "International Meeting on Reduced Enrichment for Research and Test Reactors". Website last accessed October 29, 2019.

https://www.rertr.anl.gov/

W. Rodi, "Experience with Two-Layer Models Combining the $k$-e Model with a One-Equation Model Near the Wall", 9th Aerospace Sciences Meeting, Reno, NV, AIAA 91-0216, January 7-10 1991.

A. Rohrmoser, "Core Model of New german Neutron Source FRM II", Nuclear Engineering and design 240 pp. 1417-1432, 2010.

S. Sarkar and L. Balakrishnan, "Application of a Reynolds-stress turbulence model to the compressible shear layer", ICASE Report 90-18, NASA CR 182002., 1990

E. N. Sieder and G. E. Tate, "Heat Transfer and Pressure Drop of Liquids in Tubes", Ind. Eng. Chem. 28, N 12, pp. 1429-1435, 1936. 
[Siemens, 2018] Siemens Star-CCM+, "Engineer innovation with CFD- focused multiphysics simulation". Website last accessed October 31, 2019.

https://www.plm.automation.siemens.com/global/en/products/simcenter/ $\underline{\text { STAR-CCM.html }}$

[Sudo, 1986] Y. Sudo and al. "Experimental Study of Incipient Nucleate Boiling in Narrow Vertical Rectangular Channel Simulating Subchannel of Upgraded JRR-3", Journal of Nuclear Science and Technology, vol. 23:1, pp. 73-82, 1986 DOI: 0.1080/18811248.1986.9734950.

[Thomas, 2019] F. Thomas (Institut Laue-Langevin), private communication. Email sent to A. Bergeron July 19, 2019.

[TUM, 2018] Technical University of Munich, "Research Neutron Source Heinz MaierLeibnitz (FRM II)". Website last accessed July 23, 2018.

https://www.frm2.tum.de/en/home/

[Wilcox, 1998] D. C. Wilcox, "Turbulence Modeling for CFD", 2nd edition, DCW Industries, Inc., 1998. 


\section{Acknowledgements}

This work was sponsored by the U.S. Department of Energy, Office of Material Management and Minimization in the U.S. National Nuclear Security Administration Office of Defense Nuclear Nonproliferation under Contract DE-AC02-06CH11357.

The authors would like to thank the staff from the Institut Laue-Langevin, Oak Ridge National Laboratory and the Technical University of Munich for their support and their collaboration. The work presented here could not have been possible without their help. 


\section{Appendix A - Gambill \& Bundy Report Digitized Data}

Several figures of the Gambill and Bundy report [Gambill, 1961] have been digitized to support the comparison with the results obtained with the CFD models. In this appendix are given the digitized data:

Table A-1 - Digitized data from Gambill and Bundy report [Gambill, 1961], Figure 16

\begin{tabular}{|c|c|c|}
\hline $\mathbf{X}$ (inch) & Bulk temperature $\left({ }^{\circ} \mathbf{C}\right)$ & Wall temperature $\left({ }^{\circ} \mathbf{C}\right)$ \\
\hline 0.5 & 70.63558 & 110.039 \\
\hline 3 & 82.4385 & 144.54 \\
\hline 4.5 & 89.52025 & 140.545 \\
\hline 8 & 106.0443 & 168.145 \\
\hline 10.5 & 117.8473 & 170.324 \\
\hline 13 & 129.6502 & 169.235 \\
\hline 15.5 & 141.4531 & 194.656 \\
\hline
\end{tabular}

Table A-2 - Digitized data from Gambill and Bundy report [Gambill, 1961], Figure 17. Nusselt number is normalized as described in (Equation 9)

\begin{tabular}{|c|c|c|c|c|c|c|c|}
\hline \multicolumn{2}{|c|}{ test \#4 } & \multicolumn{2}{|c|}{ test \#5 } & \multicolumn{2}{|c|}{ test \#6 } & \multicolumn{2}{|c|}{ test \#7 } \\
\hline $\begin{array}{l}\text { Reynolds } \\
\text { number }\end{array}$ & $\begin{array}{c}\text { Nusselt } \\
\text { normalized } \\
* * *\end{array}$ & $\begin{array}{l}\text { Reynolds } \\
\text { number }\end{array}$ & $\begin{array}{c}\text { Nusselt } \\
\text { normalized } \\
* * *\end{array}$ & $\begin{array}{l}\text { Reynolds } \\
\text { number }\end{array}$ & $\begin{array}{c}\text { Nusselt } \\
\text { normalized } \\
* * *\end{array}$ & $\begin{array}{c}\text { Reynolds } \\
\text { number }\end{array}$ & $\begin{array}{c}\text { Nusselt } \\
\text { normalized } \\
* * *\end{array}$ \\
\hline 65477.5 & 151.595 & 42873 & 220.806 & 78804.6 & 315.31 & 11190.5 & 59.0125 \\
\hline 86453.3 & 183.561 & 44022.9 & 210.84 & 89954.5 & 348.111 & 12276.7 & 66.8937 \\
\hline 69495.1 & 190.973 & 46109.8 & 196.08 & 99340.5 & 334.6 & 13379.4 & 59.7964 \\
\hline 78804.6 & 216.478 & 58511.5 & 203.998 & 116437 & 348.111 & 16317.1 & 71.929 \\
\hline 65912.2 & 247.013 & 53689 & 226.71 & 113396 & 369.407 & 27703.1 & 130.252 \\
\hline 67679.9 & 250.294 & 69956.4 & 267.365 & 121153 & 381.797 & 38059.2 & 154.626 \\
\hline 126896 & 301.079 & 84754.1 & 226.71 & & & 131164 & 413.253 \\
\hline 126896 & 272.71 & & & & & 159964 & 429.94 \\
\hline \multirow[t]{2}{*}{89954.5} & 352.735 & & & & & 168660 & 413.253 \\
\hline & & & & & & 262749 & 605.906 \\
\hline \multicolumn{8}{|c|}{ Sieder-Tate } \\
\hline $\begin{array}{l}\text { Reynolds } \\
\text { number }\end{array}$ & $\begin{array}{c}\text { Nusselt } \\
\text { normalized } \\
* * *\end{array}$ & & & & & & \\
\hline 10000 & 43.2786 & & & & & & \\
\hline 385662 & 820.749 & & & & & & \\
\hline
\end{tabular}


Table A-3 - Digitized data from Gambill and Bundy report [Gambill, 1961], Figure 18. Nusselt number is normalized as described in (Equation 6), Reynolds number is normalized as described in (Equation 8)

\begin{tabular}{|c|c|c|c|c|c|c|c|}
\hline \multicolumn{2}{|c|}{ test \#4 } & \multicolumn{2}{|c|}{ test \#5 } & \multicolumn{2}{|c|}{ test \#6 } & \multicolumn{2}{|c|}{ test \#7 } \\
\hline $\begin{array}{c}\text { Reynolds } \\
\text { number } \\
*\end{array}$ & $\begin{array}{c}\text { Nusselt } \\
\text { normalized } \\
*\end{array}$ & $\begin{array}{c}\text { Reynolds } \\
\text { number } \\
*\end{array}$ & $\begin{array}{c}\text { Nusselt } \\
\text { normalized } \\
*\end{array}$ & $\begin{array}{c}\text { Reynolds } \\
\text { number } \\
*\end{array}$ & $\begin{array}{c}\text { Nusselt } \\
\text { normalized } \\
*\end{array}$ & $\begin{array}{c}\text { Reynolds } \\
\text { number } \\
*\end{array}$ & $\begin{array}{c}\text { Nusselt } \\
\text { normalized } \\
*\end{array}$ \\
\hline 1509.48 & 144.544 & 1071.63 & 215.916 & 1722.07 & 300.015 & 380.916 & 57.1667 \\
\hline 1529.5 & 183.171 & 1107.51 & 204.847 & 1876.06 & 337.731 & 414.979 & 65.2057 \\
\hline 1699.53 & 207.56 & 1137.09 & 195.627 & 1977.59 & 318.315 & 440.329 & 57.1667 \\
\hline 1839.35 & 176.082 & 1288.72 & 204.847 & 2226.59 & 333.317 & 536.554 & 69.6397 \\
\hline 1509.48 & 236.748 & 1349.54 & 199.526 & 2154.43 & 353.648 & 775.966 & 130.103 \\
\hline 1470.22 & 239.883 & 1791.51 & 215.916 & 2286.04 & 372.759 & 996.711 & 148.398 \\
\hline 2347.09 & 254.516 & 1560.03 & 261.302 & & & 2409.76 & 398.107 \\
\hline \multirow[t]{2}{*}{2316.36} & 288.403 & & & & & 2749.15 & 411.42 \\
\hline & & & & & & 3485 & 586.91 \\
\hline \multicolumn{8}{|c|}{ Hausen } \\
\hline $\begin{array}{c}\text { Reynolds } \\
\text { number } \\
*\end{array}$ & $\begin{array}{c}\text { Nusselt } \\
\text { normalized } \\
*\end{array}$ & & & & & & \\
\hline 300.487 & 35.1329 & & & & & & \\
\hline 5826.12 & 691.831 & & & & & & \\
\hline
\end{tabular}


Table A-4 - Digitized data from Gambill and Bundy report [Gambill, 1961], Figure 19. Nusselt number is normalized as described in (Equation 7), Reynolds number is normalized as described in (Equation 8) - continues on other page

\begin{tabular}{|c|c|c|c|c|c|c|c|}
\hline \multicolumn{2}{|c|}{ test \#4 } & \multicolumn{2}{|c|}{ test \#5 } & \multicolumn{2}{|c|}{ test \#6 } & \multicolumn{2}{|c|}{ test \#7 } \\
\hline $\begin{array}{c}\text { Reynolds } \\
\text { number } \\
*\end{array}$ & $\begin{array}{c}\text { Nusselt } \\
\text { normalized } \\
* *\end{array}$ & $\begin{array}{c}\text { Reynolds } \\
\text { number } \\
*\end{array}$ & $\begin{array}{c}\text { Nusselt } \\
\text { normalized } \\
* *\end{array}$ & $\begin{array}{c}\text { Reynolds } \\
\text { number } \\
*\end{array}$ & $\begin{array}{c}\text { Nusselt } \\
\text { normalized } \\
* *\end{array}$ & $\begin{array}{c}\text { Reynolds } \\
\text { number } \\
*\end{array}$ & $\begin{array}{c}\text { Nusselt } \\
\text { normalized } \\
* *\end{array}$ \\
\hline 1470.98 & 119.73 & 999.505 & 266.007 & 1607.5 & 354.974 & 358.067 & 40.8055 \\
\hline 1602.81 & 127.853 & 1067.45 & 255.649 & 1639.59 & 354.954 & 405.975 & 46.8434 \\
\hline 1603.54 & 149.754 & 1012.42 & 236.252 & 1809.45 & 325.727 & 439.448 & 49.6936 \\
\hline 1531.35 & 152.764 & 1039.2 & 216.844 & 1882.2 & 313.067 & 382.748 & 53.4498 \\
\hline 1434.04 & 165.362 & 1124.69 & 216.795 & 1958.24 & 321.391 & 439.573 & 54.8553 \\
\hline 1794.09 & 165.256 & 1147.27 & 225.523 & 1957.98 & 306.906 & 454.388 & 58.9727 \\
\hline 1994.36 & 190.974 & 1177.99 & 231.528 & 2966.17 & 340.619 & 406.274 & 60.5669 \\
\hline 2231.26 & 207.984 & 1178.13 & 240.863 & 2723.37 & 371.168 & 436.933 & 66.8441 \\
\hline 1625.6 & 177.727 & 1117.71 & 245.708 & 2162.01 & 340.927 & 495.16 & 65.0823 \\
\hline 1625.82 & 186.115 & 1266.84 & 252.179 & 1985.18 & 381.424 & 521.957 & 65.0725 \\
\hline 1532.22 & 186.147 & 1389.38 & 260.556 & 2205.95 & 386.367 & 525.556 & 71.8302 \\
\hline 1636.81 & 196.184 & 1258.22 & 231.484 & 2107.13 & 426.555 & 460.71 & 73.7761 \\
\hline 1995.07 & 216.439 & 1283.16 & 221.039 & 2295.55 & 426.451 & 482.581 & 80.8938 \\
\hline 1703 & 204.071 & 1397.98 & 225.396 & 2435.09 & 386.258 & 502.219 & 91.6704 \\
\hline 1807.44 & 220.822 & 1388.65 & 216.664 & 2436.01 & 440.657 & 554.186 & 80.8618 \\
\hline 1772.27 & 229.739 & 1473.59 & 222.412 & 2468.27 & 437.747 & 580.146 & 71.8099 \\
\hline 1584.04 & 208.188 & 1454.1 & 212.396 & 2236.52 & 473.894 & 611.819 & 84.0984 \\
\hline 2368.49 & 238.804 & 1343.57 & 212.444 & 2374.08 & 544.117 & 666.78 & 95.9192 \\
\hline 2322.67 & 258.464 & 1343.37 & 201.537 & 2654.59 & 486.309 & 717.179 & 110.129 \\
\hline 2292.22 & 256.777 & 1397.19 & 184.973 & 3008.28 & 470.383 & 717.315 & 117.629 \\
\hline 2104.51 & 276.144 & 1192.81 & 182.635 & 3067.87 & 446.208 & 771.403 & 127.279 \\
\hline 2022.45 & 253.506 & 1564.19 & 253.693 & 3191.15 & 426.049 & 807.811 & 127.262 \\
\hline 1564.81 & 291.336 & 1638.26 & 267.387 & & & 824.122 & 137.724 \\
\hline 1505.41 & 389.346 & 1692.59 & 239.034 & & & 891.971 & 140.441 \\
\hline 2723.01 & 354.439 & 1692.87 & 253.635 & & & 909.912 & 148.034 \\
\hline 3006.87 & 398.952 & 1832.14 & 253.578 & & & 984.62 & 140.402 \\
\hline 3386.72 & 454.986 & 1996.16 & 262.006 & & & 965.66 & 157.05 \\
\hline 3279.2 & 576.822 & 2203.42 & 258.503 & & & 1087.24 & 156.997 \\
\hline 3741.46 & 599.854 & 1881.7 & 285.483 & & & 1200.51 & 173.255 \\
\hline 2564.79 & 290.924 & 2498.09 & 290.946 & & & 1282.49 & 183.804 \\
\hline 2433.44 & 304.701 & 2869.56 & 321.039 & & & 1397.32 & 191.168 \\
\hline & & 2105.98 & 352.371 & & & 2205.62 & 366.53 \\
\hline & & 2265.07 & 399.276 & & & 2402.53 & 349.925 \\
\hline & & 2654.19 & 461.342 & & & 2777.83 & 376.07 \\
\hline
\end{tabular}


(continued) Table A-4 - Digitized data from Gambill and Bundy report [Gambill, 1961], Figure 19. Nusselt number is normalized as described in (Equation 7), Reynolds number is normalized as described in (Equation 8)

\begin{tabular}{|c|c|c|c|c|c|c|c|}
\hline \multicolumn{2}{|c|}{ test \#4 } & \multicolumn{2}{|c|}{ test \#5 } & \multicolumn{2}{|c|}{ test \#6 } & \multicolumn{2}{|c|}{ test \#7 } \\
\hline $\begin{array}{c}\text { Reynolds } \\
\text { number } \\
*\end{array}$ & $\begin{array}{c}\text { Nusselt } \\
\text { normalized } \\
* *\end{array}$ & $\begin{array}{c}\text { Reynolds } \\
\text { number } \\
*\end{array}$ & $\begin{array}{c}\text { Nusselt } \\
\text { normalized } \\
* *\end{array}$ & $\begin{array}{c}\text { Reynolds } \\
\text { number } \\
*\end{array}$ & $\begin{array}{c}\text { Nusselt } \\
\text { normalized } \\
* *\end{array}$ & $\begin{array}{c}\text { Reynolds } \\
\text { number } \\
*\end{array}$ & $\begin{array}{c}\text { Nusselt } \\
\text { normalized } \\
* *\end{array}$ \\
\hline & & & & & & 2778.09 & 388.664 \\
\hline & & & & & & 2403.03 & 376.226 \\
\hline & & & & & & 2516.88 & 399.155 \\
\hline & & & & & & 2619 & 434.799 \\
\hline & & & & & & 2853.3 & 440.458 \\
\hline & & & & & & 2929.82 & 458.183 \\
\hline & & & & & & 3297.83 & 417.671 \\
\hline & & & & & & 3387.23 & 479.609 \\
\hline & & & & & & 3570.55 & 479.537 \\
\hline & & & & & & 3789.87 & 536.276 \\
\hline & & & & & & 3571.69 & 536.367 \\
\hline & & & & & & 3867.78 & 657.751 \\
\hline & & & & & & 4213.96 & 675.15 \\
\hline & & & & & & 4651.84 & 683.911 \\
\hline & & & & & & 5134.36 & 652.903 \\
\hline & & & & & & 5554.55 & 568.414 \\
\hline \multicolumn{8}{|c|}{ Hausen } \\
\hline $\begin{array}{c}\text { Reynolds } \\
\text { number } \\
*\end{array}$ & $\begin{array}{c}\text { Nusselt } \\
\text { normalized } \\
* *\end{array}$ & & & & & & \\
\hline 300.487 & 35.1329 & & & & & & \\
\hline 5826.12 & 691.831 & & & & & & \\
\hline
\end{tabular}




\section{Appendix B - CFD Turbulence Models}

As explained in other sections of this report, the goal of the CFD analysis was to assess how well standard turbulence models were able to reproduce the experimental results obtained by Gambill and Bundy [Gambill, 1961]. With modern CFD packages, users have the possibility to select many sub-models and options to fine-tune their turbulence models. In this appendix, more information on the turbulence models used in this analysis are provided. Recall that the software used to carry out this analysis is Siemens' STAR-CCM+ version 13.06 [Siemens, 2018]. The list of turbulence models available with this version of the software are listed in Table B-1 below. The selected models are briefly described in the following sub-sections.

Table B-1 - K-Epsilon, K-Omega and Reynolds-Stress turbulence models available in STAR-CCM+ version 13.06. Model selected for this study are highlighted in gray

\begin{tabular}{|l|l|}
\hline \multirow{5}{*}{ Reynolds Average Navier-Stokes [RANS] model } & \multicolumn{1}{|c|}{ STAR-CCM+ Model available } \\
\hline \multirow{5}{*}{ K-Epsilon } & AKN K-Epsilon Low-Re \\
\cline { 2 - 2 } & EB K-Epsilon \\
\cline { 2 - 2 } & Lag EB K-Epsilon \\
\cline { 2 - 2 } & Realizable K-Epsilon \\
\cline { 2 - 2 } & Realizable K-Epsilon two-layer \\
\cline { 2 - 2 } & Standard K-Epsilon \\
\cline { 2 - 2 } & Standard K-Epsilon Low-re \\
\cline { 2 - 2 } & Standard K-Epsilon Two-Layer \\
\cline { 2 - 2 } & V2F K-Epsilon \\
\hline \multirow{4}{*}{ K-Omega } & SST (Menter) K-Omega \\
\hline & Standard (Wilcox) K-Omega \\
\hline & Elliptic blending \\
\cline { 2 - 2 } & Linear pressure strain \\
\cline { 2 - 2 } & Linear pressure strain 2-layer \\
\cline { 2 - 2 } & Quadratic pressure strain \\
\hline
\end{tabular}

\section{B-1 - Realizable K-Epsilon two-layer}

The K-Epsilon turbulence model is a two-equation model that solves transport equations for the turbulent kinetic energy and the turbulent dissipation rate in order to determine the turbulent eddy viscosity. This model was first developed by Jones and Launder [Jones, 1972] and was applicable for high Reynolds number. To better capture the effects of the wall (viscous and buffer layer), Rodi [Rodi, 1991] suggested a two-layer approach in which computation is divided in two layers. As explained in STAR-CCM+ tutorial, in the layer next to the wall, the turbulent dissipation rate and the turbulent viscosity are specified as functions of wall distance. The values of specified in the near-wall layer are blended smoothly with the values computed from solving the transport equation far from the wall. The equation for the turbulent kinetic energy is solved across the entire flow domain. Several two- 
layer models exist. The one selected here is the realizable K-Epsilon two-layer which makes use of the equation for the turbulent dissipation rate described in [Shih, 1994]. In STAR-CCM+ manual, this model is claimed to be substantially better than the original K-Epsilon model and the two-layer approach enables the use of fine-meshes that resolve the viscous sublayer.

\section{B-2 - SST (Menter) K-Omega}

Originally developed by Wilcox [Wilcox, 1998], The K-Omega turbulence model is a two-equation model that solves the transport equations for the turbulent kinetic energy and the specific dissipation rate-the dissipation rate per unit turbulent kinetic energy - in order to determine the turbulent eddy viscosity. As explained in STAR-CCM+ tutorial, reported advantages of the K-Omega model over the K-Epsilon model is its improved performance for boundary layers under adverse pressure gradients and that it may be applied throughout the boundary layer, including the viscous-dominated region, without further modification. Furthermore, the standard K-Omega model can be used in this mode without requiring the computation of wall distance.

However, in its original form, the K-Omega model is very sensitive to the values of the specific dissipation rate in the free-stream. This translates into extreme sensitivity to inlet boundary conditions for internal flows, a problem that does not exist for the K-Epsilon models. The problem of sensitivity to free-stream/inlet conditions was addressed by Menter [Menter, 1994], who recognized that the turbulent dissipation rate transport $(\varepsilon)$ equation from the Standard K-Epsilon model could be transformed into a specific dissipation rate $(\omega)$ transport equation by variable substitution. The transformed equation looks similar to the one in the standard K-Omega model, but adds an additional non-conservative cross-diffusion term. Menter also introduced a modification to the linear constitutive equation and named the model containing this modification the SST (shear-stress transport).

\section{B-3 - Reynolds-Stress Transport / Elliptic Blending}

As described in the STAR-CCM+ manual, Reynolds Stress Transport (R-S) models, also known as second-moment closure models, directly calculate the components of the specific Reynolds stress tensor by solving their governing transport equations. R-S models have the potential to predict complex flows more accurately than eddy viscosity models because the transport equations for the Reynolds stresses naturally account for the effects of turbulence anisotropy, streamline curvature, swirl rotation and high strain rates.

The starting point for the development of an R-S model is generally the exact differential transport equation for the Reynolds stresses, which is derived by multiplying the instantaneous Navier-Stokes equations by a fluctuating property and Reynolds-averaging their product (see [Sarkar, 1990] for this exact equation). In the resulting equations, the transient, convective and molecular diffusion terms do not require modeling. The terms remaining to be modeled are the turbulent diffusion term, the dissipation term and the pressure-strain term. To model the pressure-strain term, STAR-CCM+ offers several solutions: linear pressure-strain model (with one or two layer), quadratic pressure-strain 
model and elliptic blending. The elliptic blending model, is based on a precise formulation of the pressure-strain term and it can be applied to all Y+ meshes. 


\section{Appendix C - Fits of CFD Data}

As discussed in previous sections, to ease the reading of the figures, the CFD data were presented as fit function of the actual CFD data points. In this appendix are presented the CFD data and their corresponding fits:

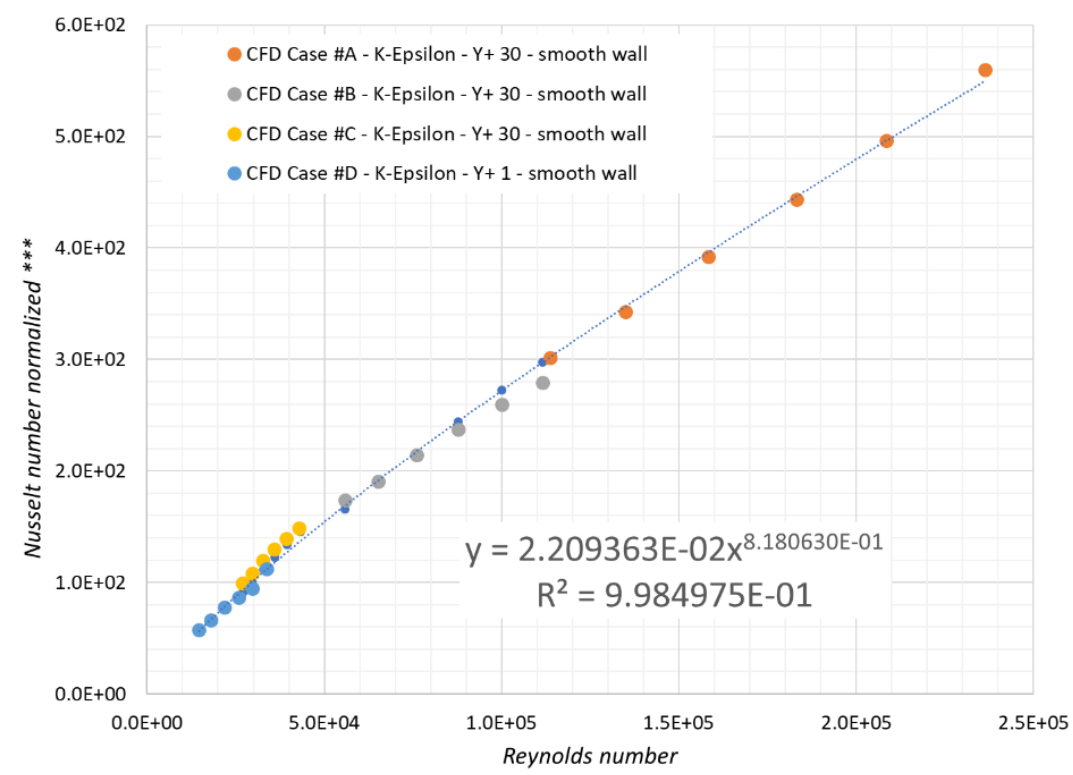

Figure C-1 - CFD data obtained with the K-Epsilon model and corresponding fit to support the comparison with Sieder-Tate and Gambill and Bundy Test \#4 to \#7 (see Figure 5-11)

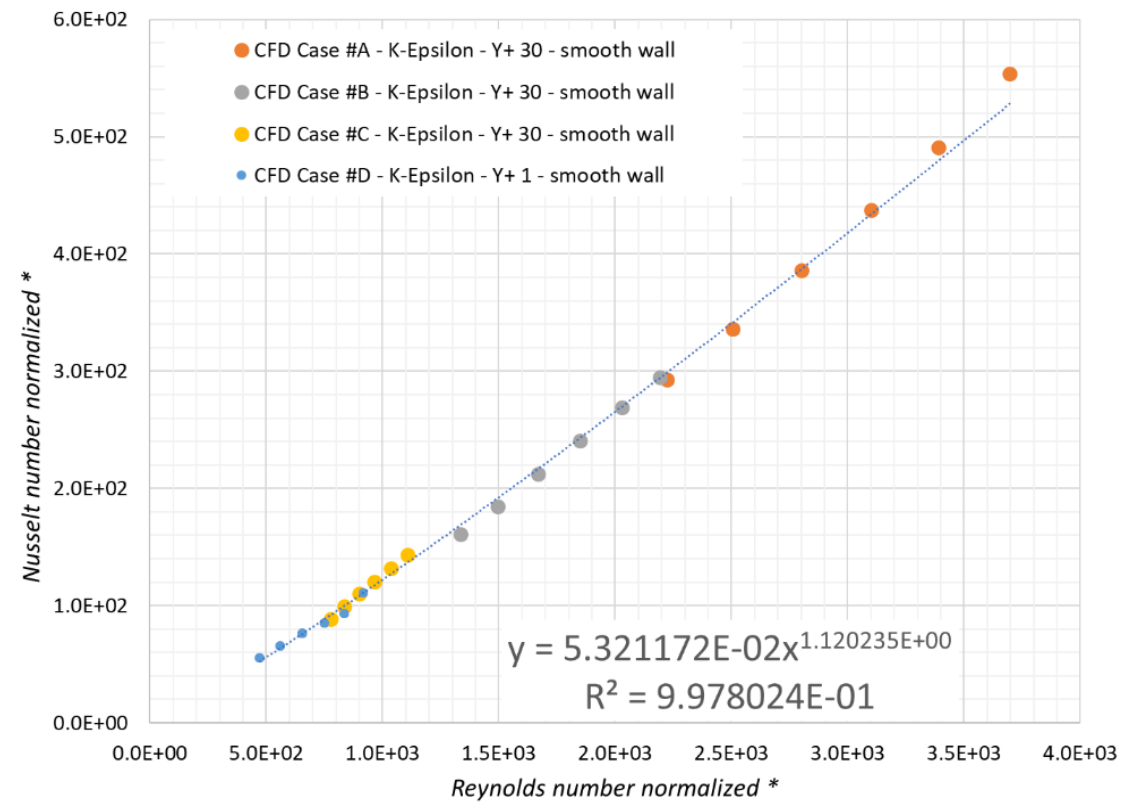

Figure C-2 - CFD data obtained with the K-Epsilon model and corresponding fit to support the comparison with Hausen and Gambill and Bundy Test \#4 to \#7 (see Figure 5-12 and Figure 5-13) 


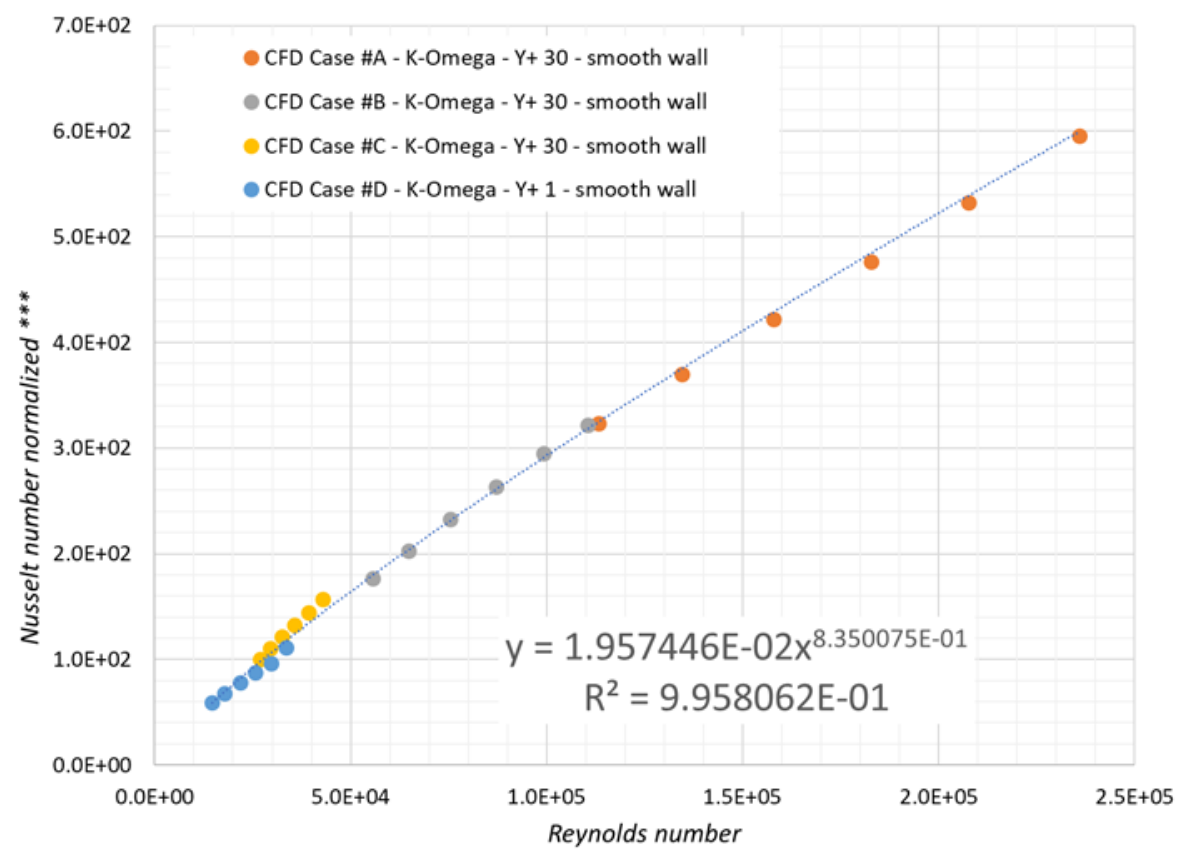

Figure C-3 - CFD data obtained with the K-Omega model and corresponding fit to support the comparison with Sieder-Tate and Gambill and Bundy Test \#4 to \#7 (see Figure 5-11)

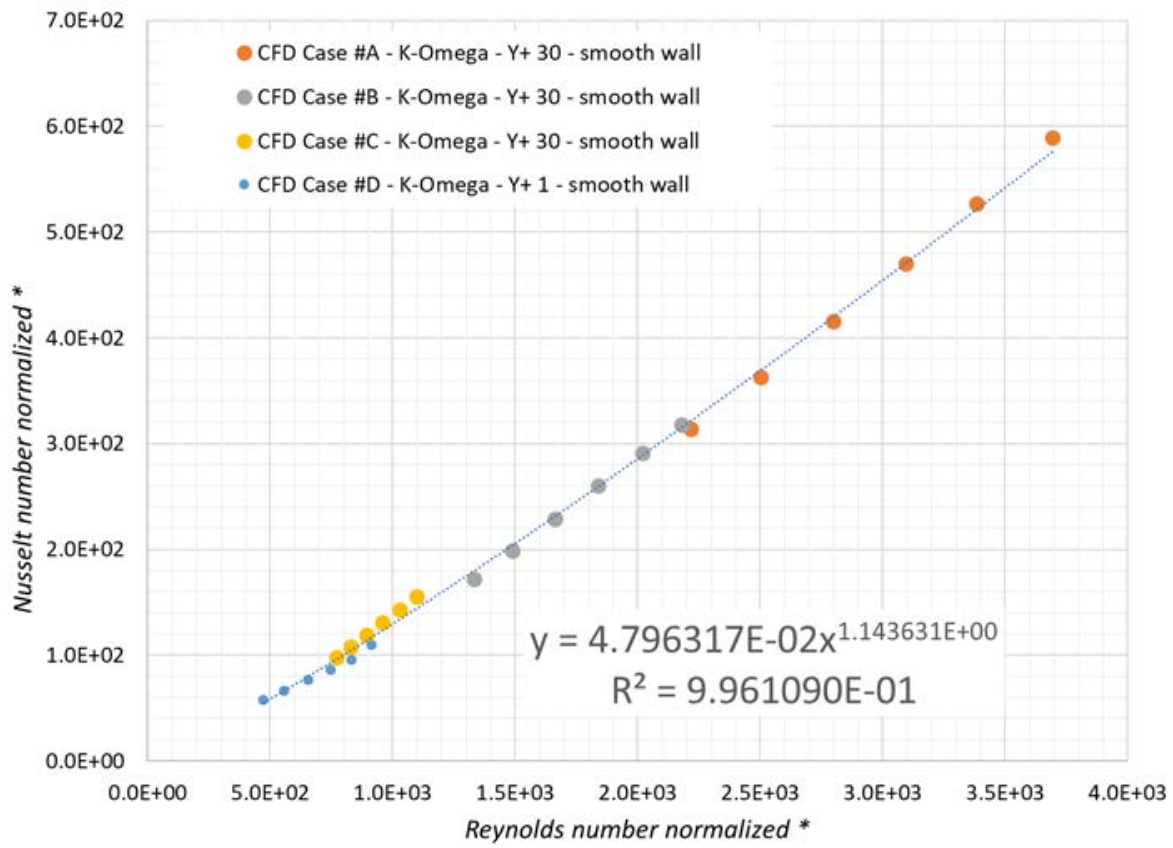

Figure C-4 - CFD data obtained with the K-Omega model and corresponding fit to support the comparison with Hausen and Gambill and Bundy Test \#4 to \#7 (see Figure 5-12 and Figure 5-13) 


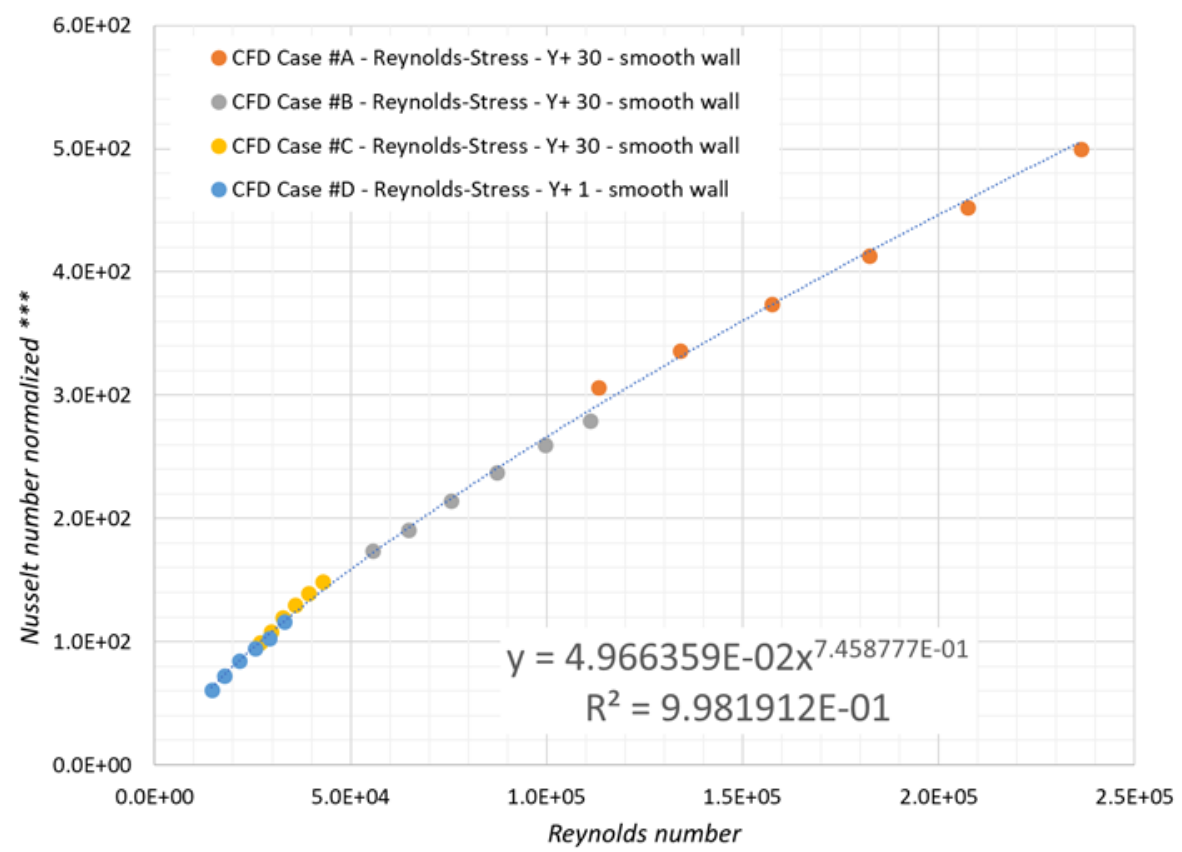

Figure C-5 - CFD data obtained with the Reynolds-Stress model and corresponding fit to support the comparison with Sieder-Tate and Gambill and Bundy Test \#4 to \#7 (see Figure 5-11)

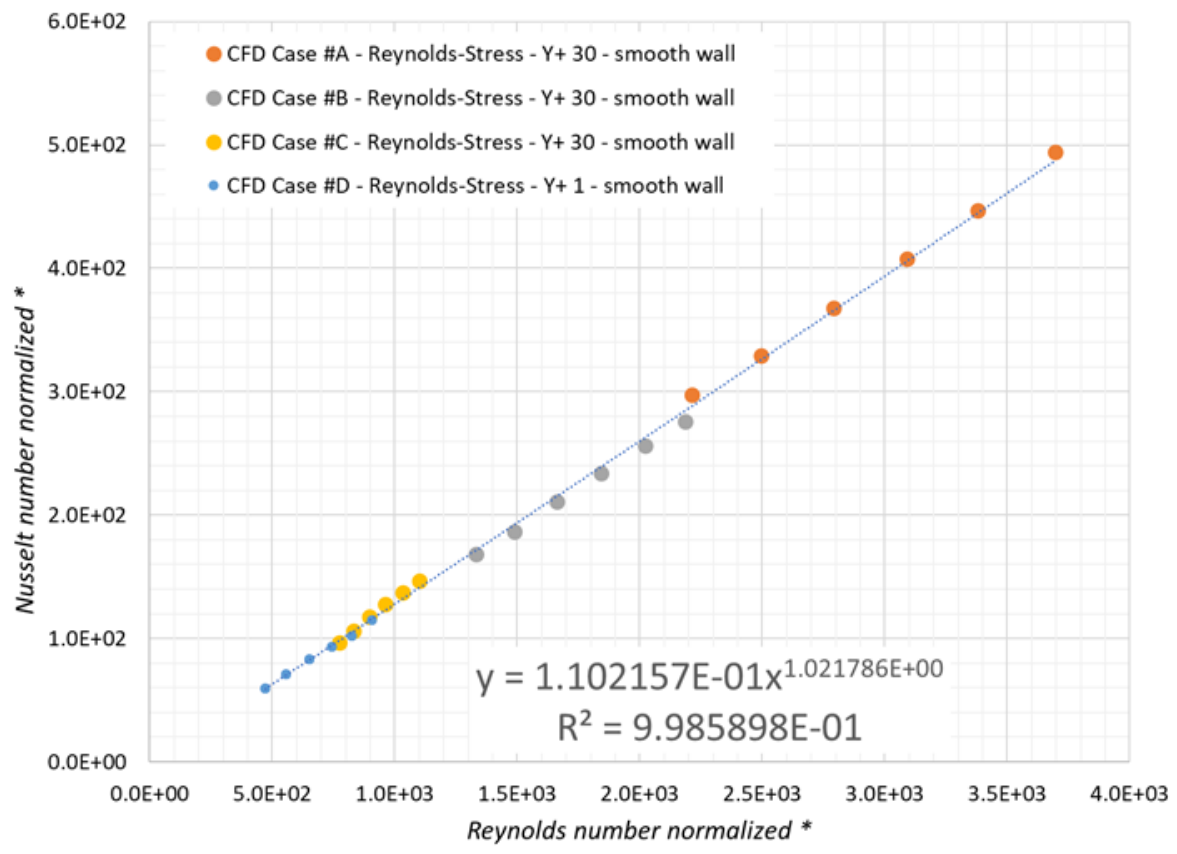

Figure C-6 - CFD data obtained with the Reynolds-Stress model and corresponding fit to support the comparison with Hausen and Gambill and Bundy Test \#4 to \#7 (see Figure 5-12 and Figure 5-13) 


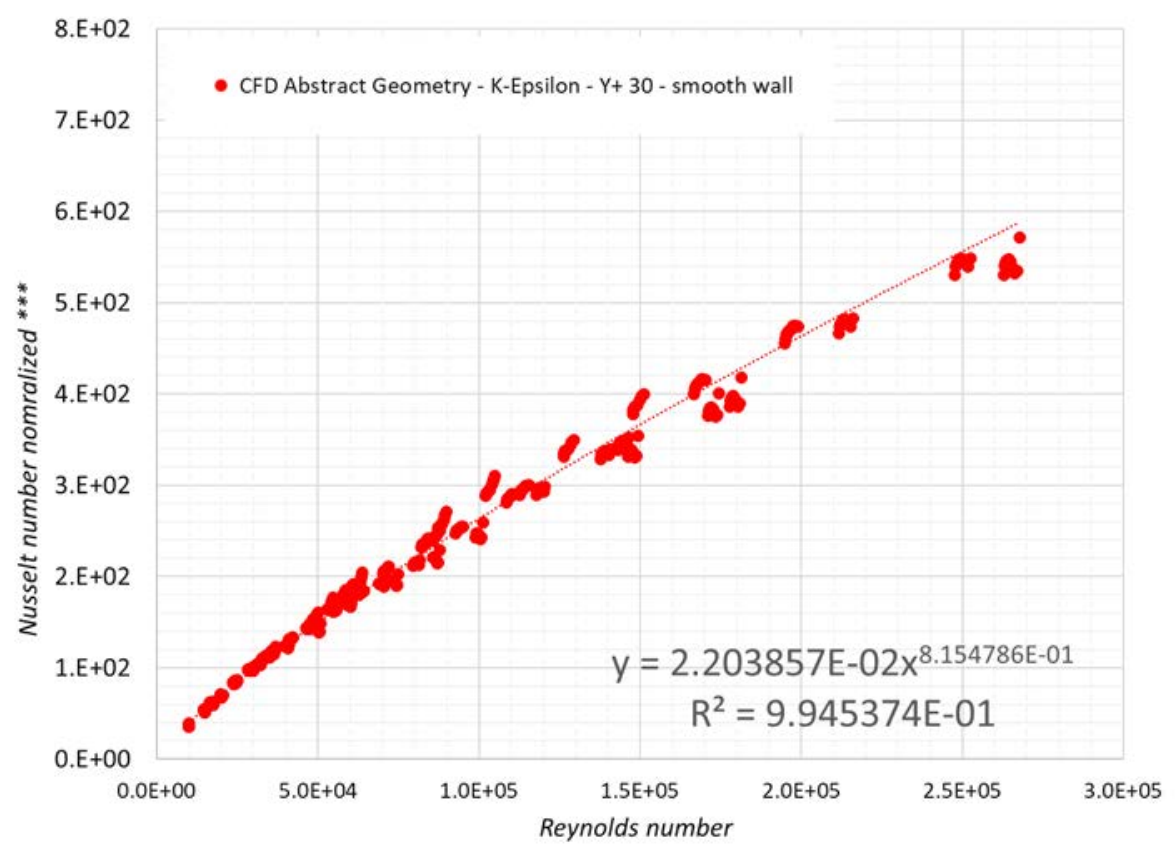

Figure C-7 - CFD data obtained with the K-Epsilon model in the abstract geometry and corresponding fit to support the comparison with Sieder-Tate (see Figure 6-2)

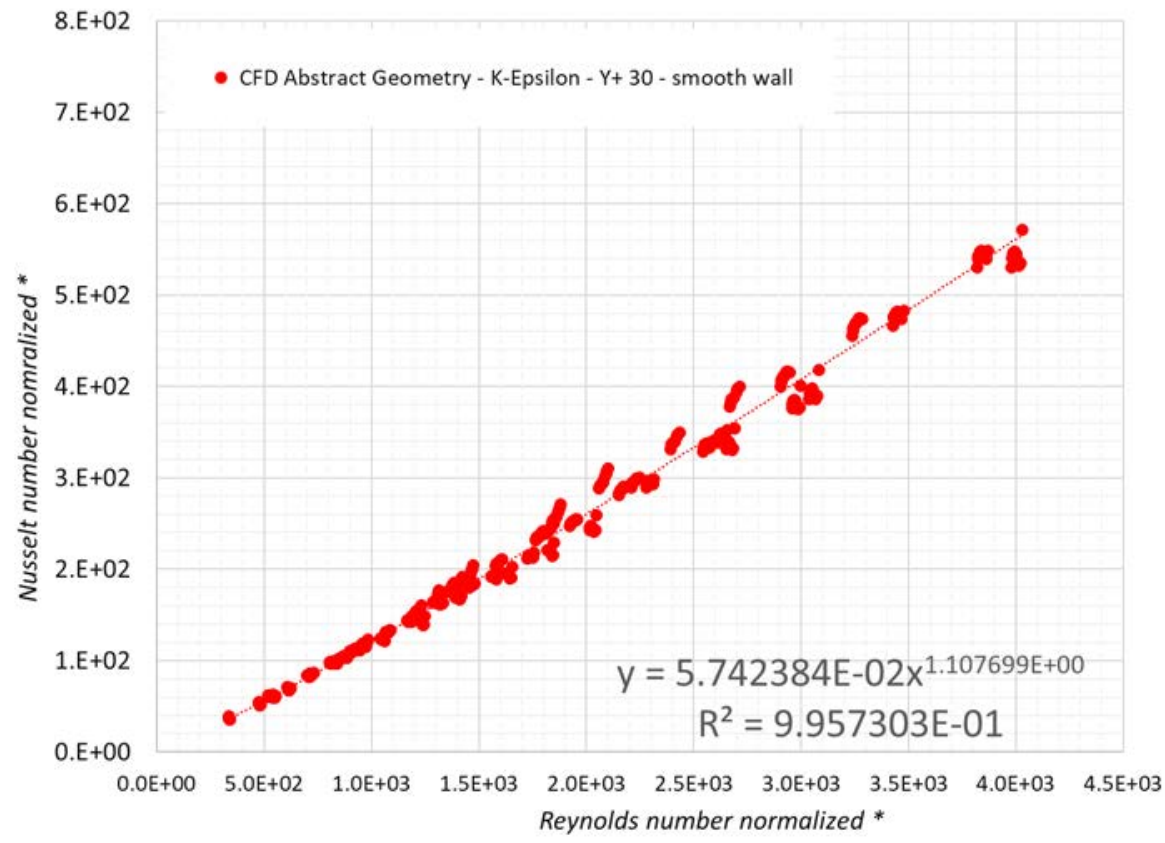

Figure C-8 - CFD data obtained with the K-Epsilon model in the abstract geometry and corresponding fit to support the comparison with Hausen correlation (see Figure 6-3) 


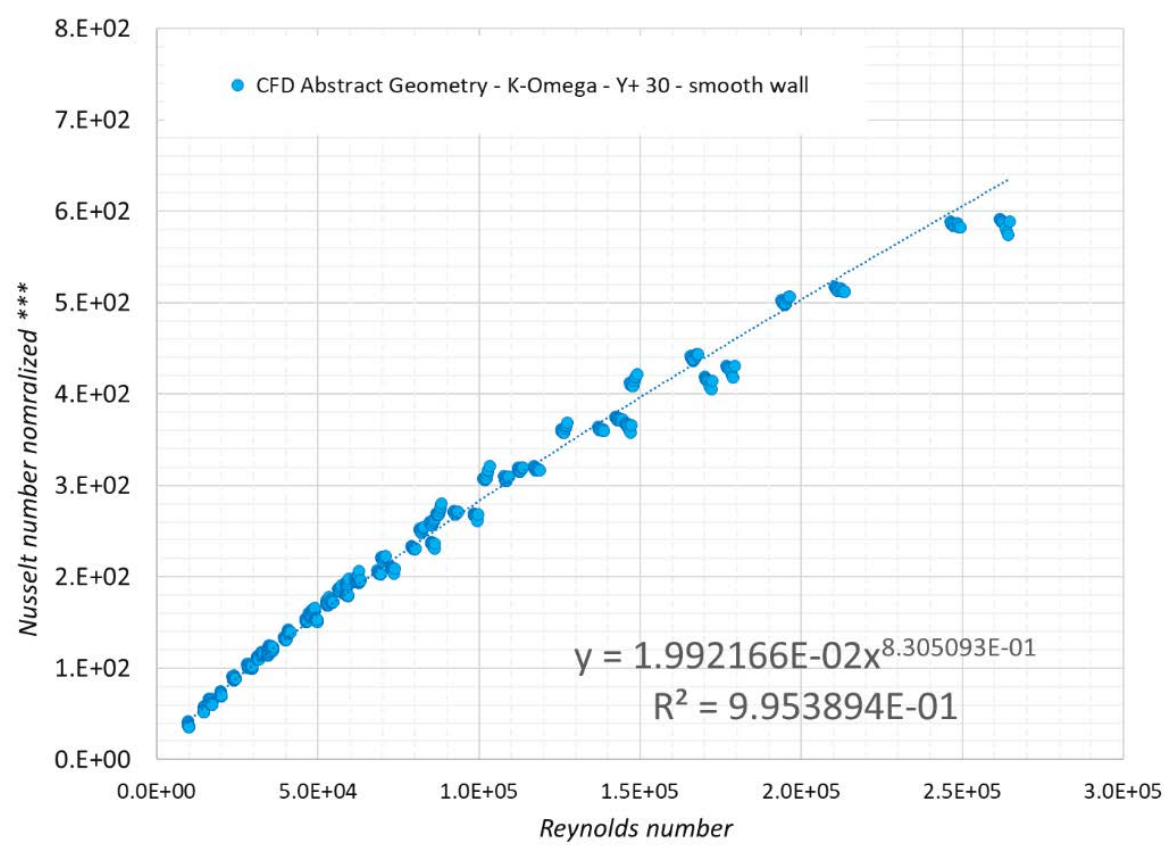

Figure C-9 - CFD data obtained with the K-Omega model in the abstract geometry and corresponding fit to support the comparison with Sieder-Tate (see Figure 6-2)

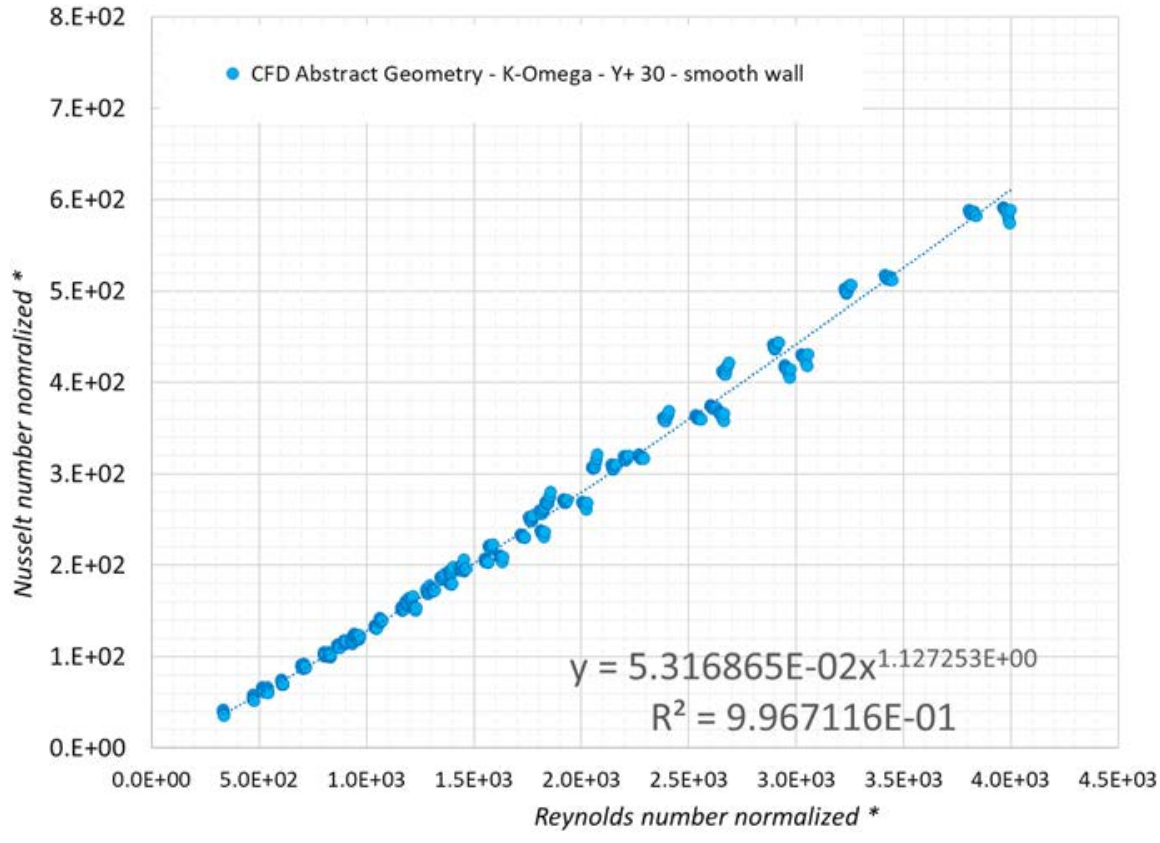

Figure C-10 - CFD data obtained with the K-Omega model in the abstract geometry and corresponding fit to support the comparison with Hausen correlation (see Figure 6-3) 


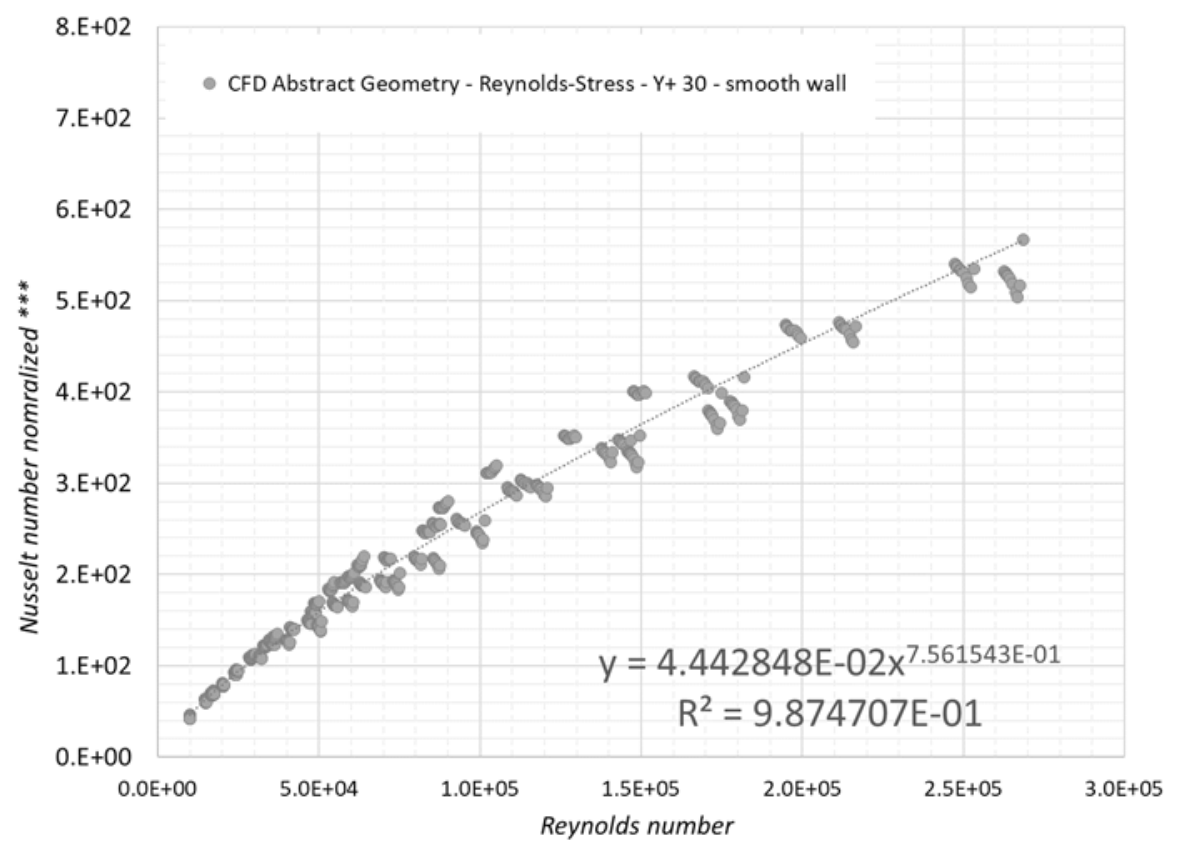

Figure C-11 - CFD data obtained with the Reynolds-Stress model in the abstract geometry and corresponding fit to support the comparison with Sieder-Tate (see Figure 6-2)

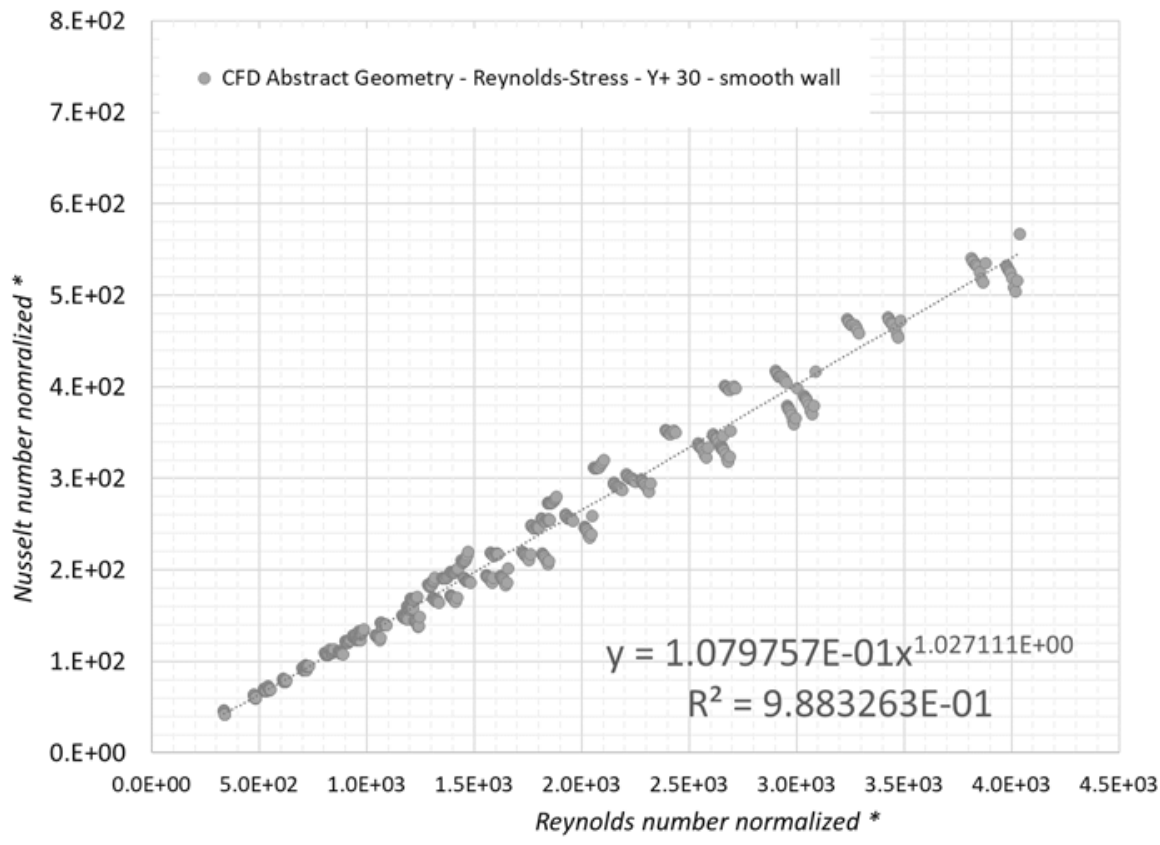

Figure C-12 - CFD data obtained with the Reynolds-Stress model in the abstract geometry and corresponding fit to support the comparison with Hausen correlation (see Figure 6-3) 




\section{Argonne $\mathbf{A}$}

\section{Nuclear Science \& Engineering Division}

Argonne National Laboratory

9700 South Cass Avenue, Bldg. 208

Argonne, IL 60439

www.anl.gov

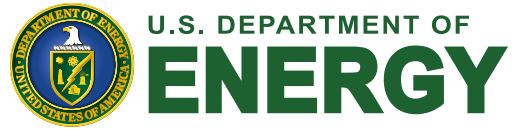

Argonne National Laboratory is a U.S. Department of Energy laboratory managed by UChicago Argonne, LLC 